\title{
A new subgenus and new species of Paratblibops, with notes on morphology and taxonomy of Scapterina (Coleoptera: Carabidae: Scaritini)
}

\section{Новый подрод и новые виды Paratblibops с комментариями о морфологии и таксономии Scapterina (Coleoptera: Carabidae: Scaritini)}

\author{
D.N. Fedorenko \\ A.H. Федоренко
}

\begin{abstract}
A.N. Severtsov Institute of Ecology and Evolution, Leninsky pr. 33, Moscow 119071, Russia. E-mail: dmitri-fedorenko@yandex.ru. Институт проблем экологии и эволюции им. А.Н. Северцова, Российская Академия Наук, Ленинский пр-т 33, Москва 119071, Россия.
\end{abstract}

KEY WORDS: Coleoptera, Carabidae, Scaritini, Parathlibops, Acanthoscelitina, Oxylobina, Scapterina, Corintascarini, new subgenus, new species.

КЛЮЧЕВЫЕ СЛОВА: Coleoptera, Carabidae, Scaritini, Parathlibops, Acanthoscelitina, Oxylobina, Scapterina, Corintascarini, новый подрод, новый вид.

ABSTRACT. Seven new species of the genus Parathlibops Basilewsky, 1958, P. (s.str.) nepalensis sp.n. from Nepal, $P$. (s.str.) alveolatus sp.n. and $P$. (s.str.) cavipennis sp.n. from Laos, $P$. (s.str.) abramovi sp.n. and $P$. (s.str.) cylindronotus sp.n. from Vietnam, $P$. (s.str.) punctipennis sp.n. from the Philippines, and P. (Scapterotlibops subg.n.) bulirschi sp.n. from southern India, are described. The genus is redescribed and key to its species provided. Relationships between Parathlibops and other members of the subtribe Scapterina Putzeys, 1866, as well as between Scapterina and other Scaritini, are discussed based on comparative morphology. Oxylobina Andrewes, 1929, syn.n., and Acanthoscelitina Csiki, 1927, syn.n., are synonymized with Scapterina. The monobasic tribe Corintascarini Basilewsky, 1973 is reinstated from synonyms of Scaritina.

РЕЗЮМЕ. ОПисаны 7 новых видов рода Parathlibops Basilewsky, 1958: Parathlibops (s.str.) nepalensis sp.n. из Непала, $P$. (S.) alveolatus sp.n. и $P$. (S.) cavipennis sp.n. из Лаоса, $P$. (s.str.) abramovi sp.n. и $P$. (s.str.) cylindronotus sp.n. из Вьетнама, P. (s.str.) punctipennis sp.n. с Филиппин и P. (Scapterotlibops subg.n.) bulirschi sp.n. с юга Индии. Составлена таблица для определения видов рода. На основе сравнительно-морфологического анализа обсуждаются отношения Parathlibops с другими представителями подтрибы Scapterina Putzeys, 1866, а также связи Scapterina с другими Scaritini. Монотипические подтрибы Oxylobina Andrewes, 1929, syn.n., и Acanthoscelitina Csiki, 1927, syn.n., помещены в синонимы подтрибы Scapterina. Триба Corintascarini Basilewsky, 1973 восстановлена из синонимов подтрибы Scaritina.

\section{Introduction}

The Oriental genus Parathlibops Basilewsky, 1958 is a member of the subtribe Scapterina Putzeys, 1866 which includes also the genera Scapterus Dejean, 1826 (northern India and Himalayas, $5 \mathrm{spp}$.); Thlibops Putzeys, 1866 (tropical Africa, 2 spp.); Passalidius Chaudoir, 1863 (South Africa, monobasic); and Steganomma MacLeay, 1887 (Australia, 3 spp.).

A significant part of the Scarititae are riparian or live close to water. However, adult Parathlibops occur away, often far away, from water, lead a cryptic life, and dig deep burrows. Many Parathlibops are known from just a few specimens. Besides, Parathlibops and Passalidius among Scapterina are apterous, which reduces migration abilities considerably and results in restricted, vicariant distribution patterns of most Parathlibops species. The genus is rather widespread in the Oriental Region, but species distribution across the range is very uneven. About half of the species are confined to Luzon in the Philippines, one to Java, and seven range from western India to Laos and Vietnam. The mainland Asian species show vicariant ranges, but $P$. crenatus (Chaudoir, 1863) and $P$. paviei (Lesne, 1896) are sympatric and may occur syntopically.

Below we describe new species of Parathlibops from Indochina, mostly collected during expeditions sponsored by the Joint Russo-Vietnamese Tropical Center, and discuss the position of Parathlibops within Scapterina and the relationships between the latter and some other Scarititae.

The material examined is curated in the following collections: collection of Petr Bulirsch, Prague, Czech Republic (CB); collection of Ricardo Sciaky, Milan, 
Italy (CS); Moscow Pedagogical State University (MPSU); Museo Civico di Storia Naturale Giacomo Doria, Genova, Italy (MSNG); author's reference collection at A.N. Severtsov Institute of Ecology \& Evolution, Russian Academy of Sciences, Moscow (SIEE); Zoological Institute, Russian Academy of Sciences, St. Petersburg (ZISP); Zoological Museum of the Moscow State University (ZMMU).

Data on type specimen labels are in quotes.

The following parameters have been analyzed: BL, maximum body length measured between apices of closed mandibles and elytra; EL, maximum length of elytron; EW, maximum width of elytra; HW, maximum width of head across eyes; PL, length of pronotum along mid-line; PW, maximum width of pronotum. Measurements were taken with an ocular micrometer within the accuracy of two decimal places. Unless otherwise indicated, the number of specimens measured (n) is only given at the first ratio in the description.

Character states $\mathbf{m}=1,2$, are arranged in transformation series $\mathrm{m} \rightarrow \mathrm{m}^{\prime} \rightarrow \mathrm{m}^{\prime \prime} \rightarrow \ldots$, and so on; symbols 'ma', 'mb', etc., refer to different transformation series of the character $\mathbf{m}$, e.g., $\left(\mathrm{m} \rightarrow \mathrm{ma} \rightarrow \mathrm{ma}^{\prime} \rightarrow \ldots\right)$. Arrows show direction from primitive to derived state.

\section{Results}

Our comparative morphological analysis is based on a set of characters, of which some have been used for classifying Scaritini by other workers [Chaudoir, 1879; Bänninger, 1937, 1938; Hogan, 2012; etc.], while others are used here for the first time.

(1) Eyes (Figs 1-10). Well-developed, convex to slightly flattened, protruding at least half-width, with genae short and posterior to eyes - primitive (Scarites, Thlibops, Scapter$u s)$. Flattened, deeply embedded to totally enclosed by the genae; these being posteroventral in lateral view - derived (Parathlibops, Passalidius, Oxylobus). Genae are conspicuously extended laterad or projecting anterolaterad into a more or less developed tooth in Passalidius as well as in some Oxylobus and Parathlibops; this pattern is also observed in some Scaritina, e.g., Prodyscherus.

(2) Supraocular setae each side: $2 \rightarrow \ldots \rightarrow 2^{\prime \prime \prime} .2$, two separated setae (many Carabidae, including Clivinini among Scarititae, Carenina). - 2', 2-3 (sub)contiguous setae (2-3 in Passalidius; a double seta in Scapterus and Thlibops). - 2", one seta (most Scaritini, few Carenina and Pasimachus). 2"', none (Parathlibops, Mouhotia and Corintascaris).

Almost all these character states are arranged here into a series of successive reductions. The presence of three, instead of two, supraocular setae in Passalidius does not seem inconsistent because in the latter some fixed (e.g., labral and pronotal) setae are also much more numerous. Therefore I treat two subcontiguous setae, anterior and posterior, as a groundplan feature of Scapterina, including Passalidius. The presence of a single, posterior, seta was erroneously indicated as a character of Scapterina (Thlibops, Scapterus, and Passalidius) by earlier authors, most recently by Hogan [2012].

(3) Clypeal seta: $3 \rightarrow 3^{\prime}$. 3, two setae present (Dyschiriini, most of the Clivinini, Carenina, most Scaritina, Acanthoscelis and Passalidius). - 3', setae missing (Scapterus, Thlibops, Parathlibops, Oxylobus, Pasimachus, Mouhotia and Corintascaris; some Scaritina, e.g., Parallelomorphus). This character state is most probably a homoplasy among the taxa listed, except for Scapterina, and a synapomorphy of at least Thlibops, Parathlibops, and Oxylobus.

(4) Dorsal seta of the antennal scape: $4 \rightarrow 4$ '. 4 , seta present (Dyschiriini, Clivinini, Corintascaris and Pasimachus). - 4', seta missing (the rest of Scaritini and some advanced, mostly Neotropical Clivinini, such as Forcipator, Kultianella, Stratiotes, etc.). The missing seta is most likely synapomorphic in most Scaritini but a homoplasy between those Scaritini and several lineages in Clivinini.

Mouthparts.

(5) Number of Labrum setae: $5 \rightarrow \ldots \rightarrow 5^{\prime \prime \prime \prime \prime}$, series of successive reductions in number of setae. -5 , five to seven evenly spaced setae (Clivinini, Dyschiriini). $-5^{\prime}$, five, with inner three close but separate (1-1-1-1-1: Carenum, Carenina). $-5^{\prime \prime}$, four subequally spaced setae (Pasimachus, Steganomma and Scapterus). - 5"', four, with median setae turned into one double seta (1-2-1: Acanthoscelis; most Scaritina, e.g., Scarites). - 5"'", three (1-1-1: Thlibops; the median seta occasionally abraded or, less likely, missing altogether). 5"'"' , two (1-1: Parathlibops and Mouhotia). - 5"'a or 5"'”a, 9-11 setae (Passalidius, secondary multiplication). Various arrangements of 3-4 setae occur within Oxylobus.

(6) Mandible scrobal ridges: $6 \mathrm{a} \leftarrow 6 \leftrightarrow 6^{\prime} \rightarrow 6^{\prime \prime}$. 6 , both dorsal and ventral scrobal ridges well-developed, the former right above the latter (Scarites, Mouhotia, Pasimachus, Carenum). $-6^{\prime}$, same, but with ventral ridge slightly reduced and concealed by dorsal ridge (Oxylobus). - 6", ventral ridge partially reduced and concealed by dorsal ridge so that mandibles flat to barely concave dorsally (Thlibops, Parathlibops). $6 \mathrm{a}$, dorsal ridge more or less reduced so that both ridges are visible in dorsal view and mandibles subconvex and oblique outwards between the ridges (Scapterus, Passalidius).

(7) Maxillar lacinia apically: $7 \rightarrow \ldots \rightarrow 7^{\prime \prime \prime} .7$, markedly hooked inwards (many Scaritina, Passalidius, Parathlibops). $-7^{\prime}$, inner hook very slightly shifted to subapical position, leaving lacinia slightly extended forward and rounded at tip (Thlibops). - 7", same, except for a blunt and much smaller preapical hook (Acanthoscelis). - 7"', rounded and not hooked (Pasimachus, Mouhotia, Carenina, Oxylobus and some Scaritina), independently developed by several taxa. 7'a, lacinia extended much forward and quite rounded apically, with inner hook shifted to median position (Scapterus).

(8) Labium: $8 \rightarrow \ldots \rightarrow 8^{\prime \prime \prime \prime} ; 8^{\prime} \rightarrow 8^{\prime}$ a, $8^{\prime} \rightarrow 8^{\prime}$ b; $8^{\prime \prime \prime} \rightarrow 8^{\prime \prime \prime}$ a. 8 , ligula subquadrate, moderately wide, thick, sclerotized, about as long as, and separate from narrow and membranous paraglossae; located clearly in front of a flat tooth of mentum, with palpigers subcontiguous; apical setae two, quite separate and inserted near latero-apical angles of ligula (Corintascaris; some Dyschiriini: Setodyschirius). - 8', ligula slender, narrow at tip, with apical setae subcontiguous, often as a dual seta (most of the Clivinini). - 8'a, same as above, but paraglossae very small and adnate to a wide and flat ligula (Pasimachus, Mouhotia). - 8'b?, nearly the same pattern, except for ligula slightly shortened and thickened (Carenum); apical setae widely separated (supposedly secondary feature). - 8 ", ligula very short and concealed ventrally by a wide dorsal process of median tooth. - 8"a, Apical setae separate and dorsal to this process (Scapterus). - 8"', same as above, but ligula thin, with apical setae widely separated by median tooth of mentum (Thlibops). - Same, but apical setae absent ( 8 "' a: Parathlibops) or multiplied ( $8^{\prime \prime \prime \prime}$ : Scaritina, Acanthoscelis, Oxylobus, Passalidius).

Patterns $8 " \rightarrow 8^{\prime \prime \prime \prime}$ correlate with the mentum tooth extended dorsad into a high and wide, subquadrate to bifid, 

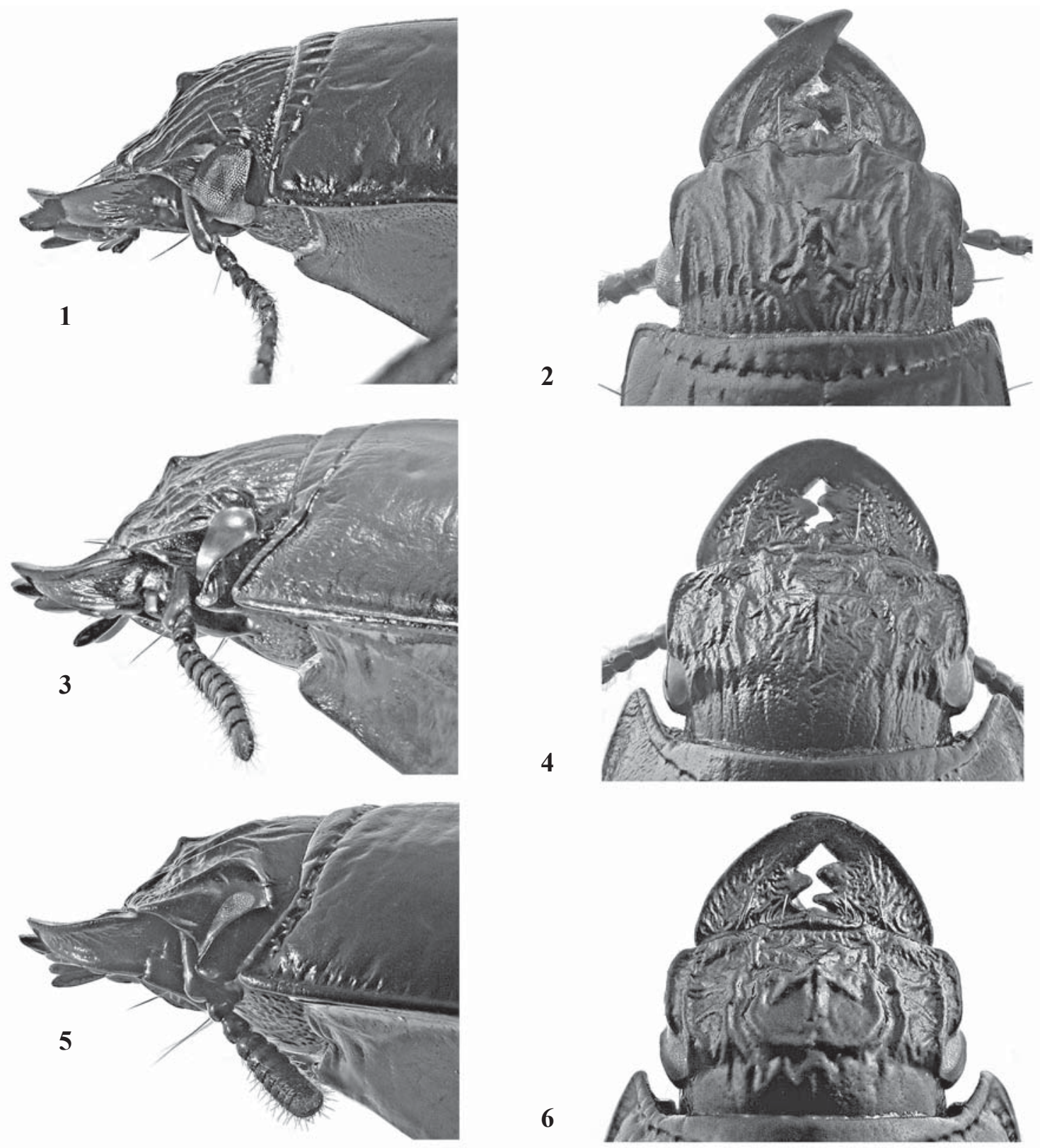

4

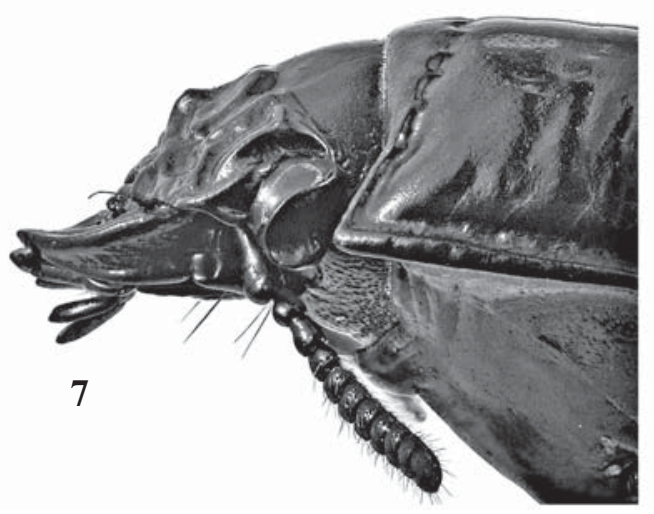

6

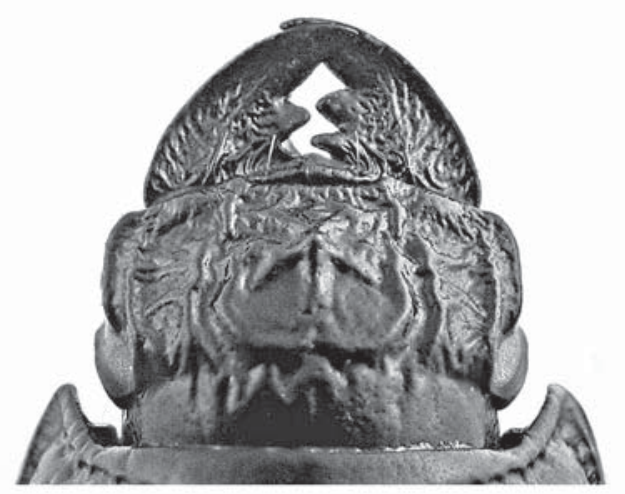

Figs 1-8. Head: 1-2 - Thlibops congoensis; 3-4 - Parathlibops integricollis; 5-6-P. minor; 7-8 - P. abramovi sp.n.; 1, 3, 5, 7 left aspect; 2, 4, 6, 8- dorsal aspect.

Figs 1-8. Голова: 1-2 - Thlibops congoensis; 3-4 - Parathlibops integricollis; 5-6 - P. minor; 7-8 - P. abramovi sp.n.; 1, 3, 5, 7 - слева; 2, 4, 6, 8 - сверху. 
dorsal process obstructing the ligula in ventral view; this arrangement is considered to be an autapomorphy of Scapterina + Scaritina.

(9) Mentum median tooth in ventral view: $9 \rightarrow \ldots \rightarrow 9^{\prime \prime \prime}$. Simple and pointed or slightly blunted at tip (9) or lanceolate $\left(9^{\prime}\right)$, or trifid $\left(9^{\prime \prime}\right)$, or subquadrate $\left(9^{\prime \prime \prime}\right)$. All the derived states have evolved as a result of the mentum apical bead becoming thicker and more raised on each side of the median tooth: the greater lateral prominence the more trifid to quadrate tooth in shape.

(10) Mentum pits, MP (e, external; i, internal, or sensorial) $: 10 \rightarrow \ldots \rightarrow 10^{\prime \prime} ; 10 \mathrm{a} \rightarrow 10 \rightarrow 10 \mathrm{~b} ; 10 \mathrm{c} \rightarrow 10 \rightarrow 10 \mathrm{~d}$. $10, M P e$ in form of two, deep, round and separate foveae situated just in front of mentum suture (in Pasimachus and some Clivinini, MPe are situated at bottom of a deep transverse groove). $10^{\prime}$, the same pattern, except for a finer or thicker carina separating between subcontiguous MPe (Thlibops and Parathlibops, Figs 11-12). - 10", MPe merged into a single large pore (some Parathlibops). - 10a, MPe reduced to small and more or less shallow round foveae or short and fine, longitudinal to oblique, lines, or almost totally (Oxylobus, Passalidius, Scaritina, Carenum). - 10b, MPe merged into a large yet shallow transverse excavation (Acanthoscelis).

Deep and large MPe (10) are peculiar to Coryza and allied genera of Clivinini; this or similar pattern is likely to have given rise to $M P i$ opened in front of mentum suture (10c: Dyschiriini and reicheine Clivinini) or into the suture directly (10d: Corintascaris, Scapterus, most Clivinini).

(11) Mentum lateral edge: $11 \mathrm{a} \leftrightarrow 11 \rightarrow 11^{\prime}$. Lateral lobes of mentum are generally beaded along sides in scaritites. This lateral bead is missing in Carenum (11a), rather faint in Pasimachus, Mouhotia and Acanthoscelis, but well-developed in many Scaritini, being flat to convex and often also subcarinate along its inner margin (11). The bead is wider and shallowly grooved in Distichus, with inner margin transformed into a fine, more or less distinct sublateral carina. This carina is blunt yet distinct in Oxylobus (Fig. 15), being combined with a fine groove running along the extreme lateral edge. This groove has become deep, wide (Passalidius, Fig. 16) or narrow (Parathlibops, Figs 11, 13), with sublateral carina transformed into secondary lateral edge additional to lateral edge proper (11'). Lateral edge ranges between species of Parathlibops from one-edged condition through two-edged condition to the primary lateral edge concealed by the secondary edge and thence traceable in ventrolateral view only. Nearly indistinct sublateral carina is likely to be secondary condition (Thlibops, Fig. 12; Scapterus, Fig. 14).

(12) Number of mentum setae: $12 \rightarrow \ldots \rightarrow 12$ ". 12 , two setae, laterobasal and medio-apical, present each side (Corintascarini, most Clivinini, many Dyschiriini). - 12', medioapical seta only retained (great majority of Scaritina, Acanthoscelis, very few Carenina). - 12", both setae missing (Scapterina, most Carenina, Pasimachus and Mouhotia).

(13) Submentum length: $13 \rightarrow \ldots \rightarrow 13^{\prime \prime \prime} .13$, moderately long (Passalidius, Oxylobus). - 13', slightly shortened (Carenina). - 13", rather short (Mouhotia, Pasimachus, Scarites, Acanthoscelis, Thlibops). - 13"', very short to almost totally reduced (Scapterus, some Parathlibops).

(14) Number of submentum setae: $14 \rightarrow \ldots \rightarrow 14{ }^{\prime \prime} .14$, four (almost all Clivinini). - 14', two (most Scaritina, Acanthoscelis and Scapterina). - 14"', missing following chifly the submentum almost totally reduced in length (Corintascaris, Mouhotia, Scapterus and some species of Parathlibops). - Four setae are peculiar to Australian Scaritina and many Carenina, while being 2-6 (some Carenina) or 2-4 (Pasimachus) in number.

(15) Gula width depends strongly on how much the head is incrassate in Scaritini - the larger (wider) head the narrower gula. Strongly incrassate heads of many Scaritini are certain to have resulted from the respective evolutionary trend. In the Scapterina, this general trend has culminated in the gula reduced to a double suture (Oxylobus and Passalidius, Figs 15-16). Accordingly the gula is broadest (primitive) chiefly in the taxa (Parathlibops and Thlibops: Figs 11-13) defined by the least incrassate head. Scapterus and Acanthoscelis are somewhat intermediate as having the gula rather wide anteriorly while tapering towards prothorax (Fig. 14), more so in the latter taxon than in the former. Scapterus and Acanthoscelis are very similar to each other in this character and more similar to Oxylobus and Passalidius than to Parathlibops and Thlibops having the gula subequally wide all along or slightly broadening basad. Gula is wide in Corintascaris and rather wide in Mouhotia, but reduced to very narrow one or to a suture in the other examined scaritines.

(16, 17) Length of buccal (maxillary) fissure, $B F$ $\left(16 \rightarrow \ldots \rightarrow 16^{\prime \prime \prime}\right)$ and presence of paragenal tooth, pgt $\left(17 \rightarrow 17^{\prime} \rightarrow 17^{\prime \prime}=17 ; 17^{\prime} \rightarrow 17^{\prime}\right.$ a) . Both characters were traditionally used to define particular groups of Scaritini. When
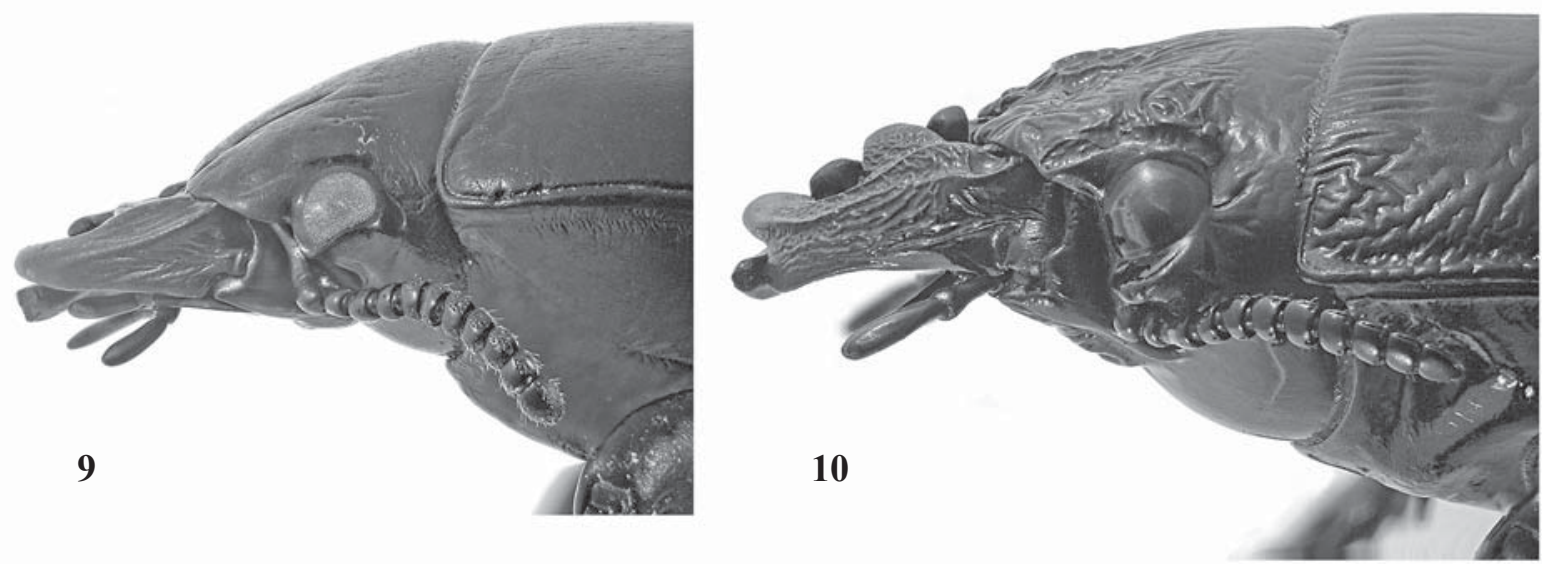

Figs 9-10. Head, left aspect: 9 - Oxylobus sp. pr. dekkanus Andrewes, 1929; 10 - Passalidius f. fortipes (Boheman, 1860).

Figs 9-10. Голова слева: 9 - Oxylobus sp. pr. dekkanus Andrewes, 1929; 10 - Passalidius f. fortipes (Boheman, 1860). 
taken separately each, they, especially the former character, are liable to ordering into a transformation series readily, and less so when combined into a pattern.
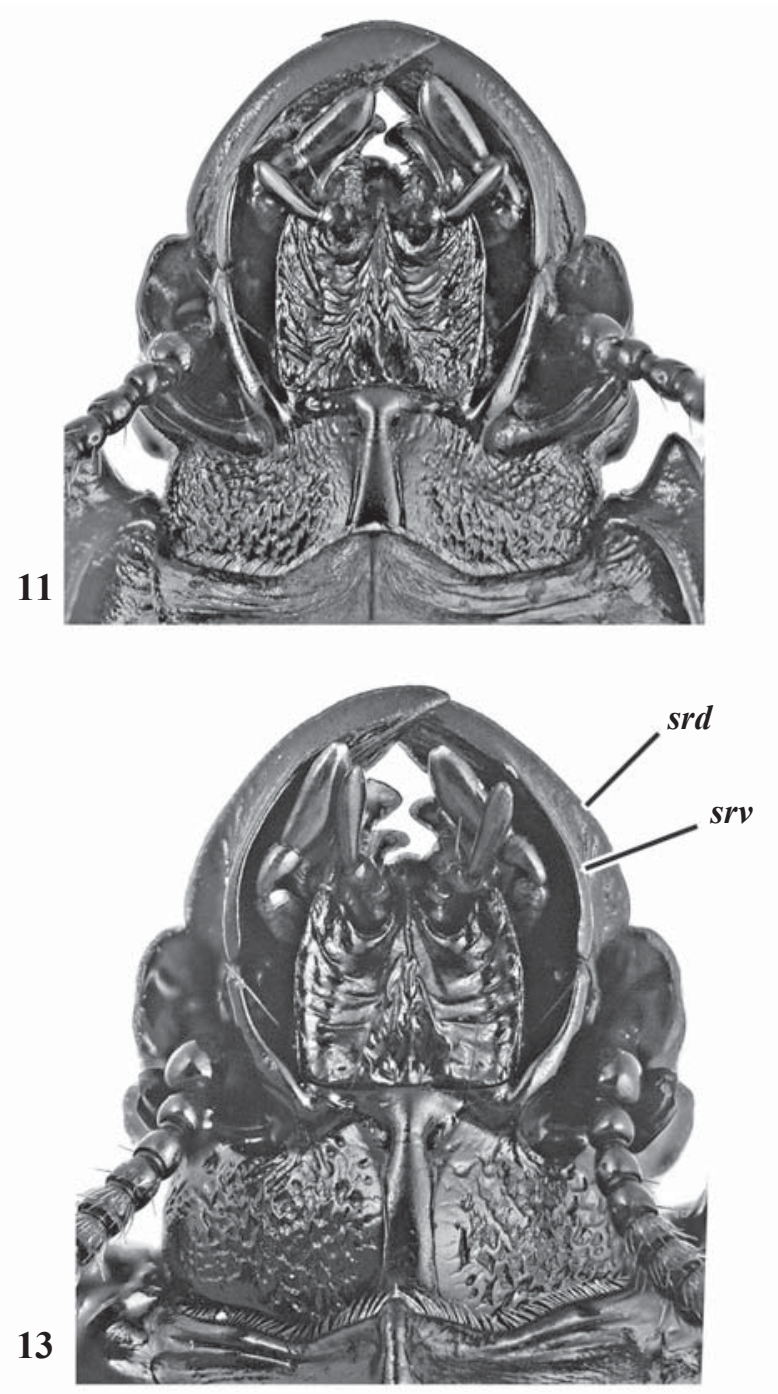

12

Pgt is a pointed apical angle of the paragena basal portion broadened and bent ventrad to cover cardo-stipital articulation from beneath. In the case of well-developed $p g t, B F$ is
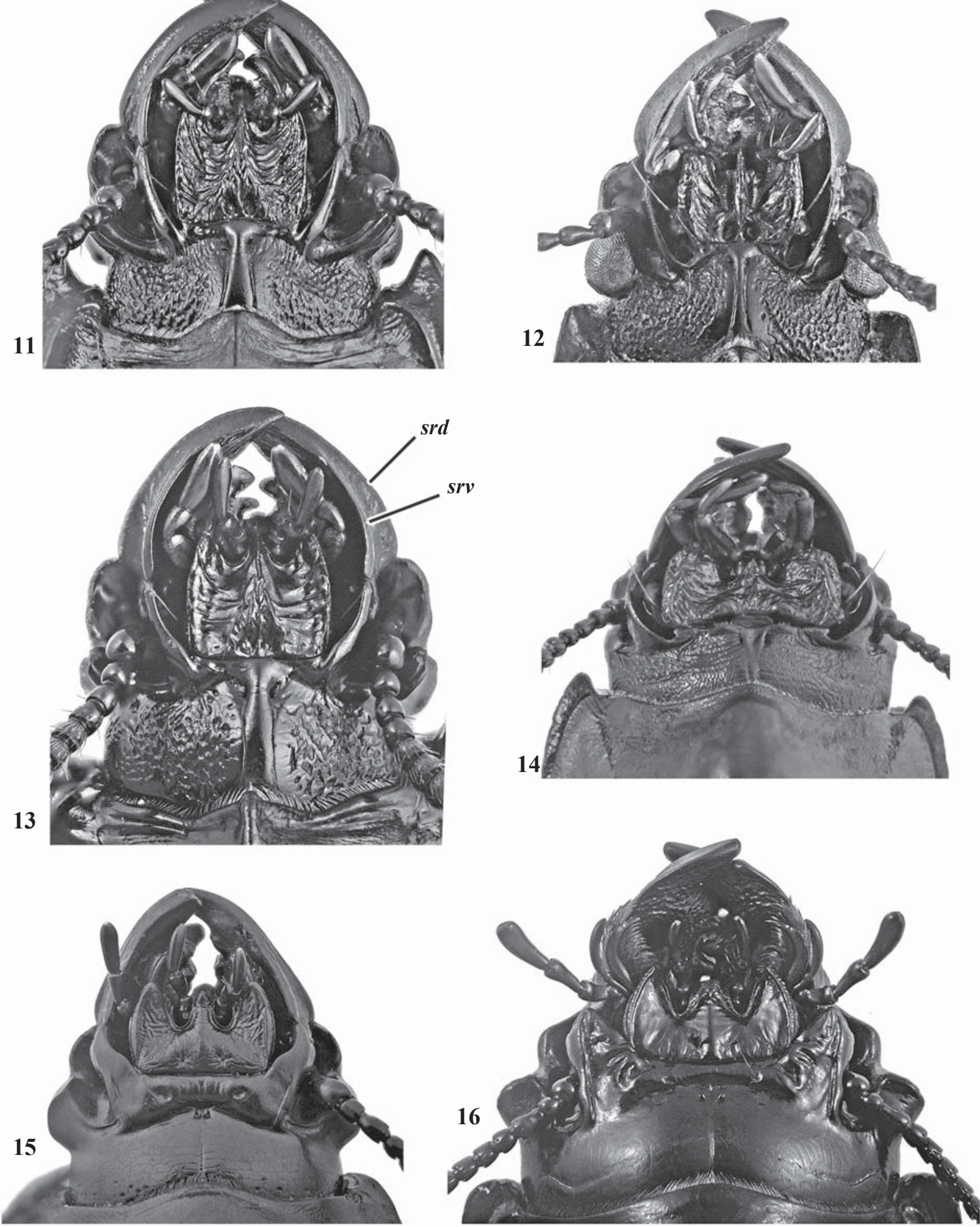

Figs 11-16. Head, ventral aspect: 11 - Parathlibops integricollis; 12 - Thlibops congoensis; 13 - P. minor; 14 - Scapterus sp. pr. sulcatus Putzeys 1863; 15 - Oxylobus sp. pr. dekkanus Andrewes, 1929; 16 - Passalidius $f$. fortipes (Boheman, 1860).

Figs 11-16. Голова вентрально: 11 - Parathlibops integricollis; 12 - Thlibops congoensis; 13 - P. minor; 14 - Scapterus sp. pr. sulcatus Putzeys 1863; 15 - Oxylobus sp. pr. dekkanus Andrewes, 1929; 16 - Passalidius f. fortipes (Boheman, 1860). 
much narrower basal than apical to pgt. This pattern defines many Scaritina, therefore it is regarded here as groundplan of the subtribe.

$16+17, B F$ entire, wide and long, almost reaching the base of the submentum, and without pgt (Corintascaris, Clivinini, Dyschiriini). - This pattern is observed in the Scaritina as well, but many other Scaritina are defined by conspicuous pgt $\left(17^{\prime}\right)$. The fact that paragena is more or less distinctly sinuose in Oxylobus and Mouhotia while apically toothed in Pasimachus implies that these character states may have resulted from $p g t$ completely reduced in the former two taxa or shifted apicad in the latter (17'a). From this entire $B F$ with distinct $p g t$ is here supposed to be plesiomorphic character state in Scaritini $\left(16+17^{\prime}\right)$

Entire $B F$ without pgt $\left(16+17^{\prime}\right)$ is peculiar to Acanthoscelis, Thlibops, Scapterus and Parathlibops, being slightly narrower in the latter three and sometimes also shortened from behind owing to a very short submentum of Scapterus and some species of Parathlibops. In the course towards reduction of $B F$ from behind, its sides step-by-step approach each other until joining together into a suture. $-16^{\prime}, B F$ very narrow, almost closed between pgt and the mentum suture while merged into a deep suture behind (Distichus). - 16", $B F$ reaching mentum suture, with only a trace of the suture behind (Mouhotia and Oxylobus). - 16"', same, but BF reaching middle of mentum only (Passalidius, Fig. 16). $16^{\prime \prime \prime \prime}$, BF totally reduced (Pasimachus).

Most carenines match well pattern 16"' [Moore \& Lawrence, 1994], but at least Scaraphites has $B F$ less reduced in length [Hogan, 2012]. I have seen also a specimen of Euryscaphus sp. with $B F$ fairly narrow and quite reaching, though gradually attenuated towards, the base of mentum, with a remnant of a suture behind. Therefore I share Hogan's supposition on the independent evolution of this character in some scaritine lineages, among them Carenina, Scapterina, and Scaritina.

In sum, the mentum-to-gula groundplan of Scaritini is deemed to be as follows: mentum more or less flat, with rounded lateral lobes and a simple, i.e., triangular median tooth clearly projecting forward; $B F$ entire; pgt present?; $M P e$ well-developed and situated in front of this suture; submentum fairly long, clearly shorter and barely narrower than mentum; gula moderately wide medially; one seta, medio-apical, present each side.

Many clivinines and some dyschiriines share quite a different groundplan. It is defined chifly by the mentum having a very wide and deep semicircular excavation limited behind by a sharp edge. Further features of this pattern are the mentum tooth projecting rather far forward beyond lateral lobes, a wide gula, two setae present each side, and pgt absent. Only the peculiar clivinine genus Forcipator has pgt or what recalls it. This structure is a toothed angle between apical (within the mentum) and basal (within the submentum) sections of the paragenal edge seen in lateral view only. The angle is supposed here to have emerged from the mentum articulated to the submentum at an obtuse, instead of nearly straight, angle as is observed in most scaritines. Since Forcipator's paragena is in vertical plane, a supposition on the paragena originally structured in a similar manner, but then broadened basally and curved ventrad may explain how pgt could have originated in course of evolution of the Scaritina.

(18) Propleural ridge/groove, $P R$, is an apparent extension of sternopleural suture towards basal angle of prothorax, fine ridge or groove, separating pleuron (='proepisternum') from posterior propleural flange (='proepimeron') that encloses the procoxal cavities from behind. The length and shape of $P R$ may characterize genera or species in the Clivinini and Scaritini.

$P R$ entire, i.e., reaching laterobasal corner of propleuron - primitive (Scarites, Distichus). In Scapterina, $P R$ may vary between genera or between species within a genus. It is entire to totally reduced in Parathlibops, somewhat interrupted in Oxylobus and Passalidius, slightly or considerably shortened in Acanthoscelis and Thlibops, respectively, and missing in Scapterus.

In Parathlibops, posterior propleural flange is margined with a fine ridge ( $p p r$, posterior propleural ridge) which is entire or broken at prosternal process into two parts, postcoxal ridge ( $p c r)$, and basal propleural ridge ( $b p r)$, the latter running just in front of mesothoracic peduncle. $\mathrm{Pcr}$ almost reaches $P R$ just outside procoxa; sometimes it curves to run parallel to the basalmost section of $P R$ or join it at highly acute angle; these two patterns are termed here 'double $P R$ ' or 'pleural triangle', respectively.

\section{$(19,20)$ General pattern of lateral elytral intervals.} $19 \mathrm{a} \leftarrow 19 \rightarrow \ldots \rightarrow 19^{\prime \prime \prime}$

In Carabidae, the extreme lateral margin is generally formed by a more or less narrow reflexed lateral edge; epipleura beneath it becomes increasingly narrow apicad until merged into the lateral edge before apex or transformed into a fine apical costa/bead visible from above.

Groundplan pattern of Scarititae seem to be as follows: intervals 7-9 subequally wide and delimited throughout by distinct elytral striae 7 and 8; interval 7 fused to intervals 5 and 3 in succession until reaching interval 1; interval 8 apically touching both interval 1 and lateral edge fused at sutural angle; umbilicate series continuous. This pattern is peculiar to Corintascaris in addition to the following secondary features: stria 8 almost reduced, interval 9 fairly narrow, and lateral margin concealed by interval 8 in basal quarter. Dyschiriini match the groundplan even better, but for umbilical setae divided into three separate groups (19a, autapomorphy). - 19b, nearly the same pattern, but interval 7 costate or subcostate before apex and meeting both interval 1 and lateral edge at sutural angle, with interval 8 not quite reaching apex (ardistomine Clivinini). - 19', interval 7 widely subcostate at apex while interval 8 carinate apically and reaching interval 1 , being separated by a widely grooved interval 9 from lateral edge (the rest of the Clivinini). $-19^{\prime \prime}$, same as above, but interval 8 reduced to a very thin carina or vanished before apex (reicheiine Clivinini, Coryza, Syleter, Whiteheadiana, etc.) - a very slight modification.

Oxylobus and, especially, Thlibops match pattern (19") better than the other Scaritini do (Figs 29-30). In Parathlibops (Figs 17-28), the apex of elytron is a seemingly costate interval 8 (which is actually homologous to interval 7 or merged intervals 7 and 8 ), with lateral edge fused to the apical costa lateroventrally (19"'). The other Scaritini show apical patterns of elytral striation more or less groundplan for Scarititae (Scaritina, Mouhotia, Pasimachus, Carenina), with lateral margin being subcostate or nearly so in Acanthoscelis and Scapterus (Fig. 31). Some Carenum have the elytral apices similar to those of Parathlibops.

Patterns of the elytral striae in the middle part of elytron (20) vary considerably. In Pasimachus, interval 9 is rather wide, with umbilical setae arranged into a straight and very slightly impressed line (herein termed 'median groove'); this groove is separated by a barely convex interval-like area from stria 8 and by a wider, slightly concave area from the lateral edge. Stria 8 is almost totally reduced yet traceable in some Scaritini (Prodyscherus), but obliterate in many others, so 
that the median groove looks like the borderline between intervals 8 and 9. This latter pattern is probably peculiar to Carenina.

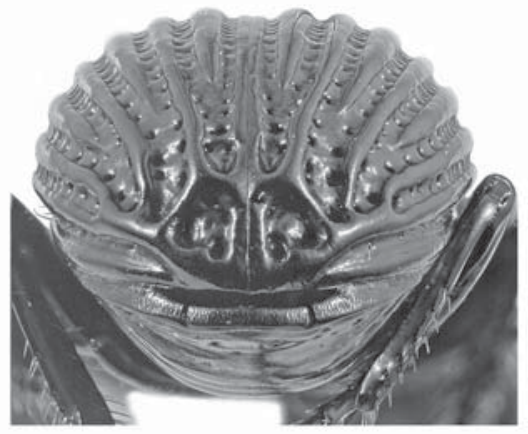

17

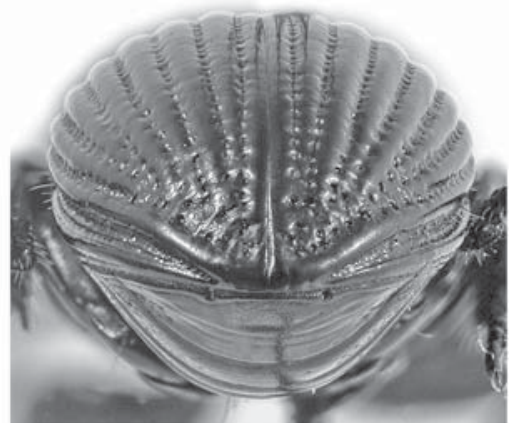

20

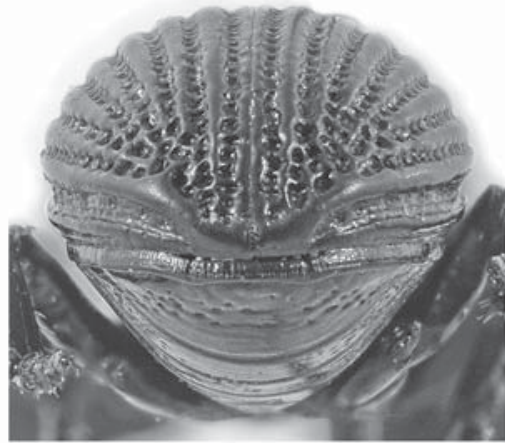

23

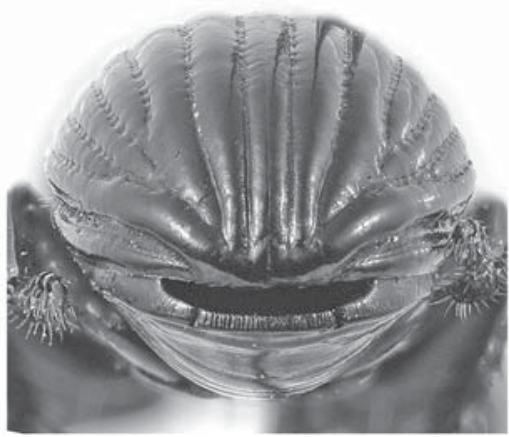

26

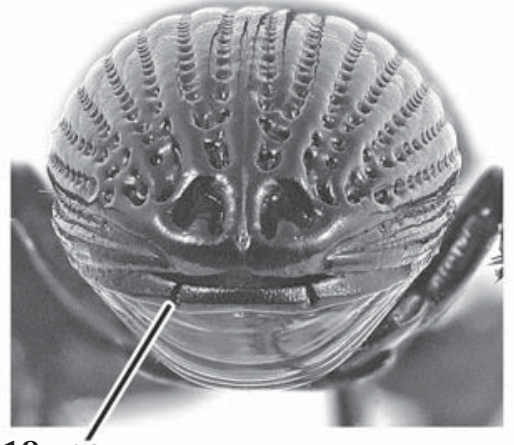

18 ag

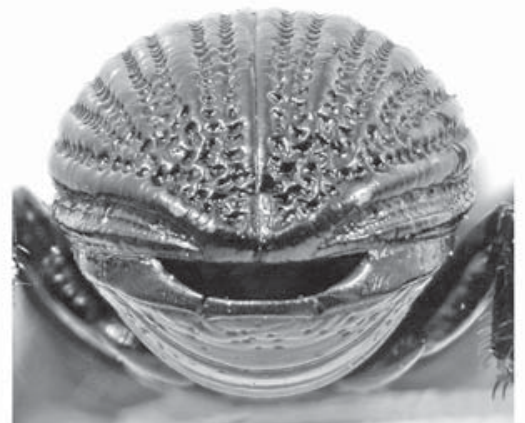

21

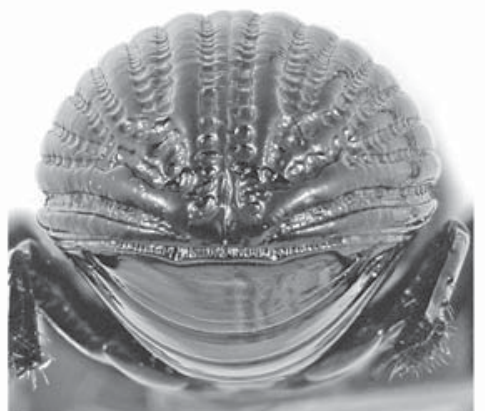

24

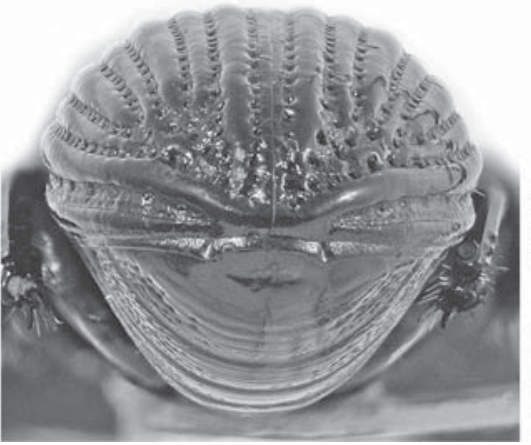

27
Scapterine patterns are of a particular kind. They are defined by the median groove deepened and somewhat broad-
ened, with its inner and outer margins of the groove being

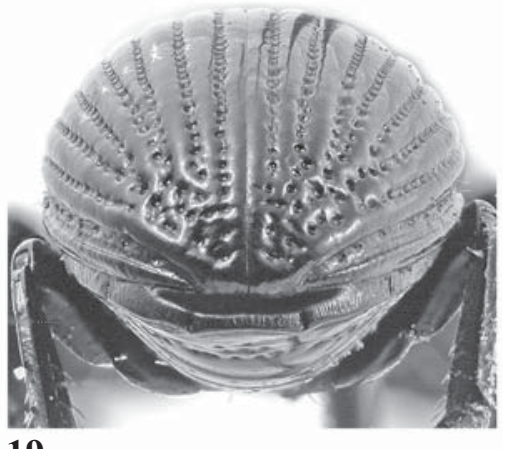

19

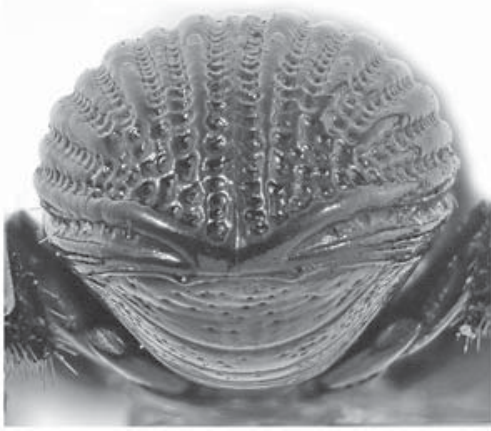

22

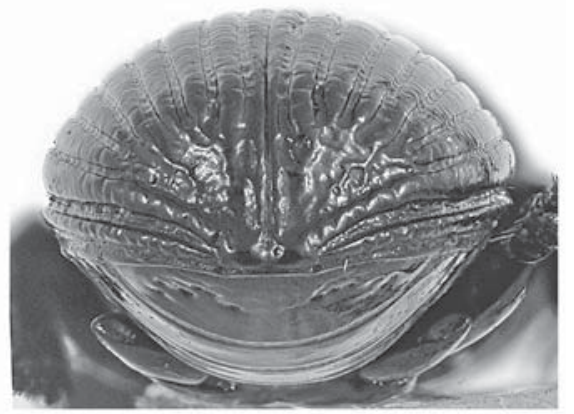

25

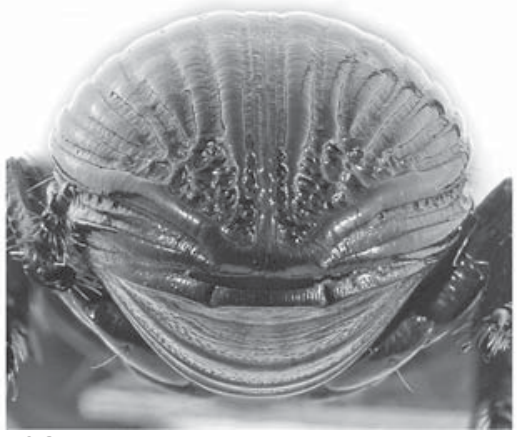

28

Figs 17-28. Parathlibops, caudal aspect: $17-$ P. abramovi sp.n.; $18-$ P. cavipennis sp.n.; $19-$ P. crenatus; $20-$ P. cylindronotus sp.n.; 21 - P. nepalensis sp.n.; $22-$ P. puncticollis; 23 - P. alveolatus sp.n.; $24-$ P. glaber; 25 - P. bulirschi sp.n.; 26 - P. paviei; 27 - P. puncipennis sp.n.; $28-P$. integricollis; ag - anal groove.

Рис. 17-28. Parathlibops, апикально: $17-$ P. abramovi sp.n.; $18-$ P. cavipennis sp.n.; $19-$ P. crenatus; $20-P$. cylindronotus sp.n.; 21 - P. nepalensis sp.n.; $22-$ P. puncticollis; 23 - P. alveolatus sp.n.; 24 - P. glaber; 25 - P. bulirschi sp.n.; 26 - P. paviei; 27 - P. puncipennis sp.n.; $28-$ P. integricollis; ag - анальная бороздка. 
firstly edged and then transformed into fine carinae (20a: Thlibops, Parathlibops). Scapterus (20b) and Oxylobus (20c) share the inner carina only present (most likely, retained), with interval 9 being reduced to the median groove in the latter genus. Obliterate stria 8, combined with the inner carina present defines Passalidius (20b'). It is the same in Acanthoscelis, but for the median groove obsolete in basal half $\left(20 b^{\prime \prime}\right)$.

Transformation series $(20 \mathrm{c} \rightarrow 20 \mathrm{a} \rightarrow 20 \mathrm{~b}) \rightarrow 20 \mathrm{~b}^{\prime} \rightarrow 20 \mathrm{~b}^{\prime \prime}$ seems intuitive. Whether deep, bi- or unicarinate, median groove is plesiomorphy or apomorphy, it separates Thlibops, Parathlibops, Oxylobus, Passalidius and Scapterus from Scaritina. Acanthoscelis probably belongs to the Scapterina because it shares very similar structure and sculpture of the elytra with Passalidius and, especially, with Scapterus (Figs 31-32). In particular, the apical declivity is abrupt and the lateral margin is conspicuously crenulate before apex in the three genera in addition to a coarse tuberculation shared by the former two of them.

A strong sublateral carina separating interval 8 from a very wide interval 9 in Mouhotia may be homologous to the inner carina of the scapterine pattern.

(21) Apical margin of abdominal sternite VII: $21 \rightarrow \ldots \rightarrow 21^{\prime \prime \prime \prime}$

In non-truncatipenne carabids, including Clivinini, Dyschiriini, and Corintascaris, a fine, blunt to sharp, carina running along the underside of interval 9 is the key part of the elytra-abdomen interlocking device. A longitudinal groove outside this carina receives lateral edge of the abdomen, leaving the extreme apices of the inter- locked abdomen and elytra only touching each other. A slightly reinforced lock has emerged from the adherent apices of sternite VII and of the elytra. This happened through modification of the extreme apex of the sternite into a narrow, flat to slightly concave, flange (21': Scaritina, Acanthoscelis). This flange is broader (higher) and usually also more or less densely striated in vertical plane in the scapterines (Figs 17-32). It is otherwise either even (21": Scapterus) or has a pair of vertical grooves termed here 'anal grooves' (ag, Figs 17-30). These grooves are rudimentary, wide and shallow (21"': Passalidius, Figs 32-33), or well-developed, narrow and deep (21"'": Thlibops, Parathlibops, Oxylobus). In the abdomen interlocked with the elytra, $a g$ are most likely to function as excretive ducts for the pygidial glands secretion and might serve also for better ventilation of the subelytral cavity.

Patterns $21^{\prime}-21^{\prime \prime \prime \prime}$ are certain to have been developed in the course of the evolution towards an increasingly consolidated hindbody, and patterns 21"' and 21"'" allow also spraying defensive secretions without unlocking the abdomen and elytra. Because of $a g$ present the sternite VII is slightly trilobed in outline.

The other examined Scarititae (Pasimachus, Mouhotia, Carenum) show simple elytra-abdomen interlocking device, with unmodified apex of the abdominal sternite VII. On the other hand, Pasimachus and Mouhotia have well-developed external openings reminiscent of and likely homologous to rudimentary ag; these openings are ventral or lateral in position, respectively (plesiomorphy?).

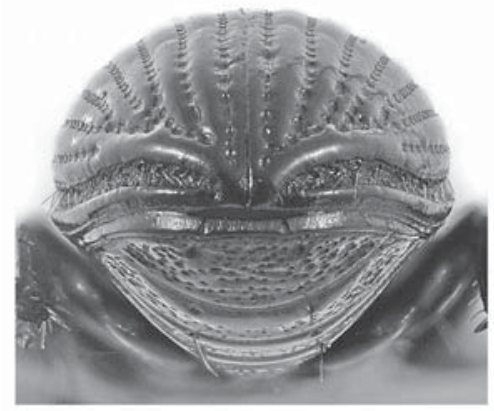
29

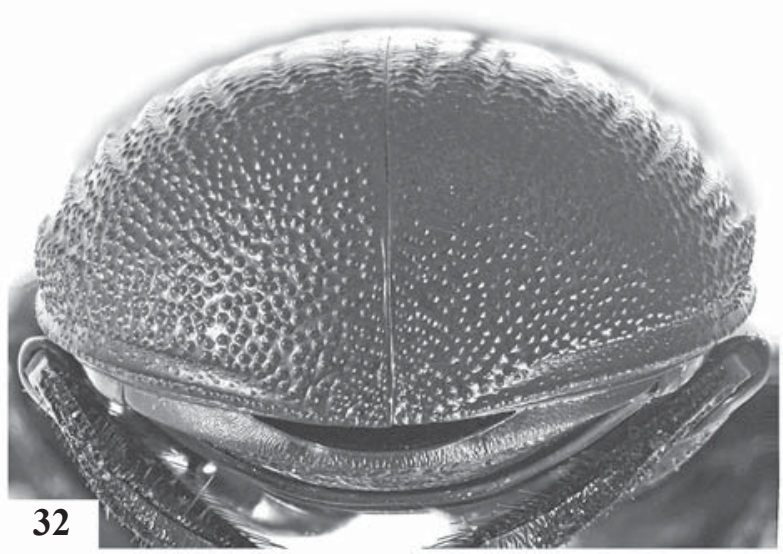

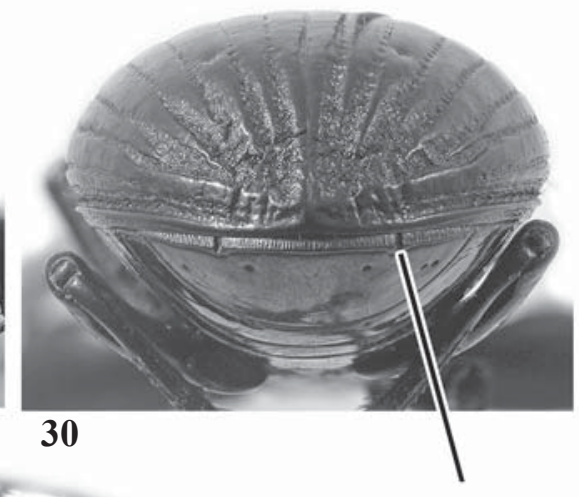

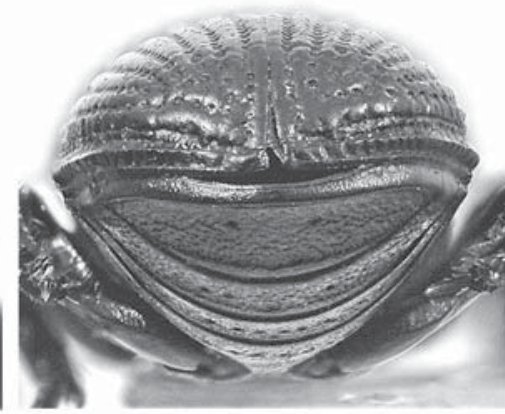

31

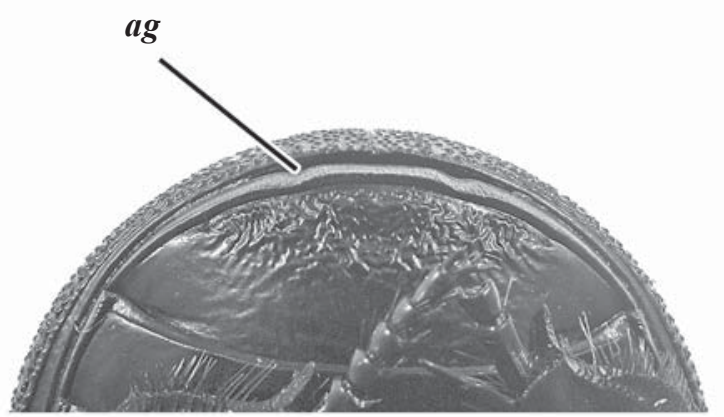

33

Figs 29-33. Scapterina: 29 - Thlibops longicollis; 30 - Oxylobus sp. pr. dekkanus; 31 - Scapterus sp. pr. sulcatus; 32-33 — Passalidius $f$. fortipes; 29-32 — caudal aspect; 33 - ventral aspect; ag - anal groove.

Рис. 29-33. Scapterina: 29 - Thlibops longicollis; 30 - Oxylobus sp. pr. dekkanus; 31 - Scapterus sp. pr. sulcatus; 32-33 — Passalidius $f$. fortipes; 29-32 - сзади; 33 - снизу; ag - анальная бороздка. 
(22) Number of abdominal setae, i.e., ambulatory setae on sternites IV-VI $(\mathrm{ams})$ plus apical setae on sternite VII: $22 \mathrm{a}^{\prime} \rightarrow 22 \mathrm{a} \rightarrow 22 \rightarrow 22^{\prime}$. The 1 plus $1-2$ combination (on each side) is most frequent in Carabidae, being a groundplan feature of the Clivinini and Scaritini. Ams are completely reduced (22') in very few scaritites: Corintascaris; Mouhotia; Passalidius and Parathlibops (Scapterina); and Kultianella (Clivinini). Hogan [2012] adds also Epilectus, Carenina, Macromorphus, Scaritina, as well as Oxylobus porcatus (Fabricius, 1798) and $O$. lateralis (Dejean, 1825), to this list. Andrewes [1929] reported 'a single normal pore on each side' for O. armatus Andrewes, 1929 while coarse punctures across abdominal sternites for most of the other species of
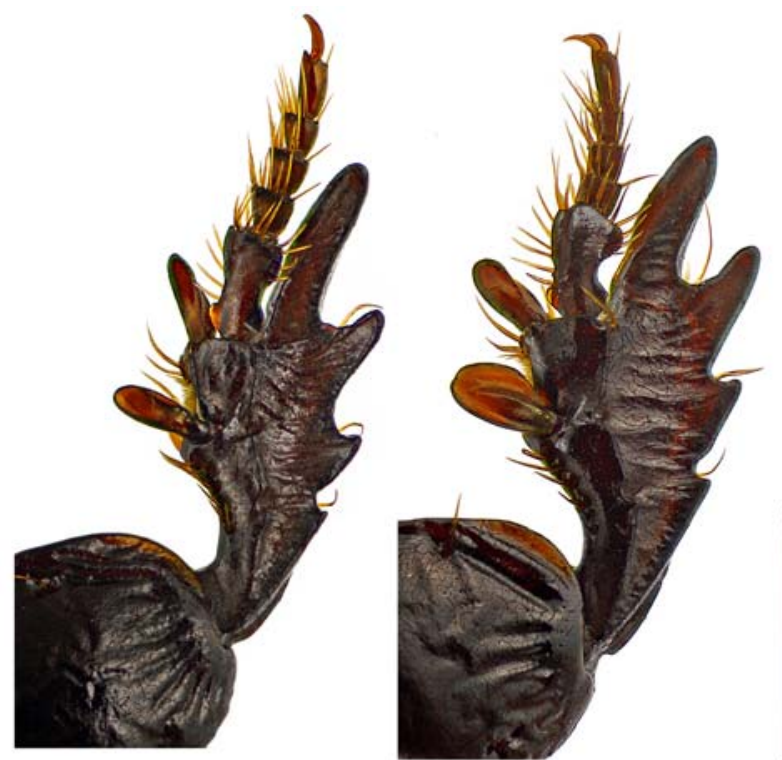

34

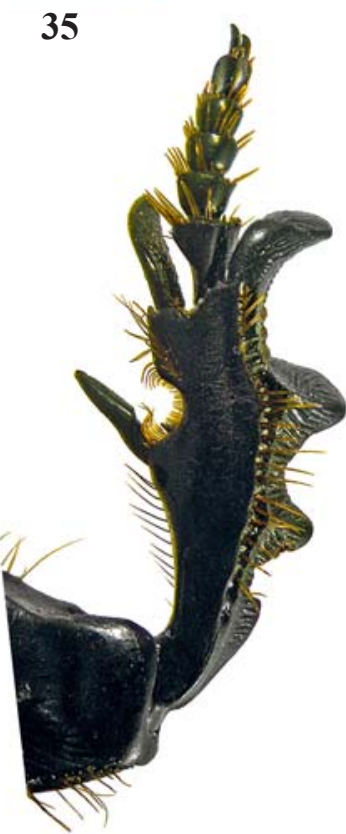

38

Oxylobus. Some of these punctures seem to have been setigerous pores (perhaps with setae abraded) because all specimens of at least four species of Oxylobus examined by me have had one ams each side. These specimens, as well as all specimens of two Thlibops species have the setigerous pores devoid of distinct setae; remnants of these pores have also been observed in one of two examined specimen of Passalidius.

In Acanthoscelis, ams are increased to two each side, accompanied by a short transverse row of additional, lateral, decumbent setae on sternites IV-V (22a). Scapterus is the same, but for 1-3 ams present on each side of sternite VI and ams indistinguishable from additional setae $\left(22 \mathrm{a}^{\prime}\right)$. Setigerous pores on sternite VII are four (Acanthoscelis, Thlibops

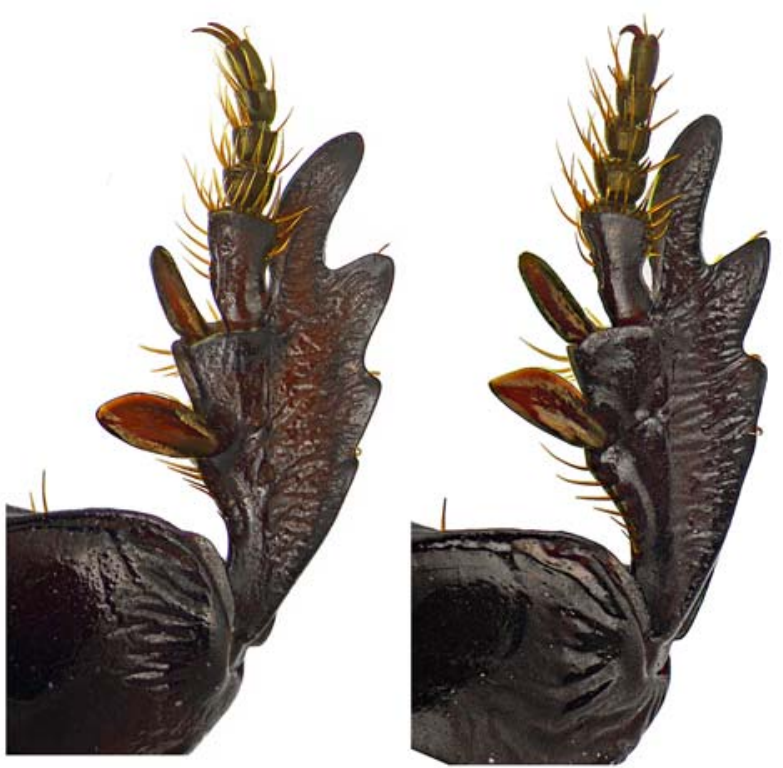

36

37

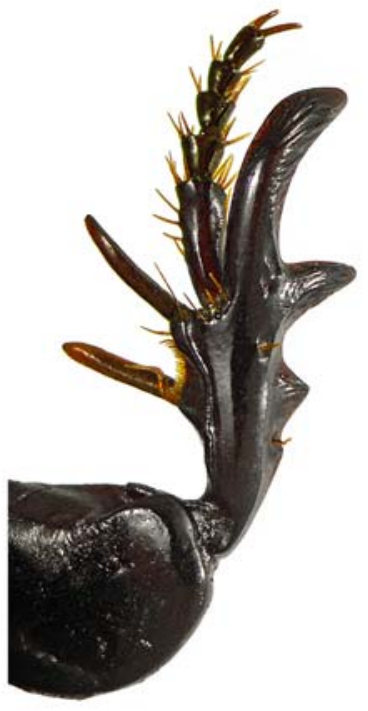

40

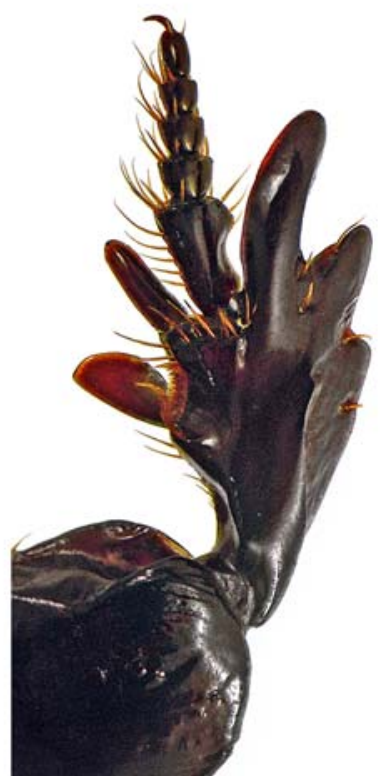

41

Figs 34-41. Protibia and protarsus: 34 - Thlibops longicollis; 35 - Th. congoensis; 36 - Parathlibops integricollis; 37,41 - P. minor; 38 - Scapterus sp. pr. sulcatus; 39 -Passalidius f. fortipes; 40 - P. bulirschi sp.n.; 34-37, 38-40 - caudal (ventral) aspect; 41 - frontal (dorsal) aspect.

Рис. 34-41. Передние голень и лапка: 34 - Thlibops longicollis; 35 — Th. congoensis; 36 — Parathlibops integricollis; 37,41 P. minor; 38 - Scapterus sp. pr. sulcatus; 39 -Passalidius f. fortipes; $40-$ P. bulirschi sp.n.; 34-37, 38-40 - сзади; 41 - спереди. 
and Passalidius) or 2-4 (Scapterus), or two (Pasimachus, Oxylobus), or none (Mouhotia, Parathlibops).

Lateral decumbent setae on sternite III are present (Acanthoscelis and most Scaritina) or absent (Mouhotia, Pasimachus, Oxylobus, and Scapterina).

Legs.

(23) Structure and chetotaxy of protibia: $23 \mathrm{a} \leftarrow 23 \rightarrow \ldots \rightarrow 23^{\prime \prime \prime}$. Scaritite groundplan pattern is considered to be a fairly slender protibia with two large lateral teeth in addition to apical spine, all running along posterolateral edge; movable apical spurs moderately long and narrow; basal tarsomere as long as the following one or two combined; anterior side with a few setae in a longitudinal sublateral row.

Most Scaritina and Oxylobus have tibia more or less flattened and broadened apicad (23'), a slightly more advanced condition; many Scaritina have one or more additional, closely set denticles just above the upper lateral tooth. $23 \mathrm{a}$, protibia tridigitate laterally and strongly incrassate, i.e., flattened in transverse plane and dilated much apicad (Thlibops and Parathlibops: Figs 34-37, 41). - 23"', protibiae long and rather slender; preapical lateral tooth much distal to the tarsal insertion; both movable spurs (flanking the antenna cleaner) long and narrow; basal tarsomere very slender, as long as tarsomere $2-5$ combined; anterior side with ca. $15-20$ dense setae in a long row extending from base of the tibia to beyond its apex (Acanthoscelis and Scapterus: Fig. 38). All the above characters, except for the long and slender movable spurs, are likely synapomorphies. - 23", nearly the same, but slightly less modified pattern: basal tarsomere clearly shorter and the preapical lateral tooth situated proximal to the tarsal insertion (Passalidius: Fig. 39). What also makes it seem transitional from $23^{\prime}$ to $23^{\prime \prime \prime}$ is the anterolateral setae varying in number within Oxylobus, from 7 to 10 .

Some Madagascan genera of Scaritina, e.g., Prodyscherus, have the protibiae similar to those of Acanthoscelis or Scapter$u s$, except for the missing anterolateral row of setae.

Fixed leg setae.

(24) Protrochanteral seta: $24 \rightarrow \ldots \rightarrow 24^{\prime \prime} ; 24^{\prime} \rightarrow 24^{\prime}$ a 24 , two ventral (one basal and one apical) setae present - supposedly primitive (Clivinini and Dyschiriini). One, distal, seta present in Scaritini $\left(24^{\prime}\right)$, in rare cases may be lacking (24"': Scapterus, Mouhotia) or double (24'a: Thlibops).

(25) Profemoral setae. We consider the following setae: ventrobasal, anterior $(v b a)$, and posterior $(v b p)$, setae, combined with one posteroventral seta $(p v): v b a \boldsymbol{n}+v b p \boldsymbol{m}(+p v)$ The $1+1+1$ arrangement, with $p v$ in preapical position, is the most common and considered primitive (Scarites and Distichus; vba may be missing or multiple, up to $3-4)$. $-P v$ at first shifted to the middle of the femur (Thlibops) and then disappeared to produce the $1+1$ (occasionally $0+1 / 1+0$ ) arrangement (Parathlibops) are further slight modifications. $P v$ is also missing in Scapterus, Carenum and Pasimachus, producing $0+1,4+0$, or $3(3+3)$ arrangement, respectively. All setae have disappeared in Mouhotia, but multiplied in Passalidius. In Acanthoscelis, the arrangement is 3-4+1+1.

(26) Mesocoxal setae. 26, Two setae present, internal and external (Scarites, Distichus, Acanthoscelis). - 26', inner seta lost (Scapterus). - 26a, outer seta lost (Thlibops, Parathlibops, Oxylobus). - Both setae lost (Passalidius, Pasimachus, Mouhotia).

(27) Metacoxal setae. The following three setae present, internal (ins), anterolateral (als) and posterolateral ( $p l s)$, constitute the groundplan arrangement of Carabidae. This also seems to be true of Scarititae, but very few scaritites have the trisetose metacoxa, including Distichus among Scaritini and Sparostes among Clivinini. Yet the Distichus tend to have some other usual setae in greater numbers. The derived character states are: als-pls (27': Clivinini, Scarites, Mouhotia, Acanthoscelis), ins-pls (27a: Oxylobus), ins-als (27b: Thlibops), als (?: Scapterus and Pasimachus). In Parathlibops, ins may be present (27b') or missing (27b"), or (sometimes) up to four in number $\left(27 b^{\prime} a\right)$. There are no traceable setae in Passalidius and in some Pasimachus species.

All we can say is that most of the seta reductions were independent, so ins is symplesiomorphic for Distichus, Thlibops, Parathlibops, and Oxylobus, and trisetose metacoxa is a groundplan feature of Scapterina, Scaritina and probably Scarititae.

Female genitalia and reproductive tract.

(28) Gonostylus: $28 \rightarrow \ldots \rightarrow 28^{\prime \prime \prime \prime}$. Divided fully or almost so (28: Pasimachus, Mouhotia), or partly (28': some Clivinini), into two segments, gonosubcoxite (= gonocoxite 1) and gonocoxite (= gonocoxite 2$)$. - 28", gonostylus entire, well-sclerotized, and falcate (many Clivinini), most likely derived condition. This gonostylys of advanced fossorial type underwent independent reductions in the course of evolution to a non-fossorial gonostylus, so an entire yet poorly sclerotized gonostylus with rounded apex and with or without tactile setae is characteristic to Dyschiriini and some Clivinini (e.g., Coryza, Eoclivina, etc.).

Some scapterines also have gonostylus of that type; in Oxylobus, it is just slightly reduced (28"'), being narrowly subcylindrical in apical half and densely pubescent in apical third; in Thlibops and Parathlibops it is strongly reduced $\left(28^{\prime \prime \prime \prime}\right)$, widely rounded apically and asetose.

(29) Female reproductive tract of Scaritini is distinctive [Liebherr, Will, 1998] due to spermathecal gland absent, and tubular, long to very long (Pasimachus, Mouhotia) spermatheca and accessory gland opening into bursa copulatrix far apart.

The Dyschiriini provide a good example of how a welldeveloped spermathecal gland (Clivinini) can be completely reduced in the course of evolution. In Dyschiriodes (the nitidus-group and the rufimanus-group), duct of a filiform spermathecal gland enters spermatheca not far from its apex. Basal to this point, ventral wall of the spermatheca has a serpentine, 'pseudohelmintoid', sclerite, which suggests a homology of the sclerite with the basalmost section of the spermathecal gland duct. In Dyschirius, spermatheca is V-or U-shaped, with its longer horn opening into bursa copulatrix while shorter horn directly extended into very fine and long spermathecal gland.

Parathlibops Basilewsky, 1958

Type species: Scapterus dohrnii Chaudoir, 1863.

REDESCRIPTION. Body (Figs 42-53) apterous, small or medium-sized for Scaritini, slender and rather shiny. Coloration black, without metallic luster. Meshed microsculpture isodiametric and very superficial in general, being barely traceable on labrum, as well as on basal declivity of elytra and sometimes also at bottom of elytral striae; ventral microsculpture barely less superficial and more evident along sides. Head and pronotum in at least apical half minutely and moderately densely punctate, combined with similar and often very dense micropunctation; pronotum otherwise smooth, sometimes with coarse and sparse to moderately dense punctures in apical half, exceptionally with rather sparse transverse rugosities, in couple with sparse longitudinal strigae behind apical transverse impression. Elytra impunctate to minutely and sparsely punctate, without dense 
multituberculate sculpture along base and sides. Underside moderately and confluently punctate on each side of gula while sparsely to densely punctate along sides of sterna and abdomen, with abdominal sternites II-III densely, finely and mostly entirely punctate.

Head (Figs 3-8) slightly incrassate, subquadrate to rounded, with a double supraocular seta on each side. Eyes almost vertical, much shorter than high, enclosed by genae throughout except anteroventrally, sometimes totally enclosed. Genae in lateral view concave, rounded to pointed anteriorly; in dorsal view not or conspicuously projecting forward in form of acute tooth. Clypeus barely sinuate between small apical teeth; these in advance of oblique clypeal wings; supraantennal plates not or barely separated from clypeal wings, rounded or straight laterally, thereby giving rounded or subquadrate outline of head, respectively. A generalized pattern of head sculpture is as follows (Figs 6, 8): frontoclypeal suture very fine, hardly traceable laterally, interrupted medially by a blunt $Y$-shaped carina bearing a conspicuous conical tubercle in the middle. Arms of this Y curved forward and reaching clypeal teeth; its stem reaching neck constriction as a median carina; this latter is surrounded with an $\omega$-shaped carina (hereinafter referred to as ' $\omega$ '. Another blunt longitudinal carina (hereafter referred to as intermediate carina) running between ' $\omega$ ' and supra-ocular carina and extended toward the apex of supra-antennal plate. More or less deep grooves between ' $\omega$ ' and intermediate carinae extended basad into slightly impressed lines barely converging towards pronotal apex. Neck constriction subconvex forward, moderately deep and smooth, gently convex forward, slightly trifid, a little deeper toward and terminating just behind eyes, sometimes obsolete. Antennae moniliform and short, closely pubescent at both ridges; a wide medial area between them smooth and glossy, but for a few sparse peripheral setae; scape moderately long, about as long as antennomeres 2-4 combined; pedicel as long as or slightly longer than wide, antennomere 3 slightly longer than wide, 4 slightly transverse, $5-10$ very so, with $6-10$ being three quarters or more wider (higher) than long. Mandibles flat dorsally and gently upturned apicad, with ventral scrobal ridge concealed with dorsal scrobal ridge; dorsal surface rugose, rugose-punctate or obliquely striate on each side of median carina. Labrum trilobed, with two lateral setae. Penultimate labial palpomere bisetose at inner margin, shorter than apical one. Apical maxillary palpomere banana-like, much larger than penultimate one, length ratio ca. 1.75-2.1. Ligula short and asetose. Mentum asetose, quadrate, deeply excavate on each side of a strongly raised median triangle terminating into a median tooth. This tooth as long lateral lobes, very pointed at tip, acutangular ventrally while acutangular to slightly trifid or quadrate dorsally; lateral edges of median triangle finely carinate in apical half or at least close to apex; these lateral carinae often merged into a median one; one pair of external labial pits situated just in front of mentum suture; these pits oblong, moderately large, deep or very deep, subcontiguous or merged into a common pit. Submentum very short and either bisetose or asetose (Table); gula moderately wide for Scaritini.

Pronotum very large and very convex, barely wider than elytra (EW/PW ca. 0.95), about a half to almost twice as long as wide, broadest a third from base, without lateral setae; sides very slightly rounded and converging slightly apicad; basal angles widely rounded and edentate, apical angles acute and projecting forward. Median line moderately deep, running from basal bead to apical transverse impression. Basal foveae as a pair of short, smooth, deep to obsolete sulci starting from basal bead, running parallel to each other or slightly diverging and disappearing less than one third from base. Lateral bead entire and extended into basal one without interruption; groove inside this marginal bead narrow lateral to basal foveae or throughout. Basal transverse impression missing or forming a slight, flat and smooth ( $P$. integricollis) or densely striate, dilation of basal groove (that just in front of the basal bead) between basal foveae. Apical transverse impression V-shaped, deep and crenate medially, very deep and smooth laterally.

Elytra connate, very convex, oval or oblong-oval, broadest a little or clearly behind the middle (ca $0.55-0.60$ times from base), more or less widely rounded apically; sides nearly straight in basal third. Base more or less deeply concave, with basal declivity vertical or nearly so, somewhat oblique from mesothoracic peduncle to humeri. Basal ridge thick, oblique to convex forward; lateral ridge (reflexed lateral margin) very narrow and visible from above just behind humerus only, if at all. Humeri distinct yet rather widely rounded, situated just behind and dorsal to rounded or obtusely dentate humeral angles. Striae entire or obliterate on basal and sometimes also on apical declivity, mostly punctate, with punctures growing larger, denser and deeper apicad, often foveate to alveolate before apex; stria 8 fine and impunctate, obliterate in apical third, rarely still shorter. Intervals very convex to costate, sometimes slightly convex; some of them, mostly even, slightly to much wider than those in between. Interval 1 mostly much or at least clearly narrower than $2^{\text {nd }}$, joining $8^{\text {th }}$ at sutural angle. Interval 8 wide and costate in at least apical third, concealing lateral edge in at least basal third and being elytral apex (Figs 17-28); lateral edge merged in this apical costa lateroventrally. Interval 9 narrow and very finely carinate on each side of a narrow and deep groove bearing an uninterrupted row of dense umbilical setae at bottom. Parascutellar stria missing or very short and distinct close to mesothoracic peduncle only. Parascutellar, basal and discal setae absent (large serial discal pores running on intervals 3,5 and 7 in the type species only).

Underside. Prosternum strongly raised and somewhat carinate along middle and angulate apically, being sinuate on each side of this angle; medial ridge blunt and grooved basally, swollen medially, terminating into a sharp, longer or shorter, apical carina. Intercoxal process pentagonal and parallel-sided between procoxae, widely triangular behind, sides of the triangle strongly diverging basad; a blunt to indistinct ridge separates ventral side from basal declivity. Sternopleural suture very fine and hardly traceable; propleura with finely carinate lateral margin; hypomera narrow and gently concave in apical portion, sometimes all along. A deep oblique concavity on each side of median prosternal carina for reception of fore leg, so that lateral margin of pronotum convex in lateral view. Pleural ridge $(P R)$ varying between species from entire to obliterate. Posterior propleural ridge (ppr) entire to reduced to basal propleural ridge (bpr) only.

Intercoxal process of mesoventrite slightly projecting forward beyond mesocoxa (better seen in lateral view). Metaventrite beaded along anterior margin, with both median and transverse grooves indistinct or barely traceable. Metepisternum long. Abdomen finely beaded along sides, sternites without transverse sulci. Sternite VII in apical view with high apical flange and a pair of deep anal grooves (Figs 1728 ); in ventral view slightly trilobed in outline owing to external openings of anal grooves projecting slightly inwards. All standard setae absent.

Legs. Tarsi with ventral median carina missing or vestigial. Profemora in frontal view strongly incrassate and nearly 
circular in outline. Protibia (Figs 36-37, 41) flat and strongly broadened apicad, with 3-4 lateral teeth decreasing in length basad (more clearly, with 2-3 teeth at posterolateral edge in addition to apical spine), upper tooth very small to indistinct; apical spine with a small excision inside base, a short longitudinal groove just mesal to it; $1-3$ setigerous pores, mostly 2 , present between bases of apical and preapical teeth; movable spurs (those on each side of antennal cleaner) varying in shape between species, mostly subequally slender, preapical spur being a little stronger than apical one, sometimes clearly dilated. Anterolateral edge of protibia sharp and adjoining preapical setigerous pore, sometimes extended apicad beyond it; anterior face with inner sulcus fine and deep, mostly obsolete or interrupted opposite excavation of antennal cleaner, rarely entire (P. paviei, $P$. puncticollis). Protarsomere 1 deeply sinuate at middle of posterior (outer) margin, as long as tarsomeres $2-4$ combined. Mesotibia moderately flattened and dilated apicad, subquadrangular in cross-section medially, with both lateral edges sharp and separate; preapical immovable spur close to apex; anterolateral edge with 4-6 small close denticles/tubercles, terminal tubercle being larger and situated (much) closer to penultimate denticle than to preapical immovable spur. Metatrochanter obliquely truncate at apex of posterior (ventral) margin; this truncate face or entire ventral margin being slightly concave or grooved. Metatibia with posterolateral edge finely carinate and asetose ( $P$. glaber only shows 1-2 ensiform setae in basal third); anterolateral edge blunt; latero-apical immovable spur rather short, conspicuous to indistinct. Chetotaxy (Table): protrochanter with ventral seta, profemur with one ventrobasal seta, protibia with 1-3 preapical anterolateral setae; mesocoxa with inner seta; mesofemur with anterior setae arranged into two rows: ventral $(0-10$ setae $)$ and dorsal $(1-7$ setae in apical third), each species showing a particular combination of anteroventral and anterodorsal setae; metacoxa with $0-1$ inner seta, metatrochanter with $0-1$ seta, metafemur asetose (sometimes mesocoxal seta double and metacoxal seta multiplied to 2-4 in number).

Aedeagus (Figs 59-78, 87-111, 119-124): Median lobe symmetrical, with apex curved downwards, triangular and pointed in lateral view; basal bulb on each side with a deep and large laterobasal impression limited by a carina. Parameres symmetrical, long and narrow, mostly with slightly broadened apices; these bearing dense and fairly short setae. Internal sac with rather a small X-shaped sclerite.

Female gonostyli rudimentary, poorly sclerotized, apically rounded and glabrous, not fit for digging; vagina with dorsal wall strongly sclerotized, transformed into a convex median sclerite; in two species examined, this sclerite varies in shape and size greatly, from small and longitudinal ( $P$. cavipennis sp.n.) to a very large and slightly transverse (P. nepalensis sp.n.).

DIAGNOSIS. This original diagnostic combination [Basilewsky, 1958] used to separate the genus from the Afrotropical Thlibops Putzeys, 1866 included the following: eyes reduced in size and enclosed by genae ( $v s$. well-developed and convex); supraocular and pronotal setae absent (vs. posterior supraocular seta and anterolateral pronotal setae present); and parameres apically pubescent ( $v s$. glabrous). Additional features of Parathlibops include: apterous condition; elytra connate, non-cylindrical, and wider (much shorter than basal sulci of pronotum); sculpture of head slightly different; teeth of anterolateral edge of mesotibia distinct and well separated from preapical spur (vs. indistinct and not separated). Chetotaxy: many fixed setae absent (vs. one double supraocular, 1-2 anterolateral pronotal, 1-2 parascutel-
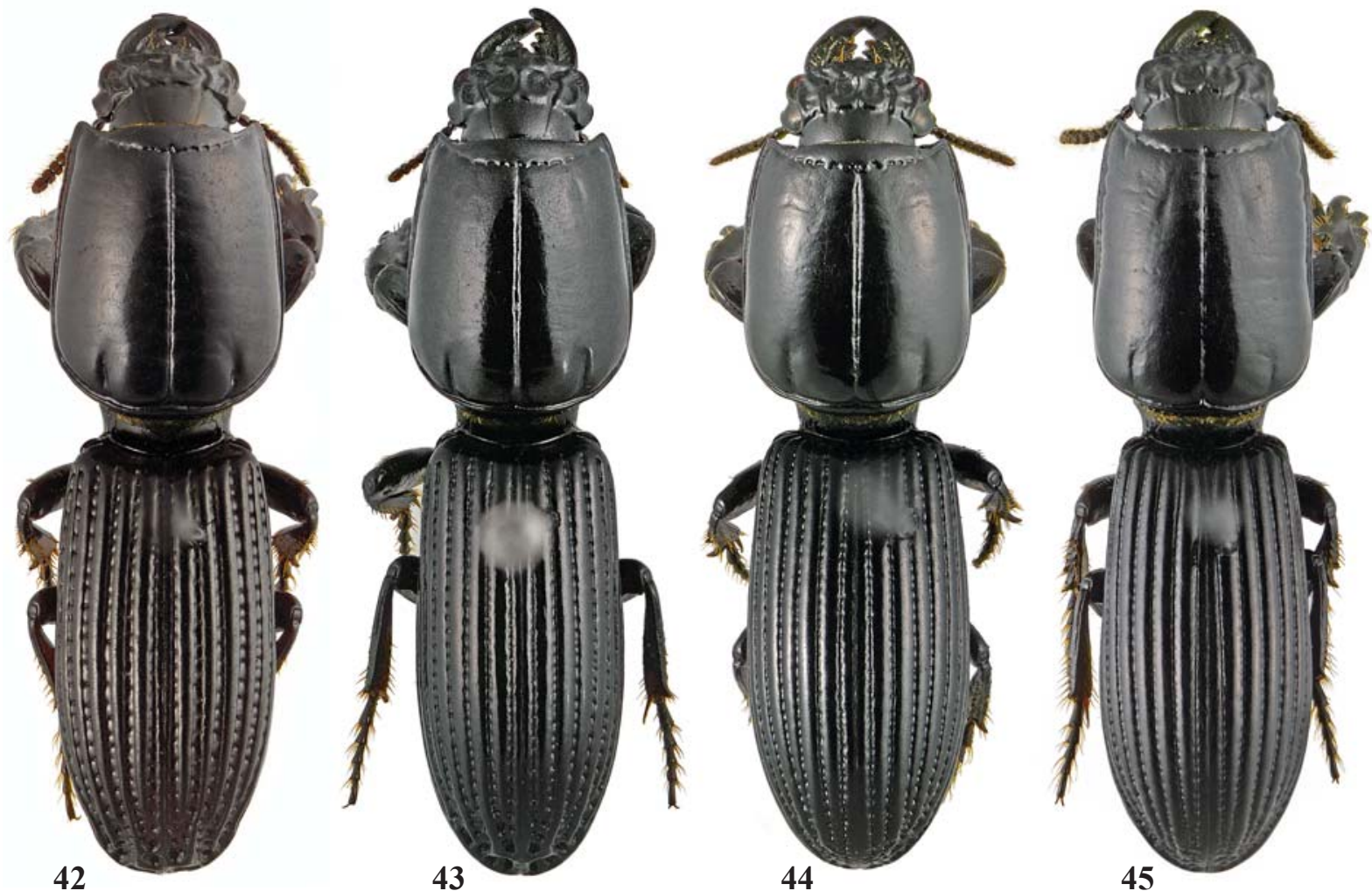

Figs 42-45. Dorsal habitus: 42 - Parathlibops abramovi sp.n.; 43 - P. cavipennis sp.n.; 44 - P. crenatus; 45 - P. cylindronotus sp.n. Рис. 42-45. Габитус сверху: 42 - Parathlibops abramovi sp.n.; 43 - P. cavipennis sp.n.; 44 - P. crenatus; 45 - P. cylindronotus sp.n. 
lar, 1 ambulatory on abdominal sternites IV-VII, 1 femoral), $0-1$ inner metacoxal seta present (vs. two, inner and anterolateral). Aedeagus in lateral view slender, with apex pointed and curved downwards. Parameres with apical setae confined to apical area and moderately dense, $v s$. sparse in Scapterus (Figs 116-117) or absent in Thlibops (Figs 112-115), or very dense and long in Passalidius (118).

HABITATS AND HABITS. The adults are fossorial, dig deep burrows, occur in tropical monsoon forests rather far from water, and avoid mountain ridges and steep slopes. Some species, e.g., $P$. paviei and $P$. crenatus, inhabit lowlands, but many others from mainland Asia have hitherto been collected at $800-1650 \mathrm{~m}$ altitudes.

COMMENTS. Great similarity between Thlibops and Parathlibops and many characters shared by the two suggest much closer relation between these two than between each of them and any other scapterine. At the same time, many characters of Parathlibops, including apterous condition and numerous missing setae, seem derived as compared to $T h$ libops, suggesting that Thlibops is more primitive than Parathlibops. All the species of Parathlibops have probably evolved from a Thlibops-like ancestor once widespread in South and Southeast Asia. Speciation followed the increasing isolation of local populations as the aptery evolved.

The genus includes 20 species, among them seven described below. They are all very similar in body proportions, except for one species from southern India; because of its unique features (structure of the tibiae, the greatly reduced stria 8 , etc.) we erect a new subgenus for that species.

Twelve essentially vicariant species are scattered over a vast area from India to Java; seven more are confined to the Philippines. Surprisingly, the two dozen Philippine specimens available to me were all either $P$. integricollis (Heller, 1923 ) or P. minor (Heller, 1916). Both show high individual and geographic variability in size and elytral sculpture. According to the descriptions, three Philippine species, $P$. $a b$ breviatus (Heller, 1923), P. intermedius (Heller, 1921), and P. omega (Heller, 1899), are all larger and have impunctate elytral striae and deep basal sulci of the pronotum. I do not discuss them since no specimens were available to me.

The three Philippine species discussed below share a character combination that separates them from the mainland Asian lineage(s): the slenderer body, EL/EW 2.072.24 (vs. 1.91-2.10), PL/PW 1.23-1.35 (vs. 1.18-1.27); the head almost square (vs. rounded) and and barely wider than neck ( $v s$. clearly wider than neck); prosternal process with basal declivity concave ( $v s$. flat or subconvex) and well separated by a blunt carina from ventral side (vs. indistinctly separated); outer elytral intervals less modified basally, due primarily to the broader interval 9 , with its outer carina distinct and entire; submentum bisetose ( $v s$. asetose in many species); and metatrochanter with a seta ( $v s$. asetose, except for one species).

All, or most, of these characters show character states that are less derived than those in most mainland species, suggesting the basal position of the Philippine lineage within the genus.

Most species from Indochina may be arranged into two loosely defined groups: the puncticollis-group (P. puncticollis, $P$. nepalensis sp.n., and probably also $P$. wittmeri and $P$. alveolatus sp.n.) and the crenatus-group (P. crenatus, $P$. cylindronotus sp.n., $P$. cavipennis sp.n., and $P$. abramovi sp.n.). Distribution patterns of the groups are slightly different: northwestern in the puncticollis-group $v s$ southeastern in the crenatus-group.

The puncticollis-group is defined chiefly by the combination of coarsely punctate pronotum, asetose submentum, and alveolate preapical punctation of the elytral striae. Some of these characters are polythetic, so that the pronotum is almost
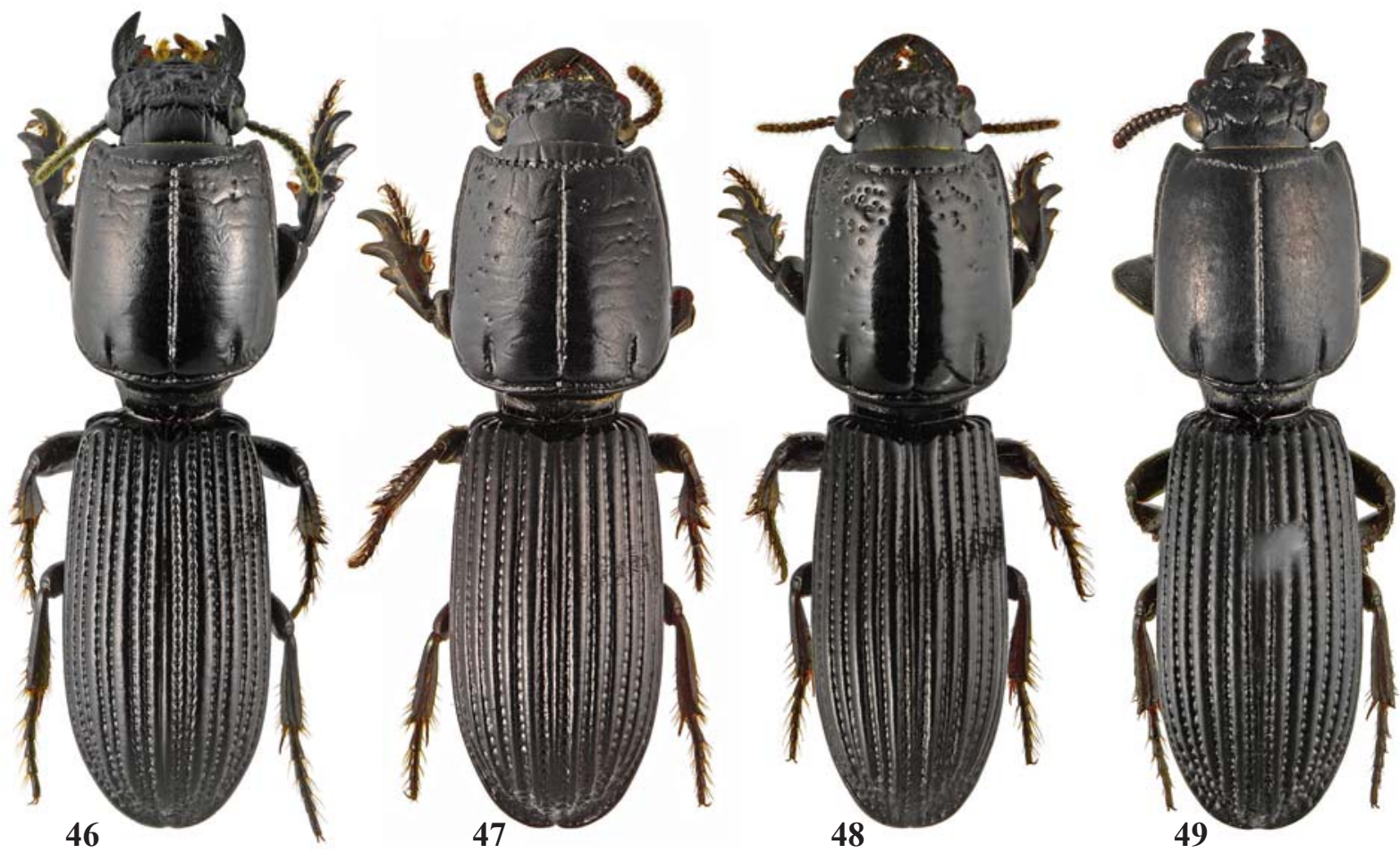

Figs 46-49. Dorsal habitus: 46 - Parathlibops nepalensis sp.n.; 47, 48 — P. puncticollis, holotype (47) and specimen from Nyaunggon (48); $49-P$. alveolatus sp.n.

Рис. 46-49. Габитус сверху: 46 - Parathlibops nepalensis sp.n.; 47, 48 - P. puncticollis, голотип (47) и экз. из Nyаunggon; 49 — P. alveolatus sp.n. 
impunctate in $P$. alveolatus sp.n. and totally impunctate in $P$. wittmeri. However, aedeagi in $P$. wittmeri and P. puncticollis are similar, suggesting that the two are closely related. Also, the striae on basal elytral declivity are deep in P. puncticollis and $P$. alveolatus sp.n. vs. obliterate in the other two species. This makes $P$. wittmeri and $P$. alveolatus sp.n. similar in certain ways to some members of the crenatus-group, namely, to $P$. cavipennis sp.n. and $P$. abramovi sp.n.

The crenatus-group is defined by bisetose mentum, combined with impunctate pronotum and elytral striae well impressed on basal declivity. On the other hand, P. cavipennis sp.n. and $P$. abramovi sp.n. are sibling species with peculiar elytral sculpture and elytral striae obliterated on basal declivity. Unlike other mainland Asian species, P. cylindronotus sp.n. has retained trochanteral setae, while in P. crenatus the submentum is asetose.

Table 1. Selected body setae in Thlibops and Parathlibops Таблица 1. Некоторые стандартные хеты в родах Thlibops и Parathlibops

\begin{tabular}{|c|c|c|c|c|c|c|c|c|c|}
\hline species setae & smt & trI & $\begin{array}{c}\text { feI vb, } \\
\text { a-p }\end{array}$ & feI pv & $\begin{array}{c}\text { cxII } \\
\text { in }\end{array}$ & $\begin{array}{l}\text { exIII } \\
\text { in/al }\end{array}$ & trIII & $\begin{array}{l}\text { felI } \\
\text { ad }\end{array}$ & $\begin{array}{l}\text { feII } \\
\text { av }\end{array}$ \\
\hline T. longicollis & 2 & 2 & $1-1$ & 1 & 1 & $1 / 1$ & + & 2 & $1-3$ \\
\hline T. congoensis & 2 & 1 & $1-1$ & 1 & 1 & $1 / 1$ & + & 2 & $1(2)$ \\
\hline P. minor & 2 & $1-2$ & $1-1$ & - & 1 & $1 /-$ & + & $3-6$ & $7-10$ \\
\hline P. integricollis & 2 & 1 & $1-1$ & - & 1 & $1-2 /-$ & + & $3-4$ & $6-10$ \\
\hline P. punctipennis & 2 & 1 & $1-1$ & - & 1 & $1 /-$ & + & $3-4$ & 5 \\
\hline P. cylindronotus & 2 & 1 & $1-1$ & - & $2-3$ & $4 /-$ & + & $3-4$ & $1-4$ \\
\hline P. abramovi & 2 & 1 & $1-1$ & - & 1 & $1 /-$ & - & $2-4$ & $1-3$ \\
\hline P. cavipennis & 2 & 1 & $1-1$ & - & 1 & $1 /-$ & - & 7 & 2 \\
\hline$P$. paviei & 2 & 1 & $1-1$ & - & 1 & $1 /-$ & - & $4-5$ & $3-4$ \\
\hline P. puncticollis & - & 1 & $1-1$ & - & 1 & $1 /-$ & - & $3-5$ & $4-5$ \\
\hline P. nepalensis & - & 1 & $1-1$ & - & 1 & $1 /-$ & - & $2-4$ & $1-4$ \\
\hline P. alveolatus & - & 1 & $1-1$ & - & 1 & $1 /-$ & - & 4 & $5-6$ \\
\hline P. crenatus & - & 1 & $1-1$ & - & 1 & $1 /-$ & - & $3-4$ & $5-6$ \\
\hline P. glaber & - & 1 & $1-1$ & - & 1 & - & - & $2-3$ & $0-1$ \\
\hline P. bulirschi & 2 & 1 & $1-1$ & - & 1 & - & - & $1-2$ & 5 \\
\hline
\end{tabular}

I, II, III, pro-, meso-, meta-, respectively; a, anterior; ad, anterodorsal; al, anterolateral; av, anteroventral; cx, coxa; fe, femur; in, internal; tr, trochanter; smt, submentum; p, posterior; pv, posteroventral.

\section{Key to SPECIES OF PARATHLIBOPS}

1(28) Body slender (Figs 42-53), pronotum clearly longer than wide, PL/PW 1.16-1.35, 1/2-3/5 wider than head. Protibia much dilated apicad, short and flat, shorter than pronotum (Figs 36-37, 41). Mesoventrite in lateral view projecting forward beyond mesocoxa

subgenus Parathlibops (s.str.)

2(3) Elytral intervals 3, 5, and 7 each with 3-5 large pores. Java ................................. P. dohrnii (Chaudoir, 1863)

3(2) Elytral intervals without large pores.

4(9) Pronotum (Figs 46-48) in apical 1/2-1/3 with more or less numerous coarse punctures (sometimes these punctures almost reaching base or reduced to a few ones in apical corners). Elytral interval 1 before apex mostly very narrow to faint due to alveolate punctures in stria 1 (Fig. 21).

5(6) Elytral striae impunctate in basal three quarters; intervals subequally wide and striate basally. Abdomen finely punctate. - Southwestern India

P. filiformis (Andrewes, 1929)

6(5) Elytral striae moderately to coarsely punctate, intervals smooth at bases. Submentum asetose. Some elytral intervals mostly alternatively wider and narrower in addition to narrow interval 1 . Pronotal basal sulci deep. Propleural ridge $(P R)$ double and long to entire.

7(8) Elytral intervals subequally wide or those 2, 4 and sometimes also 6 wider than others; all striae well impressed on basal declivity, striae 7 and 8 confluent basally, leaving interval 8 finely carinate and markedly narrower at base than behind. $P R$ 1/3-2/5 shortened from the outside. Metatibia externally with immovable apical spur conspicuous and pointed. Median lobe of aedeagus with apical lamella truncate at tip in dorsal view. BL 10.9-12.7 mm. Myanmar ...................... P. puncticollis (Gestro, 1883)

8(7) Elytral intervals 3, 5 and somewhat 7 and 8 wider than others; at least striae 5-7 obliterate on basal declivity; striae 7 and 8 separate basally, leaving interval 8 barely narrower at base than behind. Metatibia externally with immovable apical spur small and less pointed. BL 12.3-14 mm. Eastern and southern Nepal ............. P. nepalensis sp.n.

9(4) Pronotum without coarse punctures; if with 1-5 punctures in apical corners (one species), then elytral intervals equally wide. Interval 1 entire to vanished before apex.

10(11) Elytron (Figs 26, 50) with altogether eight instead of nine intervals, those 2 to $3-4$ subequally very wide, $8^{\text {th }}$ very narrow and substituted for the inner carina of $9^{\text {th }}$. Pronotal basal sulci shallow to inconspicuous. Elytral striae reaching apex, very finely punctate or only crenulate. Abdominal sternite VII transversely sulcate near apex and impunctate or almost so. BL 10.9-15.3 mm. - Cambodia, southern Vietnam .................................. P. paviei (Lesne, 1896)

11(10) All nine elytral intervals present, $9^{\text {th }}$ narrow, with a fine inner carina.

12(27) Elytral striae clearly punctate throughout but at apex. Pronotal basal bead rounded or blunt in cross-section, straight or vaguely $\Lambda$-shaped in the middle. Head with supra-antennal plates predominantly rounded on sides.

13(26) Head rounded owing to supra-antennal plates well rounded laterally and the eyes, combined with genae, more clearly projecting laterad (Fig. 8); head with both 
$\omega$-shaped carina and neck constriction distinct; neck usually nearly smooth or less coarsely sculptured than forehead. Elytra with intervals equally wide or alternatively wider and narrower, $1^{\text {st }}$ narrow yet distinct before apex.

14(15) Gena extended forward beyond eye into a subacute tooth. Pronotal basal sulci rather deep, but half shortened from behind; basal transverse impression as a fairly deep groove running just in front of basal bead between virtual bases of basal sulci. Elytral interval 6 reduced basally (Fig. 51). Abdominal sternite VII almost impunctate (Fig. 24). BL 14-14.6 mm. - Southern India

P. glaber (Andrewes, 1929)

5(14) Gena rounded and not projecting forward beyond eye. Pronotum without or with indistinct basal transverse impression; basal sulci entire.

16(19) Elytral intervals costate to carinate apically, $2^{\text {nd }}, 4^{\text {th }}$ and $6^{\text {th }}$ reduced in apical fifth; interval 3 forking before apex, its forks joining intervals 1 and 8 ; striae at apex with a few very deep foveae/cavities (Figs 17-18). Abdomen with marginal bead much thicker apically than laterally. Protibia with three lateral teeth. Submentum bisetose. Elytral striae obliterate on basal declivity. Pronotal basal sulci deep.

17(18) Elytral intervals costate, carinate apically, those 2, 4 and 6 abruptly obliterate before apex; striae sulcate, with punctures not surpassing the striae in width (Fig. 17). Abdominal sternite VII with coarse and mostly dense punctures. BL 15.8-17.6 mm. - Central Vietnam ........ P. abramovi sp.n.

18(17) Elytral intervals convex, costate apically, $2^{\text {nd }}, 4^{\text {th }}$ and $6^{\text {th }}$ smoothly obliterate before apex; striae much narrower, with punctures surpassing the striae in width (Fig. 18). Abdominal sternite VII generally smooth. BL $15.6 \mathrm{~mm}$. Southern Laos ............................... P. cavipennis sp.n.

19(16) Sculpture of elytra not as above. Abdomen with marginal bead fine throughout.

20(25) Elytral intervals subequally wide in addition to a very narrow interval 1; striae well impressed on basal declivity. Abdomen coarsely and densely punctate at sides. Median lobe of aedeagus in dorsal view with apical lamella triangular and rounded or pointed at tip.

21(24) Elytral striae subequally deep all along and moderately punctate in basal half, with punctures coarse and deep yet quite separate before apex (Figs 19-20); intervals 27 convex. Propleural ridge simple.

22(23) Pronotal basal sulci deep. Eyes well-developed. Basal declivity of elytra steep. Abdominal sternite VII coarsely and densely punctate. Metatrochanter asetose, with a faint ventral groove at apex. Propleural ridge double, a fourth shortened from the outside. Aedeagus in dorsal view symmetrical, with apical lamella triangular (Fig. 87). BL 11.8$15 \mathrm{~mm}$. - Southern Vietnam

P. crenatus (Chaudoir, 1863)

23(22) Pronotal basal sulci fine and rather shallow. Eyes very narrow. Basal declivity of elytra nearly upright. Propleural ridge $1 / 3$ its maximum length shortened from the outside; metaventrite with entire anterior bead. Abdomen coarsely and rather densely punctate along sides; sternite VII widely smooth along middle, with several coarse punctures at sides only. Meso- and metacoxae each with a triple inner seta, metatrochanter with seta and entire ventral groove. Median lobe of aedeagus slightly asymmetrical at apex, apical lamella in posteroventral view nearly parallel-sided and rounded at tip (Fig. 90). BL 14.2-16.4 mm. - Southern Vietnam (The Dalat Plateau) P. cylindronotus sp.n.
24(21) Elytral striae entire and very deep, more so behind the middle, with punctures alveolate, very deep and very close, in part confluent; intervals 2-7 costate to carinate close to apex (Fig. 23). Basal sulci very deep, sulcate. Abdominal sternite VII as in P. crenatus. Propleural ridge double, nearly same as in P. puncticollis. BL $12.6 \mathrm{~mm}$. Southern Laos ............................... P. alveolatus sp.n.

25(20) Elytral intervals 2, 4 and 6 costate and clearly wider than others in basal third, interval 1 very narrow; striae sulcate and coarsely punctate, obliterate or obsolete on basal declivity. Pronotal basal sulci wide and very deep. Median lobe of aedeagus with apical lamella truncate at tip in ventral view. BL 12.5-15 mm. - Eastern Bhutan, Himalayas ........................... P. wittmeri Casale, 1980

26(13) Head nearly parallel-sided due to supra-antennal plates parallel-sided laterally and the eyes together with genae very little projecting laterad (Figs 4, 6); a fine carina on each side of median tubercle, otherwise densely rugulosepuncate, without distinct $\omega$-shaped carina or neck constriction. Elytral intervals costate, $4^{\text {th }}$ and $6^{\text {th }}$ clearly wider than adjacent ones, $1^{\text {st }}$ nearly reduced close to apex while $2^{\text {nd }}$ wide and costate there (Fig. 27). Mesoventrite conspicuously bilobed at anterior margin, with a deep longitudinal sulcus (Fig. 126). Gena as subacute tooth projecting forward beyond eye. Abdominal sternites moderately and densely punctate, except for along middle; VII coarsely punctate at sides while minutely and densely at middle, with a transverse sulcus close to apex. BL $15 \mathrm{~mm}$. - Mindanao, the Philippines ...................................... P. punctipennis sp.n.

27(12) At least inner three elytral striae impunctate on disc or nearly so. Pronotal basal bead often sharply edged behind, with a small semilunar excision in the middle. Head parallel-sided before eyes due to supra-antennal plates straight laterally. Elytral interval 1 nearly reduced close to apex. - Species from the Philippines.

28(1) Body stout (Fig. 54), pronotum short and wider than long, much (three quarters) wider than head. Protibia long and slender (Fig. 40). Mesoventrite invisible in lateral view. - Southern India

$$
\text { P. (Scapterothlibops) bulirschi sp.n. }
$$

Parathlibops (Parathlibops) abramovi Fedorenko, sp.n. Figs 7-8, 17, 42, 59-60, 88, 98-99.

MATERIAL. Holotype $0^{\top}$ (ZMMU) and paratypes $40^{7} \sigma^{7}$ (SIEE) labelled: 'S-Vietnam, Gia Lai Province, $\sim 50 \mathrm{~km}$ N of An Khe, Kon Chu Rang Nat[ure]. Reserv[e], 14³0-312N, 108 $322 \mathrm{E}, \mathrm{h}=1000$ $1040 \mathrm{~m}$ [asl], 24.V-2.VI.2016, D Fedorenko leg.’

DESCRIPTION. Body (Fig. 42), BL 15.8-17.6 mm. Labrum, sides of neck, pronotum in basal half and elytra, except for along middle of intervals, with superficial microsculpture. Head and pronotum rather densely micropunctate, combined with minute and moderately dense punctures becoming increasingly sparse towards base of pronotum; elytra similarly, but very sparsely and superficially, punctate to impunctate. Dorsum shiny, pronotum slightly dull because of meshed microsculpture being more distinct along base and especially outside basal sulci.

Head (Figs 7-8). Eyes rather wide behind, genae not projecting forward, in lateral view concave and well-rounded anteriorly. Supra-antennal plates rounded laterally. Intermediate carinae angulate: parallel at sides of $\omega$-shaped carina yet strongly diverging in front. Mentum tooth acutangular and very pointed, medial triangle flat and finely carinate at lateral edges; a fine median sulcus traceable throughout or at tip of median tooth only; lateral concavities deep and reaching base; lateral edge double, primary edge being concealed with sec- 
ondary one; mentum pits merged into a common pit, barely separated at its bottom; submentum bisetose.

Pronotum truncate apically, barely rounded at sides, PW/ HW 1.52-1.54 (1.53, n=5), PL/PW 1.21-1.26 (1.24). Apical transverse impression evenly concave, moderately deep, crenate medially, straight and smooth laterally; basal bead slightly angulate in the middle; median line entire and deep, indistinctly sulcate (i.e., flat at bottom). Basal sulci deep and parallel, each with a fine and not quite even impressed line at bottom.

Elytra about twice as long as wide, EL/EW 1.94-2.0 (1.97), with sides almost straight in basal half, basal margin concave, basal declivity almost vertical, humeri distinct yet widely rounded; basal ridge rounded, without or with a vague trace of humeral tooth; EW/PW 0.94-0.98 (0.96), EL/PL 1.48-1.57 (1.53). Striae deep, sulcate (Fig. 17), obliterated on basal declivity, slightly deeper and wider posteriorly; striae $1-7$ free at base, with $7^{\text {th }}$ running very close to $8^{\text {th }}$. Punctures in striae coarse and very deep, yet narrower than striae. Intervals $2-8$ subequally wide and costate, subcarinate before apex; $1^{\text {st }}$ very narrow; $8^{\text {th }}$ increasingly narrower basad and carinate in basal quarter; $9^{\text {th }}$ deeply grooved along middle, with inner carina conspicuous in anterior $3 / 5$. Interval 3 forking before apex; intervals 7,5 , and outer fork of $3^{\text {rd }}$ successively joining interval 8 there while inner fork of interval 3 joining interval 1 . Intervals 2,4 and 6 disappearing abruptly before apex, leaving striae 1 and 2, 3 and 4, 5 and 6 confluent pairwise behind, with punctures foveate, increasingly larger and deeper, thereby forming several deep cavities inside interval 8.
Underside. Prosternum more or less swollen before procoxae, with a fairly deep median sulcus running from between procoxae to this swell and with a sharp median carina in front; the median sulcus slightly wider both basally and apically; intercoxal process evenly declivous basad, without transverse carina delimiting between ventral side and basal declivity; latter slightly convex and rather finely longitudinally rugulose-striate. Propleural ridge obliterate in lateral 1/ $2-1 / 3$, double just outside procoxa or forming 'pleural triangle'; posterior propleural ridge interrupted. Mesoventrite flat or indistinctly concave between mesocoxae, truncate at anterior margin. Metaventrite not or vaguely beaded. Abdominal sternite VII with lateral bead increasingly thick apicad, much thicker apically than lateral beads of sternites II-VI; sternites IV-VI widely smooth along middle, sparsely to moderately densely punctate along sides; punctures medium-sized, combined with very fine ones - sternite IV with ca. 30 punctures each side, V with 9-20, VI with 3-14; VII with 16-26 coarse to very coarse punctures in apical half and along sides, mostly combined with 1-4 minute punctures in corners (one paratype shows one apical and $2+4$ lateral coarse punctures of totally 11 larger punctures present).

Legs. Protibia with three lateral teeth, $4^{\text {th }}$, upper, tooth totally reduced or almost so; both apical movable spurs narrow. Mesofemur with 2-4 anterodorsal and 1-3 anteroventral setae in apical $2 / 5$; mesotibia at anterolateral edge with 4-5 minute teeth above another, large, apical tooth situated much closer to preapical tooth than to latero-apical immovable spur. Metatrochanter asetose, with entire apical (ventral) margin sulcate; metatibia with latero-apical im-

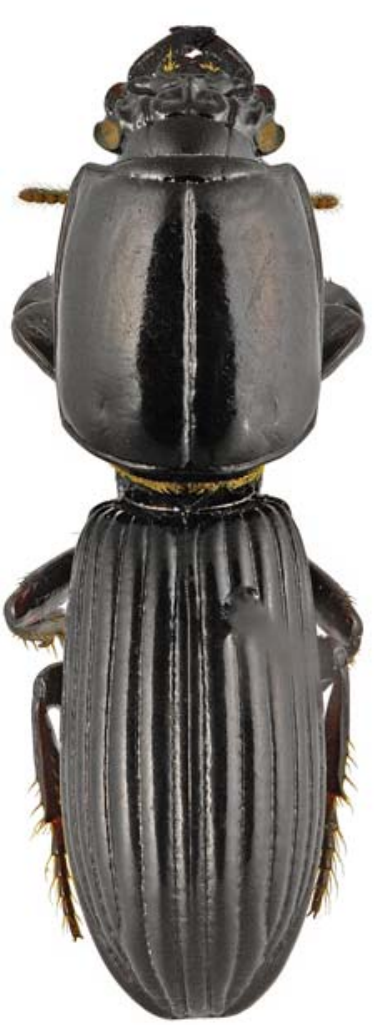

50

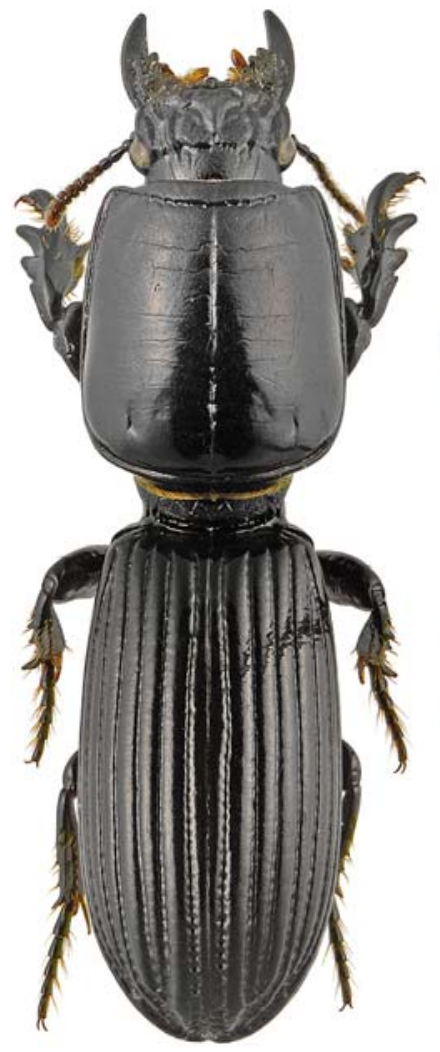

51

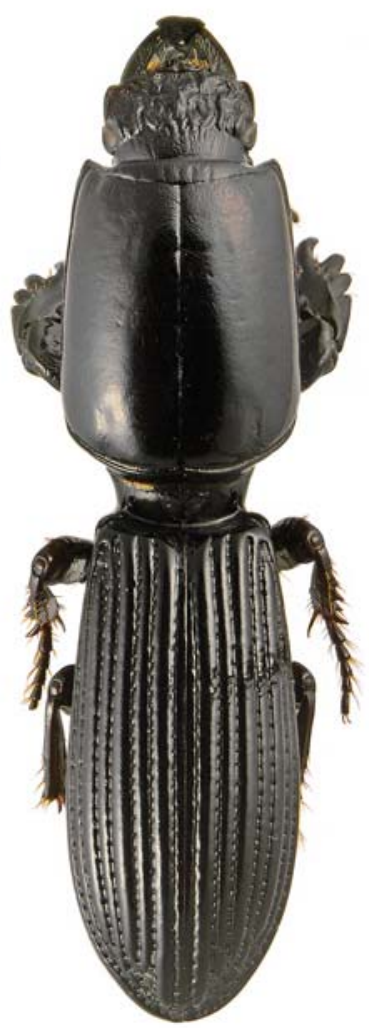

52

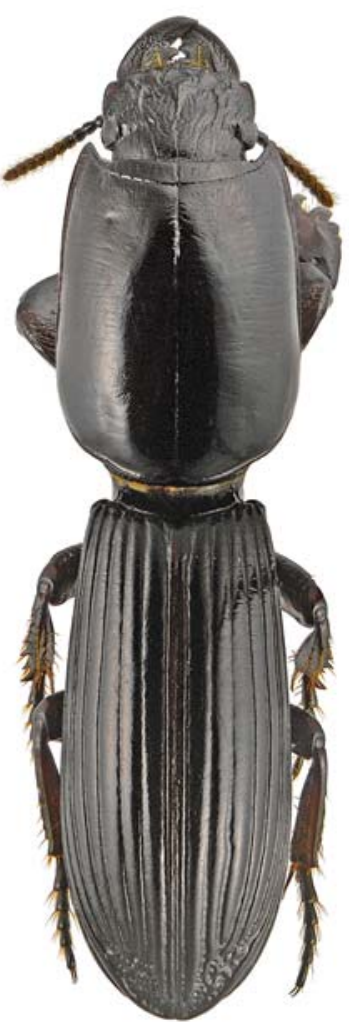

53

Figs 50-53. Dorsal habitus: 50 - Parathlibops paviei; $51-$ P. glaber; $52-$ P. punctipennis sp.n.; $53-P$. integricollis. Рис. 50-53. Габитус сверху: 50 - Parathlibops paviei; 51 - P. glaber; 52 - P. punctipennis sp.n.; $54-P$. integricollis. 


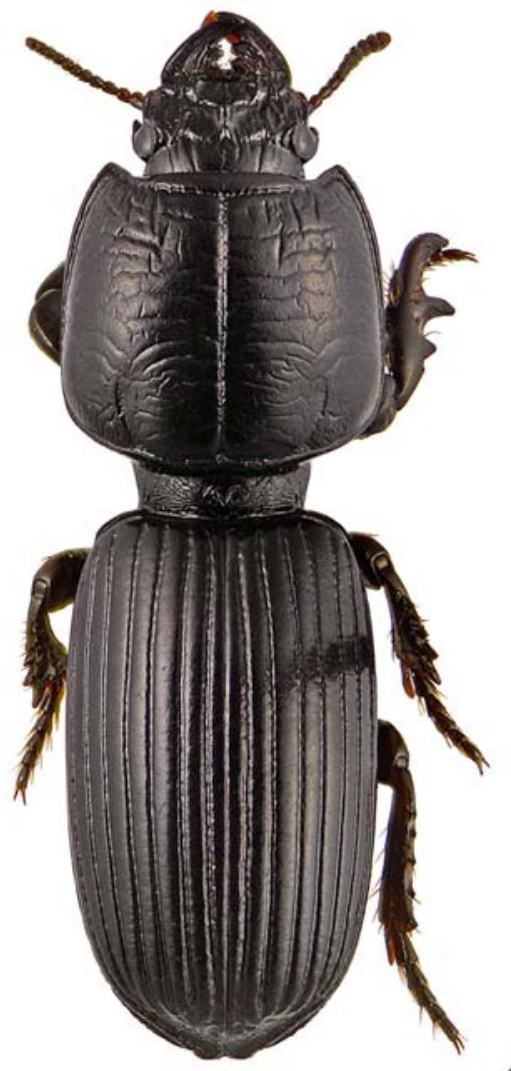

54
(2)

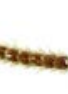

seose

13
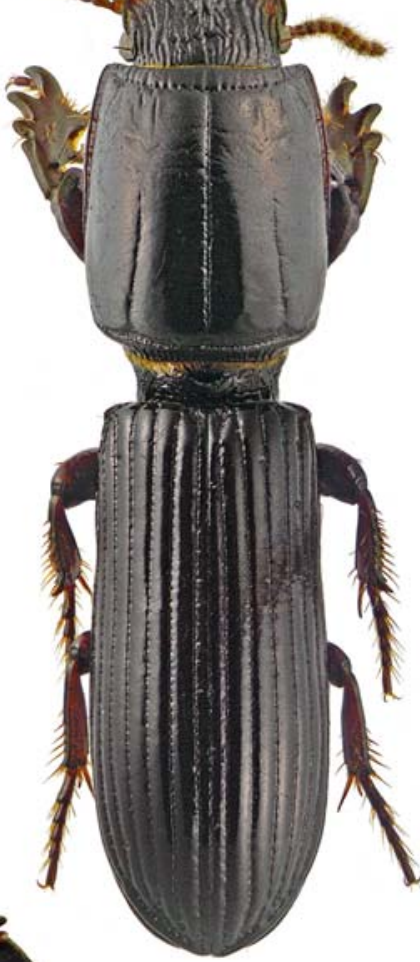

55

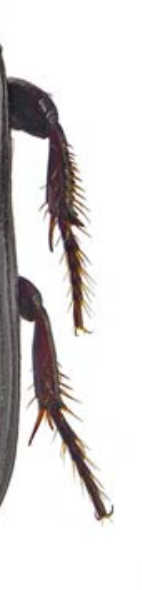

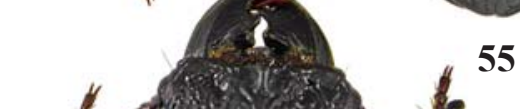
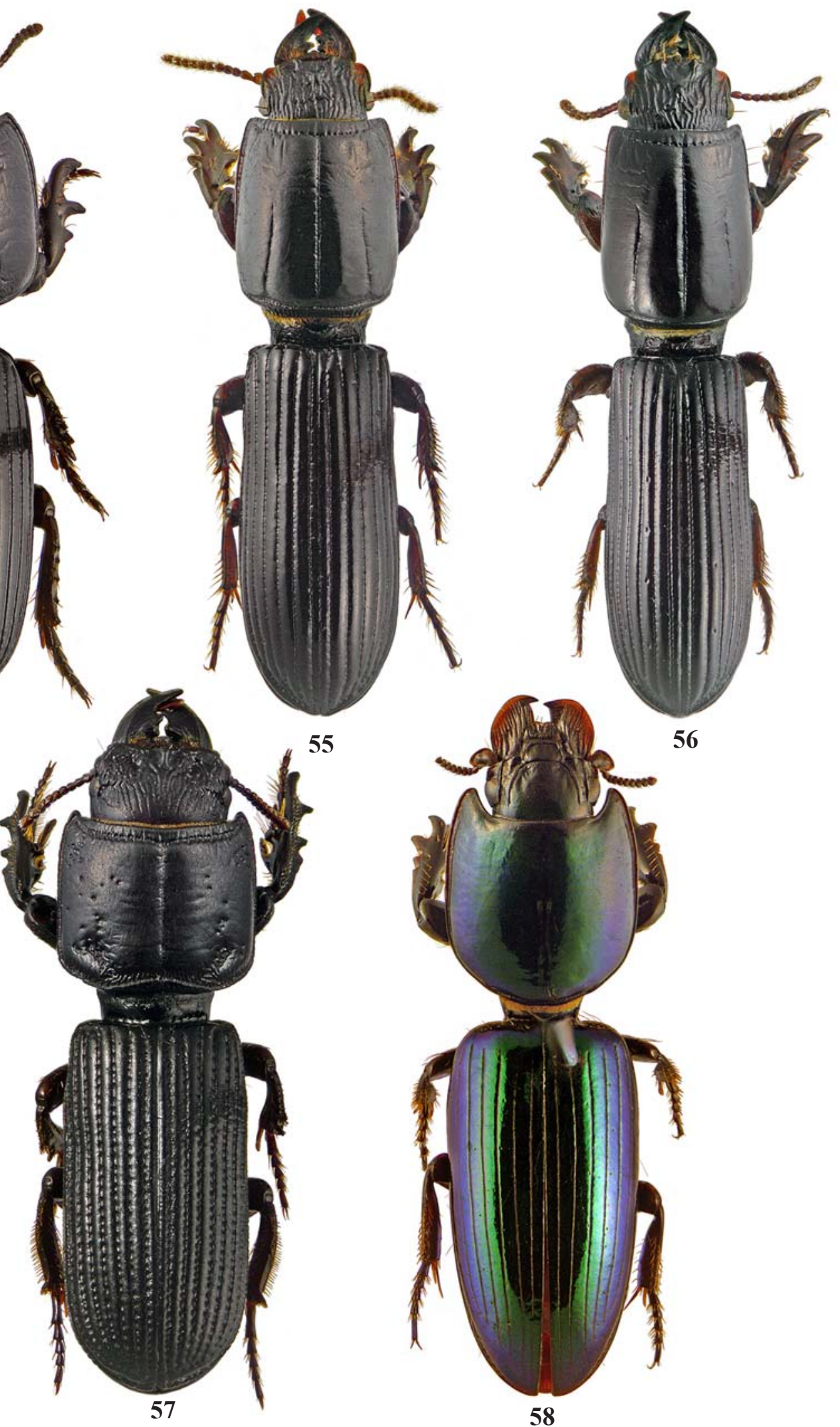

Figs 54-58. Dorsal habitus: 54 — Parathlibops bulirschi sp.n.; 55 — Thlibops longicollis; 56 - Th. congoensis; 57 — Scapterus sp. pr. sulcatus; 58 - Corintascaris ferreirae.

Рис. 54-58. Габитус сверху: 54 - Parathlibops bulirschi sp.n.; 55 - Thlibops longicollis; 56 - Th. congoensis; 57 - Scapterus sp. pr. sulcatus; 58 - Corintascaris ferreirae. 
movable spur moderately large and pointed; an ensiform seta inserted at its tip.

Aedeagus (Figs 59-60, 88, 98-99): median lobe with a very fine, median, ventro-apical carina; apical lamella strongly bent downward in lateral view, tapering and very narrow in ventral view. Parameres narrow, very gently broadening at apices; these obliquely truncate, somewhat rounded and rather sparsely setose.
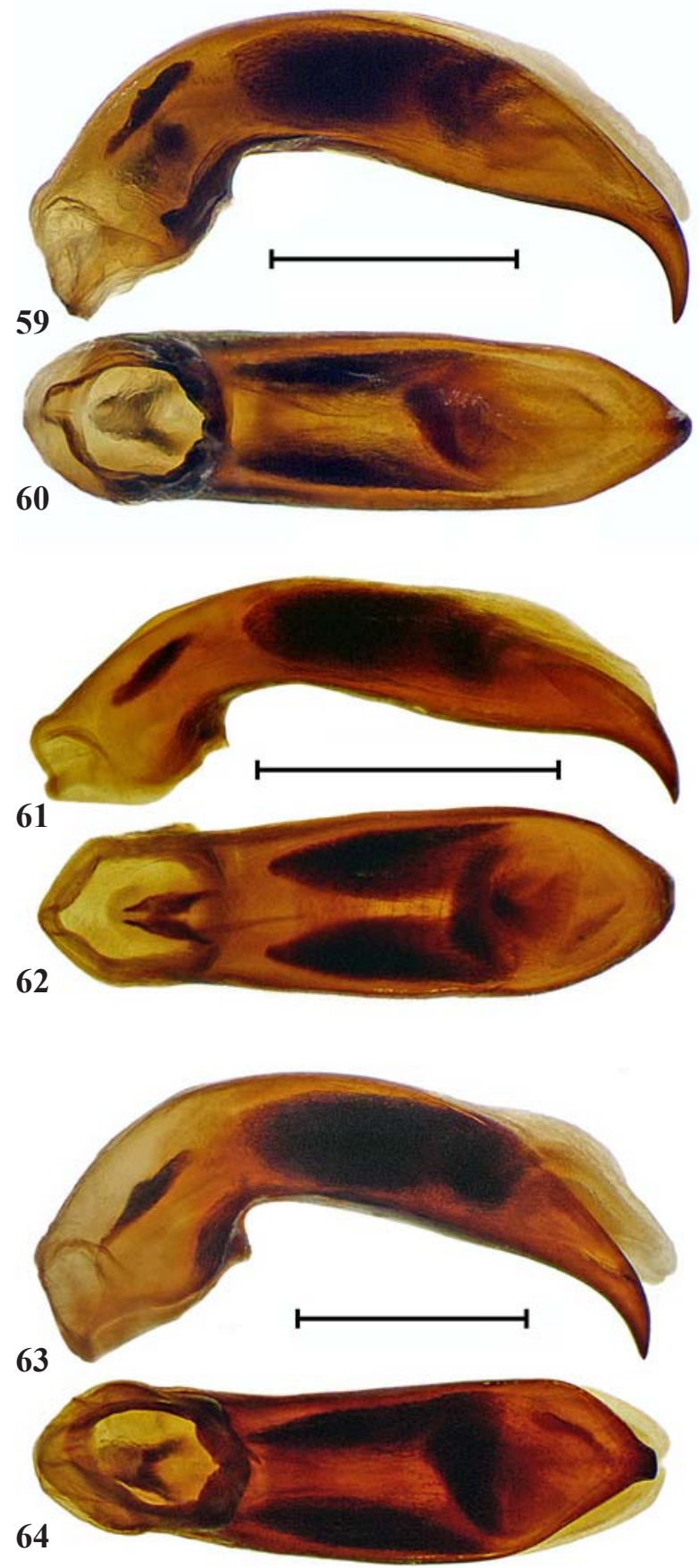

65

66

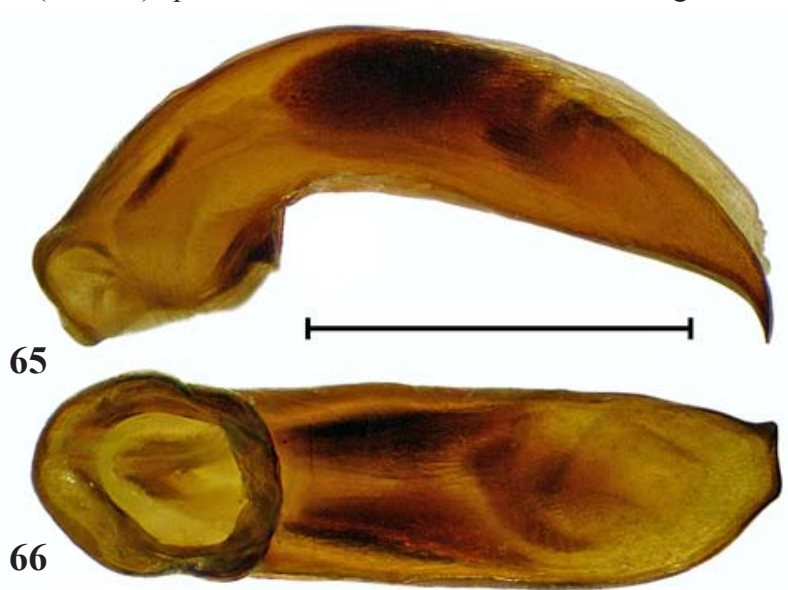

67

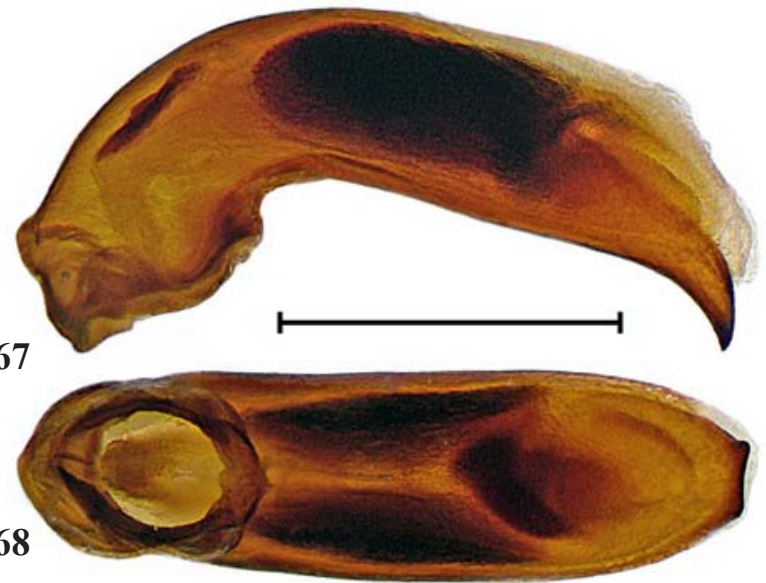

DIAGNOSIS. The species is distinctive chiefly in having an unusually coarse sculpture of the elytral apex, combined with very thick apical bead of the abdominal sternite VII. A similar sculpture of the elytral apex, including somewhat anastomosing odd intervals, is also found in $P$. wittmeri, but the latter is distinctive in having the even elytral intervals clearly wider than odd ones in basal third, and a differently shaped (truncate) apical lamella of the median lobe of aedeagus.

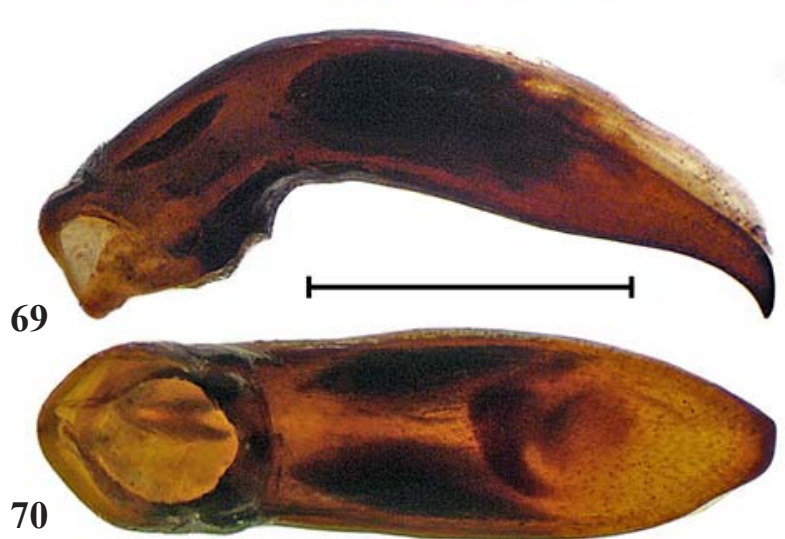

Figs 59-70. Aedeagus median lobe: 59-60 - Parathlibops abramovi sp.n.; 61-62 - P. crenatus; 63-64 - P. cylindronotus sp.n.; 6568 - P. puncticollis, holotype (65-66) and specimen from Nyaunggon (67-68); 69-70 - P. alveolatus sp.n.; 59, 61, 63, 65, 67, 69 - left lateral aspect; $60,62,64,66,68,70$ - ventral aspect. Scale bar - $1 \mathrm{~mm}$.

Рис. 59-70. Средняя доля эдеагуса: 59-60 - Parathlibops abramovi sp.n.; 61-62 - P. crenatus; 63-64 - P. cylindronotus sp.n.; 65-68 - P. puncticollis, голотип (65-66) и экз. из Nyaunggon (67-68); 69-70 - P. alveolatus sp.n.; 59, 61, 63, 65, 67, 69 — слева; 60, $62,64,66,68,70-$ снизу. Масштаб - 1 мм. 
NAME. Given after Dr. Alexei V. Abramov, a mammologist, my good friend and companion during expeditions to Vietnam, who helped me collect many interesting carabids, including three paratypes of this species.

DISTRIBUTION. Known from the type locality only.

HABITATS AND HABITS. All the specimens were taken in a mixed monsoon forest at $1000 \mathrm{~m}$ altitude, two by pitfall traps and three by hand in leaf litter along a trail or running across the trail.

\section{Parathlibops (Parathlibops) cavipennis Fedorenko, sp.n.} Figs 18, 43.

MATERIAL. Holotype + (ZISP) labelled: 'Laos Attopeu, Si-Su riv., 10.3.1986, Kabakov', 'Thlibops paviei Lesne, Kabakov det. 1987'.

DESCRIPTION. Same as previous, except as follows. Body (Fig. 43) $15.6 \mathrm{~mm}$ in length. Pronotum shiny due to very superficial meshed microsculpture; elytral intervals without microsculpture.

Head with intermediate carinae nearly straight and diverging forward. Pronotum: PW/HW 1.56, PL/PW 1.23; basal sulci straight. Elytra slightly longer, EL/EW 2.10; basal ridge without humeral tooth; EW/PW 0.92, EL/PL 1.57. Striae deep yet rather narrow, only a little sulcate (Fig. 18). Intervals convex, costate before apex; $8^{\text {th }}$ narrower than $7^{\text {th }}$ in middle two quarters; $2^{\text {nd }}, 4^{\text {th }}$ and $6^{\text {th }}$ disappearing smoothly before apex; apical cavity behind forks of interval 3 smaller and thence seemingly deeper, in form of inverted ' $U$ '. Abdominal sternites V-VI similarly yet finely and rather sparsely punctate, with punctures confined mainly to basal halves of the sternites; sternite VII quite smooth but 4-6 very fine punctures in corners VII. Mesofemur with 7 anterodorsal and 2 anteroventral setae in apical 2/5.

NAME. Refers to a distinctive concavity of the elytral apex.

DISTRIBUTION. Xe Xou River, Attapeu Province, southern Laos.

COMMENTS. This species and very similar P. abramovi sp.n. are found in two fairly close localities and may be just subspecies of the same species.

Parathlibops (Parathlibops) crenatus (Chaudoir, 1863) Figs 19, 44, 61-62, 87, 100-101.

Chaudoir, 1863: 118 (Scapterus; 'Cochinchina' [=Southern Vietnam])

MATERIAL. O7 (SIEE): Southwestern Vietnam, Phu Quoc Island, Expedition of Russo-Vietnamese Tropical Center, 26.XI20.XII.2003, leg. A. Anichkin.

REDESCRIPTION. Unnecessary, except for the following additional characters. Body (Fig. 44), BL $11.8-15 \mathrm{~mm}$. Dorsum shiny, without meshed microsculpture, except for on labrum and on basal declivity of elytra.

Eyes fairly large, genae not projecting forward. Supraantennal plates well rounded laterally; $\omega$-shaped carina illdefined anteriorly; intermediate longitudinal carinae imperceptible at the level of median tubercle; converging lines on neck fine and starting (in the specimen listed) between intermediate and supra-antennal carinae. Mentum with labial pits contiguous yet separate.

Pronotum smooth, without basal transverse impression; basal sulci deep, subsulcate; basal bead transversely straight medially; PW/HW 1.49, PL/PW 1.19.

Elytra almost twice as long as wide, EL/EW 1.94, EW/ PW 0.97; basal declivity steep; no humeral tooth. Striae entire and deep, subsulcate (Fig. 44), coarsely punctate; 1-7 free at base. Punctures in striae dense yet quite separate before apex. Intervals convex, $1^{\text {st }}$ slightly narrower than $2^{\text {nd }}$, intervals $2-7$ not quite reaching apex.
Underside: Propleural ridge double, obliterate in its outer fourth; Mesoventrite with a vague median sulcus. Metaventrite with anterior bead conspicuous except for just medially. Abdominal sternites IV-VI coarsely and densely punctate except just medially; sternite VII very coarsely and densely punctate, except for along sides, apex and middle of base.

Legs. Protibia with four lateral teeth, but upper tooth nearly indistinct; both apical movable spurs narrow. Mesofemur with 3-4 anterodorsal and 5-6 anteroventral setae in apical 2/5. Metatrochanter asetose and faintly grooved at apex of ventral margin only.

Aedeagus (Figs 61-62, 87, 97-101) median lobe with apical lamella of aedeagus triangular in ventrobasal view. Parameres subequally wide throughout their length, rounded and moderately densely pubescent at tips.

DISTRIBUTION. Lowlands of southern Vietnam, including Phu Quoc Island.

\section{Parathlibops (Parathlibops) cylindronotus Fedorenko, sp.n.}

Figs 20, 45, 63-64, 90, 102-103.

MATERIAL. Holotype $\sigma^{7}$ (ZMMU) and paratype $\sigma^{7}$ (SIEE) labelled: 'S[outh]-Vietnam, Dak Lak Prov[ince]., Chu Yang Sin Nat[io]n[al]. Park, $12^{\circ} 222363 \mathrm{~N}, 108^{\circ} 212133,1.5 \mathrm{~km} \mathrm{~W}$ of $\mathrm{Chu}$ Pan Phan Mt, h=1650 m [asl], 19.III-2.IV.2013, D.Fedorenko leg.'.

DESCRIPTION. Same characters as in P. abramovi sp.n., except as follows. Body as in Fig. 45, BL 14.2-16.4 mm. Microsculpture on pronotum reduced to extreme middle of basal bead and groove in front of it.

Head. Eyes almost enclosed anteriorly, very narrow behind. Neck constriction with a few oblong punctures or very short lines behind; converging impressed lines on neck begin between $\omega$-shaped carina and intermediate carina (holotype) or between intermediate and supra-ocular carinae (paratype).

Pronotum nearly cylindrical, with sides barely converging apicad, straight or barely concave at middle, very gently rounded before, PW/HW 1.51-1.52, PL/PW 1.21-1.23. Basal sulci fine and rather shallow.

Elytra oblong-oval, EL/EW 2.0-2.03, with basal declivity nearly upright, EW/PW 0.93-0.97, EL/PL 1.55-1.60. Striae entire and deep, a little sulcate behind, finely punctate in basal third, moderately punctate behind, slightly foveate before apex, with punctures partly confluent close to apex (Fig. 20). Intervals subcostate; $8^{\text {th }}$ slightly narrower than $7^{\text {th }}$ at middle, very narrow in basal third, carinate behind humerus; $9^{\text {th }}$ bicarinate all along, but inner carina obliterate apically; intervals 3 and 5 slightly longer and wider than adjacent ones.

Underside. Mentum with double lateral edge and one large and deep labial pit; median tooth triangular, indistinctly trifid as being slightly angulate on each side. Prosternum with median carina blunt and deeply sulcate before and between apical halves of procoxae while sharp in front; a blunt transverse carina hardly separates between ventral side and very slightly excavated basal declivity of intercoxal process. Mesoventrite with a shallow median sulcus. Metaventrite entirely beaded anteriorly. Abdomen densely and rather coarsely punctate along sides, with a considerable admixture of finer and shallower punctures; a fairly wide medial area very minutely and densely punctate; marginal bead fine throughout.

Legs. Protibia with four lateral teeth, but upper one subtle; both apical movable spurs narrow. Mesotibia at anterolateral edge with 4-5 small teeth; of them, apical tooth large, situated a little or clearly closer to preapical one than to latero-apical immovable spur, truncate at tip and bearing several strong and close setae. Metatrochanter with seta and sulcate ventral margin; metatibia fairly small yet pointed apically. Mesocoxa with 
2-3 inner setae, mesofemur with 3-4 anterodorsal and 1-4 anteroventral setae in apical 2/5; metacoxa with four setae.

Aedeagus (Figs 63-64, 90, 102-103): slightly asymmetrical apically, with left side convex while right side straight; apical lamella narrow, subcylindrical, rounded at tip and slightly curved to the right. Parameres not or barely broadening at apices, each with a fringe of dense and long setae.

DIAGNOSIS. Most similar to P. crenatus, except for the very narrow eyes, the subcylindrical pronotum, and the shallower basal pronotal sulci. Moreover, $P$. cylindronotus sp.n. is the only mainland Asian species that has the metatrochanteral seta, like its Philippine congeners. For additional differences see the key to species.

NAME. Refers to the shape of the pronotum.

DISTRIBUTION. Only known from the type locality.

HABITATS AND HABITS. Both specimens have been collected under logs in a tropical monsoon forest at rather high altitudes.

COMMENTS. In the paratype, the striae look obliterated on basal elytral declivity, perhaps due to abrasion during burrowing. Damage of this kind is common among fossorial insects.

Parathlibops (Parathlibops) nepalensis Fedorenko, sp.n. Figs 21, 46

- ? wittmeri: Balkenohl, 2003: 231 (part.).

MATERIAL. Holotype + (CB) labelled: 'Nepal East, Kosi Zone, Dhankuta Distr.Arun Valley, Hille-Shidua-Bhedetar, 20002700, 5.6.-8.6.1999, M. Pejcha lgt.'. Paratypes: \& (CB), same data; o (CB): 'S ASIA S-Nepal, Chitwan R.Nat.Park V-2001, Sauhara vill, Rapti riv.flumen, lgt dr.M.Häckel'; + $(\mathrm{CB})$ : 'NEPAL east, 5.8.1997, DHANKUTA env./ Hille vill., 1500m/ A.Kř́žzová lgt' 'Parathlibops wittmeri CAS., det.Balkenohl, 1998'. All type specimens are suplied also with the label 'PARATHLIBOPS wittmeri Casale, 1980, P. Bulirsch det. 2010'.

DESCRIPTION. Samecharacters asin P. abramovi sp.n. except as follows. Body (Fig. 46) $12.3-14 \mathrm{~mm}$ in length; palps deep red, antennae reddish-brown. Dorsal microsculpture traceable on labrum and basal declivity of elytra near mesothoracic peduncle, hardly traceable in larger foveate punctures of elytral striae before apex, absent from pronotum. Head and pronotum with moderately dense to sparse micropunctation, combined with minute punctures.

Head irregularly and densely rugose in general, so that ùshaped carina less distinct anteriorly or distinct only behind; intermediate carinae short and well-defined behind median tubercle only; neck constriction slightly trifid or almost bifid, crenulate and/or with sparse punctures; neck rather uneven, with rather numerous short longitudinal striae in addition to convergent impressed lines.

Pronotum with sides almost straight and very gently converging forward, sometimes parallel-sided in basal half, PW/HW 1.46-1.59 (mean 1.55), PL/PW 1.18-1.22 (1.20). Basal sulci parallel, very deep, often deeper or foveate anteriorly. Basal bead straight medially; marginal groove fine and usually clearly wider yet shallow in apical half, but deep and fairly wide, tuberculate or longitudinally striate, between basal sulci. Median line deep and fine to narrowly sulcate. Disc with about a dozen fine, undulate, transverse rugosities more distinct along middle and along sides, but very shallow or obliterate in between; apical $1 / 3-2 / 5$ with six to about 30 , irregularly spaced, in part confluent, coarse punctures; sometimes these punctures reduced to $3-5$ in number and confined to apical angles only.

Elytra oblong-oval, EL/EW 1.93-1.97 (1.96), with sides very gently rounded, almost straight in basal half, EW/PW 0.98-0.99 (0.98), EL/PL 1.59-1.63 (1.61); basal declivity almost upright; basal ridge running parallel to base, terminating into obtuse and blunt yet distinct humeral angle (tooth). Striae deep, densely and rather coarsely punctate, obliterated on basal declivity, free at bases or with only $7^{\text {th }}$ and $8^{\text {th }}$ adjoining basally; sometimes striae 1,2 and parascutellar striole traceable on basal declivity. Intervals subcostate, $1^{\text {st }}$ and $2^{\text {nd }}$ equally very narrow; $3^{\text {rd }}$ and $5^{\text {th }}$ in apical $3 / 4$ clearly or much wider than intervals 1,2 and 4 , wider than $6^{\text {th }}$, as wide as or slightly wider than subequally wide intervals 7 and 8 . Punctures in striae becoming increasingly dense and coarse apicad, in part confluent and irregularly alveolate before apex, thereby leaving intervals $2-7$ and mostly 1 obliterate there (Fig. 21). Interval 9 very narrow basally, with outer carina reduced in basal 1/4-1/5.

Underside. Mentum with lateral edge double; median tooth indistinctly trifid due to its lateral bead abruptly disappearing just behind apex; submentum asetose. Propleural ridge nearly entire and double. Mesoventrite indistinctly projecting forward beyond mesocoxae. Metaventrite entirely beaded anteriorly. Abdomen with lateral bead narrow throughout; all sterna coarsely and moderately densely punctate along sides, combined with sparse to fairly dense coarse or very coarse punctures in apical half of sternite VII (paratype from Chitwan NP show abdomen densely punctate at sides in couple with sternite VII smooth medially).

Legs. Protibia with four lateral teeth. Mesotibia with 4-5 minute teeth at anterolateral edge, apical tooth situated closer to preapical tooth than to latero-apical immovable spur. Metatrochanter faintly grooved at apex of ventral margin only; metatibia with latero-apical immovable spur small or very small. Mesofemur in apical 2/5 with 2-4 anterodorsal and 1-4 anteroventral setae; metatrochanter asetose.

DIAGNOSIS. Closely related and very similar to $P$. puncticollis in appearance; can be separated from the latter by having odd intervals ( 3 and 5 ) markedly wider than even ones, with intervals 1 and 2 subequally narrow (vs. even intervals, or at least interval 2, wider than odd ones and much wider than the very narrow interval 1).

NAME. Refers to the provenance of the specimens.

DISTRIBUTION. Eastern and southern Nepal.

\section{Parathlibops (Parathlibops) puncticollis (Gestro, 1883)}

Figs 22, 47-48, 65-68, 91-92, 104-105.

Gestro, 1883: 302 (Thlibops; Minhla, Myanmar); Heller, 1923: 297; Andrewes, 1929: 335 (part.).

MATERIAL. Holotype $\sigma^{7}$ (MSNG) labelled: 'Minhla, Birmania 81, Comotto', 'Typus', 'puncticollis Gestro', 'Mus. Civ. Genova', 'Thlibops puncticollis Gestro, typus!', 'Thlibops puncticollis Gestro., typus!', 'HOLOTYPUS, Thlibops puncticollis Gestro, 1883'.

Additional material. $2 \sigma^{\top} \sigma^{7}, q$ (CB): Burma (Myanmar), Rangoon-Taikkyi, Nyaunggon, 19-31.V.2001, Klícha M. lgt.

REDESCRIPTION. Very similar to $P$. nepalensis sp.n. except as follows. Body (Figs 47-48), BL 11.3-12.7 mm. Neck constriction moderately and rather densely punctate; neck nearly smooth and even.

Pronotum with median line fine, deep and smooth (HT) to crenulate, PL/PW 1.19-1.23 (1.20), PW/HW 1.42-1.52 (1.46). Disc with coarse punctures denser in general, more in number, sometimes (including in the holotype) reaching apices of basal sulci. Marginal groove equally narrow from apical angle to basal sulcus while very deep between the latter; this basal groove and basal sulci minutely and confluently punctate/crenulate (HT) to quite smooth.

Elytra. EL/EW 1.97-2.04 (2.0), EW/PW 0.93-0.97 (0.95), EL/PL 1.56-1.60 (1.58). Basal ridge subequally wide or wider 
at humeral angle than at mesothoracic peduncle; humeral angle/tooth a bit more distinct, humeri less widely rounded and barely more prominent. Sides scarcely convex (HT) to straight or barely concave in basal third. Elytral striae well impressed on basal declivity, from thence subsulcate and moderately punctate all along; preapical punctures each situated at bottom of a quadrangular to hexagonal alveole; striae 1-6 free at base, $7^{\text {th }}$ and $8^{\text {th }}$ converging toward humerus and merging into lateral groove just behind it. Interval 1 very narrow, intervals 2,4 and usually also 6 clearly or barely (HT) wider than $3^{\text {rd }}, 5^{\text {th }}$ and $7^{\text {th }}$. Apical 1/4-1/5 elytra with more regular alveolate sculpture, alveoles in stria 1 (and to lesser extent in stria 2) arranged in a row, so that interval 2 traceable up to apex (Fig. 22).

Propleural ridge double and 2/5-1/2 shortened from the outside. Abdomen rather finely and densely punctate throughout except along middle in addition to very sparse punctures in apical halves of sternites; sternite VII coarsely and moderately densely punctate throughout except at middle of base.

Anterolateral edge of mesotibia with apical tooth situated much closer to preapical one than to latero-apical immovable spur. Metatrochanter with posterior (ventral) margin grooved at apex and almost indistinctly so inside it; metatibia with latero-apical immovable spur fairly long and very pointed. Mesofemur in apical $2 / 5$ with 3-5 anterodorsal and 4-5 anteroventral setae.

Aedeagus (Figs 65-68, 91-92, 104-105): median lobe with apical lamella truncate, subquadrate, in posteroventral view; parameres fairly wide all along, clearly broadened and obliquely truncate apically; apices with a fringe of dense and moderately long setae.

DIAGNOSIS. See the key to species.

DISTRIBUTION. Hitherto reported from two close localities in Myanmar. 'North Khasi' and Assam records [Andrewes, 1929] may refer to a different species and need confirmation.

COMMENTS. This species was well described originally, and re-described by Andrewes [1929]. However, the specimen illustrated by Andrewes [1929] shows a very wide head, PW/HW 1.16 (vs. 1.35 as indicated in his redescription), while the holotype's head is narrower relative to the pronotum (see below).

The ratios given in my redescription above are based on the additional material only. The holotype (Fig. 47) is a bit smaller (BL $10.9 \mathrm{~mm}$ ) and somewhat stouter due to slightly wider pronotum and elytra: PW/HW 1.57, PL/PW 1.14, EW/PW $0.94, \mathrm{EL} / \mathrm{EW} 1.87, \mathrm{EL} / \mathrm{PL} 1.59$. It is further different in having the abdomen less densely punctate, as densely as in P. nepalensis sp.n.; sternite VII with few fine punctures in the corners and a total of about two dozen coarse punctures along sides and in apical half; median lobe of aedeagus with apical lamella slightly shorter (compare Figs 91 and 92). Otherwise the male genitalia are nearly identical. Also, the mentum with median triangle evenly $\Lambda$-shaped as formed by blunt yet fine and high carinae converging forward into a pointed median tooth, and
71

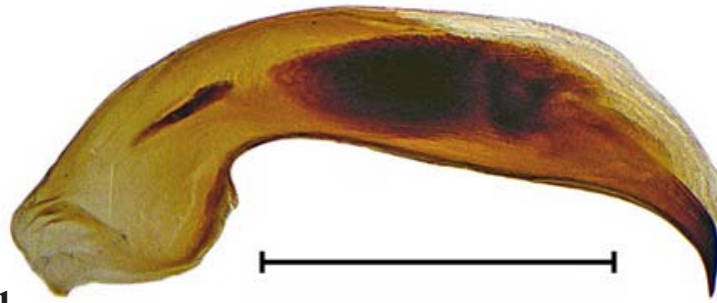

72

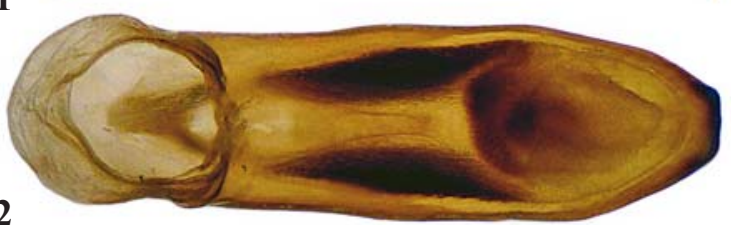

73

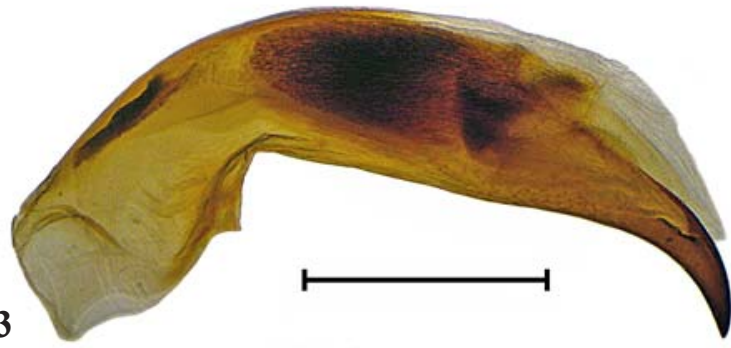

74

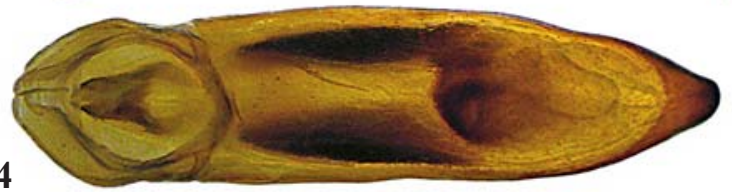

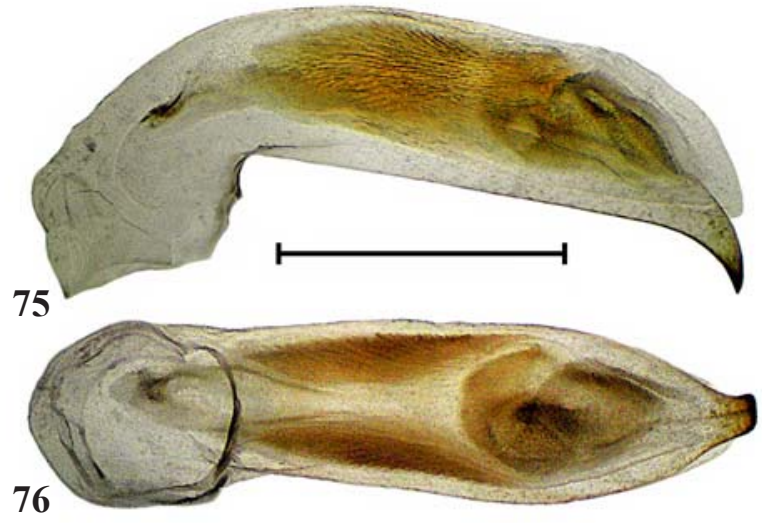

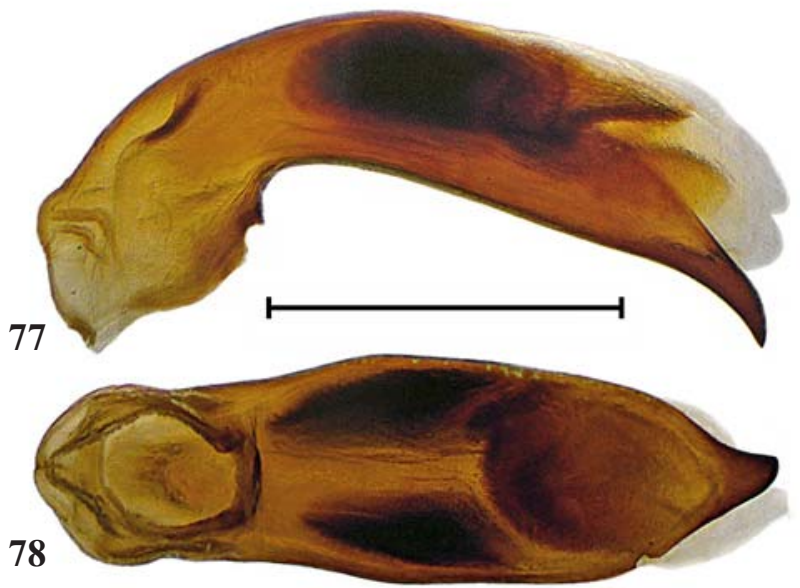

Figs 71-78. Aedeagus median lobe: 71-72 - Parathlibops paviei; 73-74- P. integricollis; 75-76-P. minor; 77-78 - P. bulirschi sp.n.; 71, 73, 75, 77 — left lateral aspect; 72, 74, 76, 78 — ventral aspect. Scale bar — $1 \mathrm{~mm}$.

Рис. 71-78. Средняя доля эдеагуса: 71-72 - Parathlibops paviei; 73-74-P. integricollis; 75-76 - P. minor; 77-78 - P. bulirschi sp.n.; 71, 73, 75, 77 - слева; 72, 74, 76, 78 - снизу. Масштаб - 1 мм. 
with deep triangular pit between the carinae; only secondary lateral edge of mentum is traceable in ventral view.

The above differences should be attributable to intraspecific variability.

Parathlibops (Parathlibops) alveolatus Fedorenko, sp.n. Figs 23, 49, 69-70, 89, 106-107.

MATERIAL. Holotype $\sigma^{7}$ (ZMMU) labelled: 'Laos, Prov. Vientiane, env. Van Vieng, $18^{\circ} 552123 \mathrm{~N} 102^{\circ} 262 \mathrm{E}, \mathrm{h}=230 \mathrm{~m}, 7-9 . X I .2015$, leg. I.Melnik'.

DESCRIPTION. As for P. puncticollis, except as follows. Body (Fig. 49) $12.6 \mathrm{~mm}$ in length. Microsculpture and micropunctation apparently same, but hardly traceable over much abraded body integuments; microsculpture traceable at least on basal declivity of elytra.

Pronotum: PW/HW 1.45, PL/PW 1.18. Basal sulci parallel and very deep. Few (one on left side and four on right side) moderately coarse yet vague punctures situated at bases of apical angles very close to apical transverse impression or touching it.

Elytra without distinct humeral angle or tooth, EL/EW 2.02, EW/PW 0.97, EL/PL 1.66. Striae slightly more coarsely punctate, with punctures becoming gradually deeper and denser apicad, at first foveolate and then alveolate (Fig. 23) Intervals convex in basal $2 / 3$, subcostate behind, subcarinate before apex, subequally wide in addition to very narrow interval 1 ; intervals $2-7$ obliterate before apex, those $2-4$ decreasing gradually in length; $7^{\text {th }}$ slightly narrower than $8^{\text {th }}$ in middle third.

Underside. Pleural ridge barely longer and running very close to $p c r$. Abdomen rather coarsely and moderately densely punctate along sides; sternite VII coarsely punctate except at middle of basal half.

Legs (armature considerably abraded). Mesofemur with four anterodorsal setae in apical third and 5-6 anteroventral setae in middle two quarters; mesotibia with apical tooth large and equidistant from preapical tooth and latero-apical immovable spur. Metatrochanter faintly grooved at apex of ventral margin only, apparently asetose.

Aedeagus (Figs 69-70, 89, 106-107): apical lamella of median lobe triangular in ventrobasal view; parameres slightly narrowing apicad.

DIAGNOSIS. Very similar to P. crenatus and P. puncticollis yet closer to the latter, from which it can be distinguished in having only traces of coarse pronotal punctation; elytral intervals 2-7 equally wide; apex of aedeagus median lobe triangular ( $v s$. truncate) in ventrobasal view; parameres slightly dilated apicad, with apex rounded (vs. clearly dilated, with apex obliquely truncate and very wide.)

NAME. Refers to alveolate sculpture of elytral apex.

DISTRIBUTION. Known from the type locality only.

Parathlibops (Parathlibops) paviei (Lesne, 1896) Figs 26, 50, 71-72, 93, 108-109.

Lesne, 1896: 239 (Thlibops; Battambang, Cambodia); 1904: 63.

MATERIAL. $0^{7}+$ (SIEE), Vietnam, Dongnai Province, Cat Tien National Park, I-II.2004, leg. A. Anichkin; 1 ex. (CB), same locality, but 1-15.V.1994, Zacharda lgt.

DESCRIPTION. Unnecessary, except for the following additions. Body as in Fig. 50, BL 10.9-15.3 mm. Dorsum shiny; meshed microsculpture absent, highly superficial on elytral base; vague transverse meshes sometimes traceable between basal sulci and lateral margin of pronotum; elytra with nearly indistinct dull opalescent luster in apical third.

Pronotum impunctate, without basal transverse impression; basal sulci shallow to inconspicuous; basal bead nearly straight medially; PL/PW 1.21-1.22 (1.21, n=3); PW/HW 1.46-1.49 (1.47). Apical transverse impression deep, crenulate medially.

Elytra with base concave and basal declivity almost vertical; EW/PW 0.97-0.99 (0.98), EL/EW 1.91-1.98 (1.95), EL/PL 1.57-1.60 (1.58). Striae deep, very narrowly sulcate, crenulate rather than punctate, entire in general; striae 3 and 4 , as well as 5 and $6(+7)$ joining a fifth from apex. Intervals convex and reduced to 8 (instead of 9 ) in number; intervals $2-$ 3 or $2-4$ subequally very wide (Fig. 26$) ; 6^{\text {th }}$ wanting; $9^{\text {th }}$ with inner carina somewhat broadened.

Propleural ridge almost entire. Abdomen very finely and sparsely punctate at sides; sternite VII impunctate or nearly so, with a transverse sulcus close to apex.

Protibia with four lateral teeth and entire inner sulcus at anterior face. Mesofemur with 4-5 anterodorsal and 3-4 anteroventral setae.

Aedeagus (Figs 71-72, 93, 108-109): apical lamella of median lobe pentagonal and pointed at tip; parameres very gently broadened and rounded at apices, with rather short apical setae.

DIAGNOSIS. Very distinctive, due primarily to the elytral sculpture.

DISTRIBUTION. Described from western Cambodia; reported from southern Vietnam ('Cochinchina', exact locality not specified) [Lesne, 1904].

Parathlibops (Parathlibops) glaber (Andrewes, 1929) Figs 24, 51.

Andrewes, 1929: 338 (Thlibops; 'South Malabar, Parli' [= Parli Railway Station, Kerala], India).

MATERIAL. + (CB): India, Karnataka, Hassan, 16-17.VI.1994, A. Križova lgt.

DESCRIPTION. Unnecessary, except as follows. Body (Fig. 51), BL 14-14.6 mm. Gena extended forward beyond eye into a subacute tooth. Neck slightly uneven between impressed converging lines, these starting between intermediate and supra-ocular carinae. Submentum asetose.

Pronotum with basal angles hardly projecting forward, basal sulci rather deep yet half shortened from behind; basal transverse impression as a fairly deep groove running close to basal bead between virtual bases of basal sulci; basal bead transversely straight in the middle; PL/PW 1.17, PW/HW 1.58.

Elytra rather short, EL/EW 1.89, EL/PL 1.60. Striae obsolete on basal declivity, deep and finely punctate in basal half, with outer striae impunctate at middle, sulcate before apex, with punctures close, shallowly foveate, irregular and partly confluent; striae 5 and 6 merged just behind base, so that interval 6 reduced in front. Interval 1 only a little narrower than $2^{\text {nd }}$.

Propleural ridge obliterate in its outer half; anterior metasternal bead obliterate between and before mesocoxae. Abdomen very finely and sparsely punctate near lateral margins only, with sternite VII almost impunctate (Fig. 24).

Protibiae with four lateral teeth. Mesofemur with 2-3 anterodorsal and 0-1 anteroventral setae. Outer margins of mesotibia and metatibia with immovable apical spur very long or long and pointed, respectively.

DISTRIBUTION. Hitherto known from two localities in southern India.

\section{Parathlibops (Parathlibops) punctipennis Fedorenko, sp.n. \\ Figs 27, 52, 126.}

MATERIAL. Holotype $+(\mathrm{CS})$ : 'Philippine - Mindanao, Bukidnon, IX.2013'

DESCRIPTION. Body (Fig. 52), BL $15.1 \mathrm{~mm}$. Dorsal microsculpture superficial on labrum, as well as in elytral 
striae, otherwise absent. Head and mandibles minutely and very densely, in part confluently punctate, pronotum minutely and moderately densely punctate in apical third, more finely and increasingly sparsely behind; elytra with fine individual punctures; forebody densely micropunctate.

Head subquadrate, parallel-sided before eyes due to supra-antennal plates straight laterally. Eyes narrow and almost enclosed anteriorly; genae in lateral view concave, rounded dorsally, with ventral margin straight and terminating in a subrectangular tooth; in dorsal view clearly projecting anterolaterad in the form of a rounded tooth. Clypeus with apical margin straight between lateral teeth and with a subtle median emargination; its wings separated by a gentle sinuation from supra-antennal plates. Frontoclypeal suture fine yet distinct throughout but latero-apically, interrupted by median tubercle. Surface irregularly and densely yet rather finely rugulose-punctate, with a pair of parallel lateral carinae running from frontoclypeal suture to neck constriction, $\omega$-carina reduced to its posterolateral parts only. Neck constriction distinct at sides only; neck slightly uneven, rather densely and shallowly rugulose-striate in addition to one pair of slightly impressed converging lines.

Pronotum almost cylindrical, very faintly tapering apicad, with sides very faintly rounded, almost straight, $\mathrm{PW} / \mathrm{HW}$ 1.57, PL/PW 1.31. Apical transverse impression deep at sides, rather shallow and faintly crenate medially. Basal bead narrow, very gently angulate in the middle; marginal groove fine throughout. Basal sulci nearly indistinct. Median line fine and deep.

Elytra long, EL/EW 2.14, oblong-oval, broadest behind middle, much narrower across base, nearly parallel-sided in anterior half, EW/PW 0.97, EL/PL 1.58. Basal margin slightly concave, basal declivity almost upright; humeri rounded yet somewhat prominent due chiefly to a rounded humeral angle traceable between basal and lateral ridges; no humeral tooth. Striae deep, slightly sulcate and moderately punctate, obliterated on basal declivity; $1-4$ free at base, 5 and 6 , as well as 7 and 8 , adjoining basally; stria 1 deepened at base. Intervals subcostate, $1^{\text {st }}$ very narrow, $2^{\text {nd }}$ slightly while $4^{\text {th }}$ and $6^{\text {th }}$ clearly wider than others; interval 8 carinate along stria 7 in basal quarter. Outer carina of interval 9 obliterate in basal third. Interval 1 reaching apex, $2^{\text {nd }}$ interrupted just before, $3-$ $7^{\text {th }}$ obliterate before apex, leaving short preapical area confluently rugulose-punctate in addition to sparse and deep foveae (Fig. 27).

Underside. Mentum entirely rugose, with lateral edge double in basal half while secondary in apical half, i.e. with genuine lateral edge running slightly inside lateral carina; a sharp median carina running from base to apex and separating mentum pits; median tooth slightly trifid; submentum bisetose. Prosternal median ridge sharp in front of an oblong, fairly small, depressed median swell while blunt behind it; prosternal process with a blunt transverse carina separated ventral side from slightly concave basal declivity. Propleural ridge totally reduced. Mesoventrite deeply sinuate at anterior margin, bilobed, with a deep median sulcus behind (Fig. 126). Metaventrite with a short, wide and deep longitudinal impression at inner mesocoxal process, then beaded only behind and outside inner mesocoxal seta. Abdomen with fine lateral bead, moderately and densely punctate along sides, with individual punctures almost meeting along extreme bases; sternite VII impunctate in apical half, with a deep and transverse, slightly sinuous, impression near apex.

Legs. Protibia with four lateral teeth, upper tooth welldeveloped; lower apical movable spur moderately wide, but much longer than wide; upper spur lost. Mesofemur with 34 anterodorsal and 5 anteroventral setae in apical half; mesotibia with 4-5 teeth at anterolateral edge, apical of them very large and subequally distant from preapical tooth and lateroapical immovable spur. Metatrochanter asulcate ventrally and obliquely truncate and flat at apex of ventral margin only, with seta; metatibia with latero-apical immovable spur reduced to a sharp tubercle.

DIAGNOSIS. The species is closest and very similar to $P$. integricollis, but generally smaller, with elytral striae clearly punctate throughout ( $v s$. impunctate) and the mesoventrite distinctive in shape and structure $v s$. truncate anteriorly, with a wide and flat central depression (compare Figs 122 and 126). Entirely punctate elytral striae also differentiate this new species from the other Philippine congeners.

NAME. Refers to punctate elytral striae.

DISTRIBUTION. The Philippines: Mindanao.

\section{Parathlibops (Parathlibops) \\ integricollis (Heller, 1923)}

Figs 3-4, 11, 28, 36, 53, 73-74, 96-97, 123-125.

Heller, 1923: 296 (Thlibops; Luzon).

MATERIAL. 8 ex. (CB, CS, SIEE): 2 ex., Philippines, N Luzon, Ifugao, XI.2012 and VIII.2014, local collector; 1 ex., Cagayan, XI.2013; O', Nueva Viscaya, VI.2010; 2 ex., same data, but Dupax del S, V.2012; 1 ex., E Luzon, Sierra Madre, Quirino, VII.2010; $0^{7}$, Bukidnon, Kalatungan VII.2014.

REDESCRIPTION. Given here for comparison with $P$. punctipennis sp.n. Body (Fig. 53), BL 16.4-20.7, sometimes $14.5 \mathrm{~mm}$. Head (Figs 3-4) rugulose-striated on neck, otherwise finely rugulose, with only fine intermediate carinae running parallel on vertex and frons and often also with some additional, short and not quite even carinules on each side of the carinae; neck constriction distinct at sides only. Eyes fairly wide dorsally, not quite enclosed by genae anteroventrally; gena projecting forward beyond eye into a distinct tooth. Mentum with dense carinulate sculpture (Fig. 11).

Pronotal basal sulci obsolete to indistinct; basal bead blunt and very slightly angular forward in the middle; basal transverse impression as in $P$. minor, but obsolete.

Elytra with basal declivity short and upright. Striae deep, sulcate, impunctate, sometimes very finely punctate before apex, obliterate at bases; $2^{\text {nd }}$ and $3^{\text {rd }}$ slightly to clearly shallower from $1 / 4$ to $3 / 5$; all striae or only $1-6$ free at bases, with $5^{\text {th }}$ and $6^{\text {th }}$ often joining there or starting from a short common base. Intervals $1-7$ obliterate in apical sixth or only $1^{\text {st }}$ as a fine costa or very sharp carina extending to apex, leaving apical sixth rugulose as being formed by large yet very shallow to almost indistinct confluent punctures (Fig. 28).

Propleural ridge short. Mesoventrite truncate anteriorly, flat ventrally, with a pair of oblong impressions; these mostly fairly deep and merged in a common flat depression, sometimes widely separated and very shallow. Abdomen densely punctate throughout.

Protibia with four lateral teeth (Fig. 36); both apical and preapical movable spurs slender or the latter broadened to elliptic, with apex slightly pointed. Mesofemur with 3-4 anterodorsal and 6-10 anteroventral setae.

Aedeagus (Figs 73-74, 96-97, 123-124): median lobe triangular apically in ventral view, without ventro-apical carina; parameres subequally wide up to apex, obliquely subtruncate apically, with tips pointed and very short setae.

DIAGNOSIS. Easily recognizable by having basal pronotal sulci very shallow to obsolete, gena projecting forward beyond eye into a tooth, distinctive head sculpture, etc. 
Parathlibops (Parathlibops) minor (Heller, 1916)

Figs 5-6, 13, 37, 41, 75-76, 95, 119-122.

Heller, 1916: 275 (Thlibops; Mt. Banahao, Luzon, the Philippines). - ? glabriventris Heller, 1916: 276 (Thlibops; same type locality).

MATERIAL. 14 specimens, including $20^{7} O^{7}(\mathrm{CB})$, Philippines, Negros Oriental, Central Visayas, Dumaguete, IV.2013 and V.2014 1 ex. (CS), same data, but XI.2012; 우 (CB), Negros, L. Honagan; 우 (CB), Negros, VII.1990; 3 ex. (SIEE, CB, CS), Mindanao, Bukidnon, VIII and XI.2013, VII.2014; ㅇ (SIEE), Bukidnon, Cabanglasan; 4 ex. (CS): Bukidnon, Kalatungan V.2014; South Catabato, I.2013; Agusan del Norte, Esperanza, IV.2014; Compostela Valley, Masara, VIII.2014; OT (CB), North Luzon, Cagayan, XI.2013.

REDESCRIPTION. Unnecessary, except as follows. BL 13.5-16.4 $\mathrm{mm}$ in general. Head (Figs 5-6) coarsely rugose, Y-shaped carina with horns short and mostly imperceptible; $\omega$-shaped carina more or less distinct, often less distinct in the middle of base; intermediate longitudinal carinae much closer to $\omega$-carina than to supra-ocular carinae, obliterate before ' $\omega$ '; neck nearly smooth, with a pair of converging impressed lines, or additional, shorter or longer, strigae. Eyes rather narrow dorsally, quite close anteroventrally. Gena not projecting forward beyond eye in dorsal view, very gently concave in lateral view, with a deeper concavity at apex

Pronotal basal sulci well-developed; basal bead edged basally, slightly angulate in the middle anteriorly and with a small semicircular excision posteriorly; basal transverse impression reduced to a flat and quite smooth sulcus just in front of basal bead, being slightly wider than marginal groove outside basal sulci. Apical transverse impression indistinctly crenate, repeatedly interrupted. Mentum (Fig. 13) with median triangle edged at sides and terminating into a sharp medioapical carina; lateral concavities deep and nearly smooth, with sparse and faint subtransverse carinulae; dorsal process of median tooth bifid.

Elytral striae obliterate on basal declivity, otherwise deep, clearly punctate before apex and often also minutely punctate or crenulate in apical half; striae 1-3 quite smooth in basal half, 5-7 finely punctate or crenulate nearly throughout; $1-8$ free at base, but $5^{\text {th }}$ and $6^{\text {th }}$ mostly joining basally. All striae coarsely and densely punctate before apex. Intervals usually convex, with those 2,4 and often also 6 clearly wider and thence higher than others.

Propleural ridge long, only a third shortened from the outside (often widely interrupted basally or reduced to a short apical remnant in specimens from Mindanao). Mesoventrite mostly truncate anteriorly, with a very shallow median groove behind. Abdomen rather densely and coarsely punctate at sides, smooth over wider or narrower median area, sometimes these or those sternites punctate medially as well; sternite VII similarly or slightly more coarsely punctate, including in apical half.

Protibia (Figs 37, 41) with three apical teeth, $4^{\text {th }}$, upper, tooth totally reduced or almost so; apical movable spur fairly slender, with rounded tip, preapical one stout, nearly straight or slightly convex at outer edge while very convex at inner edge and rounded or blunt at apex. Mesofemur with 3-6 anterodorsal and 7-10 anteroventral setae.

Aedeagus (Figs 75-76, 95, 119-122): median lobe ventrally with a fine yet well-developed medio-apical carina; apical lamella subcylindrical and rounded at tip; parameres parallel-sided to slightly broadened apicad in apical half, setulose and somewhat rounded apically.

COMMENTS. $P$. glabriventris, described with reservation that it may have been a female of $P$. minor, appears to be just a smaller individual of the latter.
Punctation in elytral striae varies between populations. In specimens from Luzon and Mindanao, it tends to be slightly finer and mostly confined to a variable preapical area, sometimes with very fine punctures traceable in striae 4-6 throughout their length. Specimens from Negros tend to show a slightly coarser punctation, with striae rather coarsely punctate behind the middle, and striae 4-7 finely to moderately punctate throughout, sometimes combined with very fine to indistinct punctures in basal halves of striae 2 and 3.

The status of the two females from Negros needs clarification because of their larger size (BL 18.7-20.5 mm) and abdominal sternite VII very sparsely punctate at sides only.

The small semicircular incision of basal bead, shared by $P$. minor and $P$. intermedius, suggests closer relationships between the two than with $P$. integricollis and $P$. punctipennis sp.n.

\section{Scapterothlibops Fedorenko, subg.n.}

Type species: Parathlibops bulirschi Fedorenko, sp.n.

DESCRIPTION. With characters of the genus, except as follows.

Body (Fig. 52) stout, pronotum slightly wider than long, elytra only three quarters longer than wide. Dorsum impunctate; pronotum with rather sparse transverse rugosities, coupled with sparse longitudinal strigae behind apical transverse impression. Venter very sparsely punctate along sides of metasternum and abdominal sternites IV-VII only.

Head. Eyes moderately developed for the genus, very finely edged with genae at sides and not quite enclosed anteriorly; genae toothed anteriorly, much projecting beyond eyes. Antennae with pedicel and antennomere 4 about as long as wide and slightly shorter than antennomere 3. Mentum slightly raised medially, with lateral concavities less deep and shortened from behind; lateral margin two-edged, with a finest groove between the edges; mental pits large and quite separated. Submentum bisetose.

Pronotum very short (EL/PL 1.81) and wider than long, with basal sulci moderately deep and clearly diverging apicad; lateral margin nearly straight in lateral view.

Elytra short, three quarters longer than wide, broadest slightly before middle, widely rounded apically but two rounded tubercles contiguous at suture. Basal margin gently concave; humeri widely rounded; basal declivity declivous and short, apical declivity nearly abrupt. Elytral striae abruptly disappearing before apex (Fig. 25), stria 8 shortened, traceable in basal $1 / 5$ only. Intervals subequally wide; interval 9 as an extremely narrow groove in basal $3 / 4$, with outer carina fine and hardly traceable while inner carina reduced throughout except at base.

Prosternum slightly angulate medio-apically; median carina blunt, without longitudinal sulcus before procoxa, thence sharp. Prosternal process with ventral side indistinctly separated from basal inclination. Pleural carina fine and obliterate in its outer half. Mesoventrite declivous anteriorly and very short, not projecting forward beyond mesocoxae in lateral view. Metaventrite with anterior bead totally obliterate between mesocoxa.

Legs. Protibia (Fig. 40) long, slender and only slightly flattened, subquadrate in cross-section, about as long as pronotum, with three strong lateral teeth and a trace of upper tooth; apical tooth (spine) very long, barely shorter than tarsus; both apical movable spurs long and thin, lower movable spur as long as tarsomere 1; protarsomere 1 as long as tarsomeres 2-5 combined. Mesotibia strongly flattened, with antero- and posterolateral edges only slightly separated; anterolateral edge with five teeth equally spaced and increasing apicad in size 
(apical of these teeth being preapical immovable spur). Metatibia with both antero- and posterolateral edges finely carinate and supplied with setae; outer apical spur conspicuous and blunt at tip. Protibia with 3-4 preapical anterolateral setae; mesofemur with 1-2 anterodorsal setae at apex and 5 anteroventral setae; both metacoxa and metatrochanter asetose.

Aedeagus (Figs 77-78, 94, 110-111) as for the genus, but parameres very narrow.

DIAGNOSIS. Readily distinguishable from the nominate subgenus by more robust body with short prothorax (EL/PL ca. $1.8 v s .1 .5-1.6$, rarely $1.70-1.76)$, by the elytral stria 8 reduced to basal fifth only, and by the structure of the legs, especially tibiae.

NAME. Combination of Scapterus and Thlibops.

\section{Parathlibops (Scapterothlibops) bulirschi Fedorenko, sp.n.}

Figs 25, 54, 40, 77-78, 94, 110-111.

MATERIAL. Holotype $\sigma^{7}(\mathrm{CB})$ labelled: 'S India, Tamil Nadu, salt industry area $\mathrm{W}$ of TUTICORIN, $8.472^{\circ} \mathrm{N} 78.062^{\circ} \mathrm{E}, 24$.26.I.1994, Z.Kejval lgt.'.

DESCRIPTION. With characters of the subgenus.

Body (Fig. 52). Microsculpture superficial and reduced to elytral basal declivity and striae, hardly traceable on prosternum and propleura anteriorly, as well as on the latter behind. Sides of abdominal sterna IV-VI with about six fine and sparse punctures at a distance from lateral margin, St VII

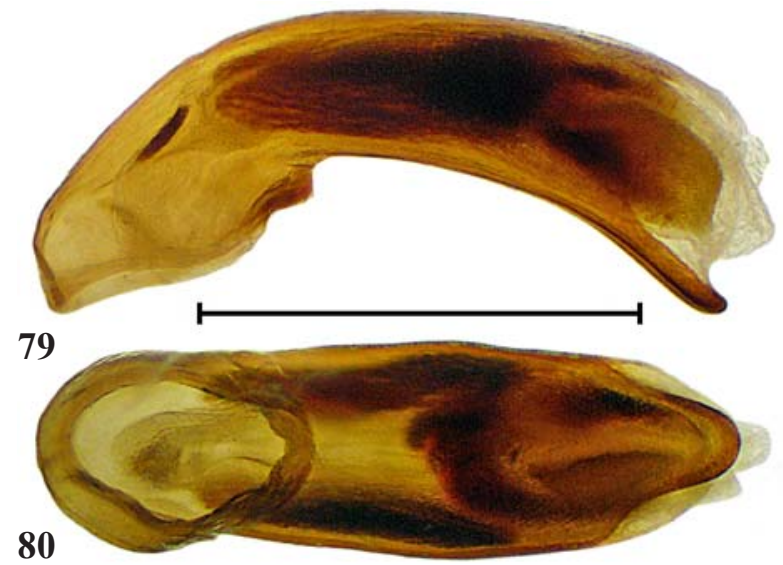

83

with about six very coarse and very dense to confluent punctures each side, leaving base and apical margin smooth.

Head subquadrate, with supra-antennal plates very gently rounded laterally. Frons with high median tubercle. Frontoclypeal suture conspicuous only close to median tubercle, indistinct laterally; an $\omega$-shaped flat-top elevation instead of $\omega$-shaped carina. Sharp intermediate carinae just outside it, diverging from frontoclypeal suture to neck constriction; this latter convex basad medially, angulate anterad just inside intermediate carinae, deeper at sides, shallow and with a few fine punctures at middle. Surface rugulose outside intermediate carinae and faintly rugulose between them. Neck with two deep, slightly converging lines, a similar yet shallower stria on each side of them and a few additional, but slightly uneven and shorter striae here and there. Mentum on each side with a fine sublateral carina (quite the same as that of Distichus) in addition to irregular cariniform rugosities in apical half; tooth of mentum with a blunt median carina.

Pronotum slightly transverse, PL/PW 0.91, PW/HW 1.76, broadest at basal angles, with sides gently converging forward and gently rounded in apical half. Lateral bead clearly thicker while lateral groove barely wider apicad. Both median line and apical transverse impression deep, latter faintly crenulate.

Elytra rather short, EL/EW 1.74, EW/PW 0.95, without humeral tooth. Striae deep, rather crenulate than minutely punctate, obliterate on basal declivity; only stria 1 and parascutellar striole reaching mesothoracic peduncle. Intervals sub-

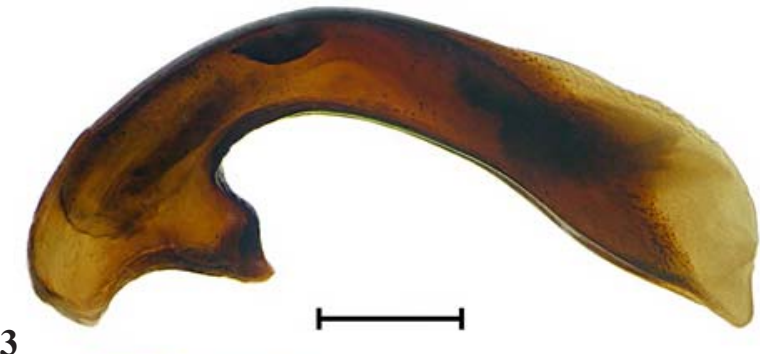

84

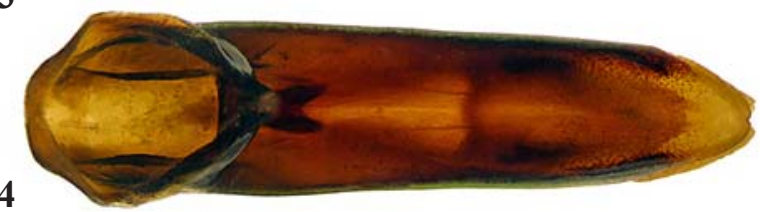

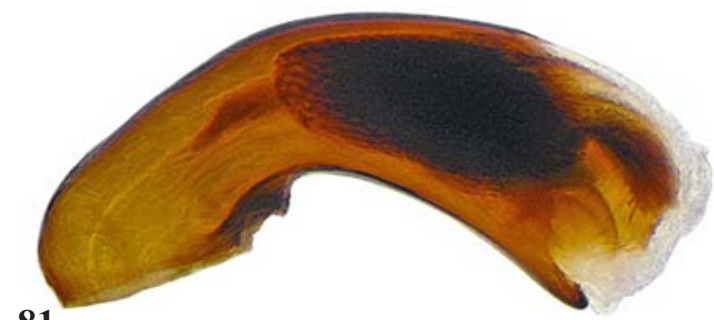

81

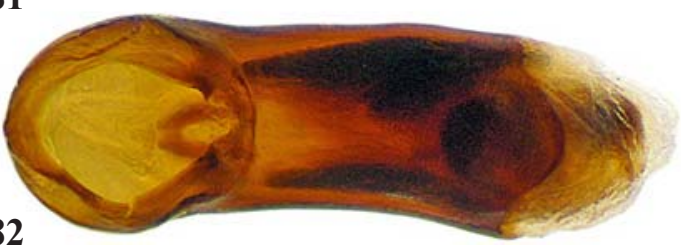

85

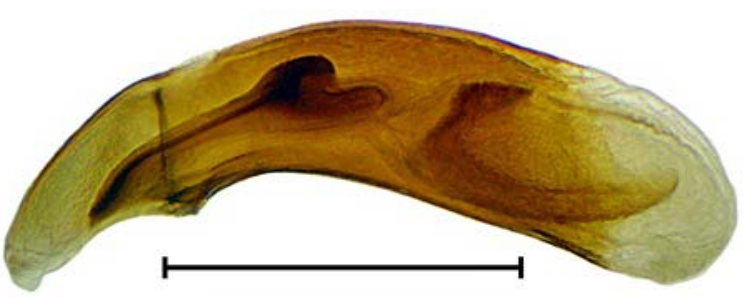

86

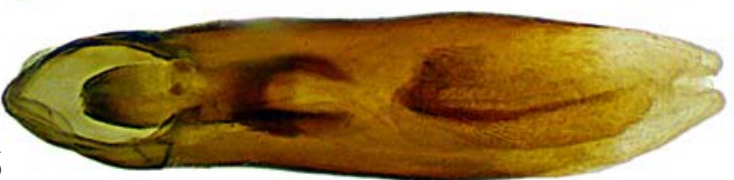

Figs 79-86. Aedeagus median lobe: 79-80 — Thlibops longicollis; 81-82 - Th. congoensis; 83-84 - Passalidius f. fortipes; 85-86 Scapterus sp. pr. sulcatus; 79, 81, 83, 85 — left lateral aspect; 80, 82, 84, 86 — ventral aspect. Scale bar $1 \mathrm{~mm}$.

Рис. 79-86. Средняя доля эдеагуса: 79-80 — Thlibops longicollis; 81-82 — Th. congoensis; 83-84 - Passalidius f. fortipes; 8586 - Scapterus sp. pr. sulcatus; 79, 81, 83, 85 -слева; 80, 82, 84, 86 - снизу. Масштаб 1 мм. 
equally wide, convex before apex, barely so on disc, with no pores.

Metaventrite with anterior bead straight laterally, not curved behind to become lateral bead.

NAME. Given after Petr Bulirsch (Prague), my good friend and a leading expert on Scarititae.

DISTRIBUTION. Known from the type locality only.

\section{Thlibops Putzeys, 1866}

Type species: Scapterus longicollis Putzeys, 1846, designated by Andrewes [1929].

DIAGNOSIS. According to Basilewsky [1958], the following characters separate Thlibops from Parathlibops: eyes

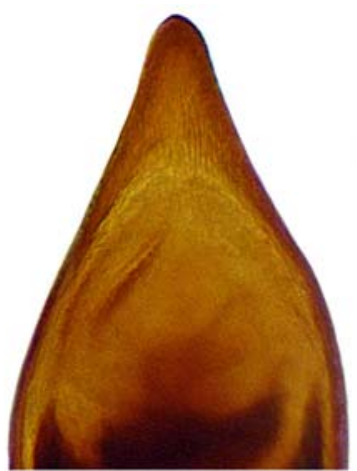

87

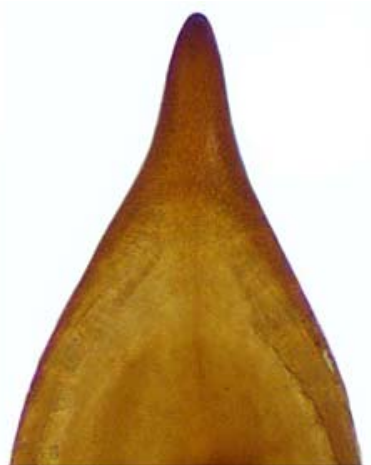

88

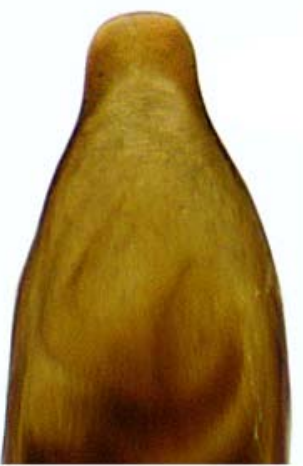

91

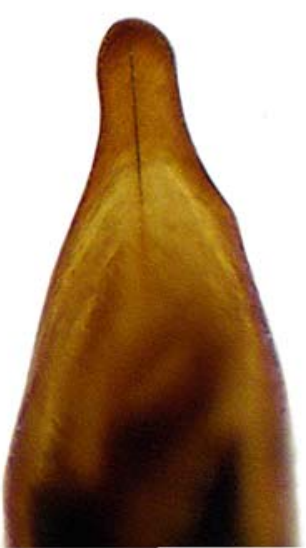

95

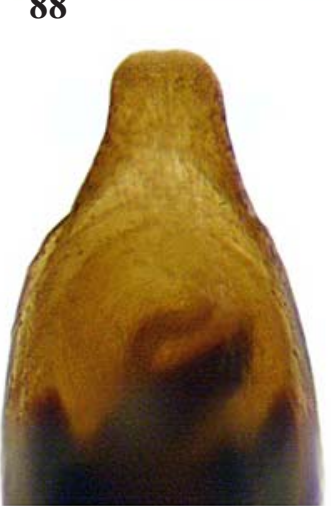

92

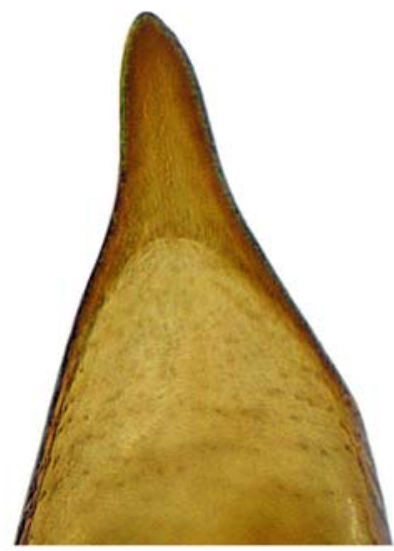

96 well-developed and convex (Figs 1-2), one supraocular seta and anterolateral pronotal setae present, parameres of aedeagus glabrous apically (Figs 112-115).

The most important additional distinctive features are: body macropterous, small and slender; elytra cylindrical, with base subtruncate and basal ridge very fine; basal pronotal sulci long; head sculpture slightly different, strigose throughout, with no neck constriction (transverse groove behind eyes); teeth at anterolateral edge of mesotibia equally small and reaching the level of immovable preapical spur. Chetotaxy: one double supraocular seta, 1-2 anterolateral pronotal setae, 1-2 parascutellar setae, one pair of ambulatory setae on abdominal sternites IV-VII; protrochanter bisetose; two, inner

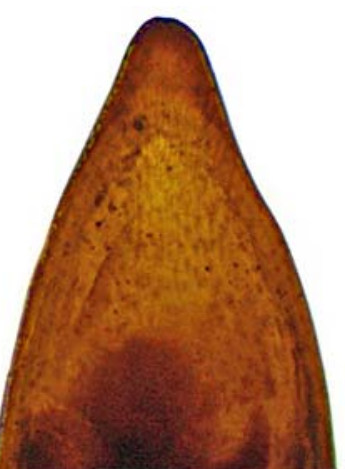

89

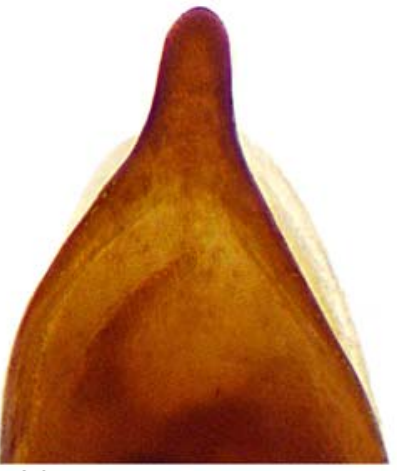

90

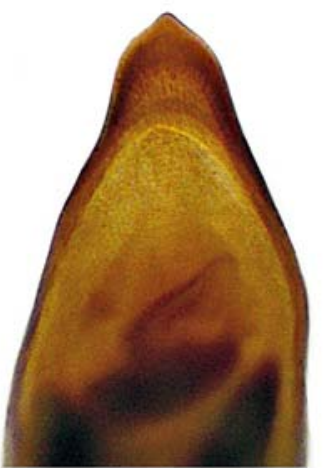

93

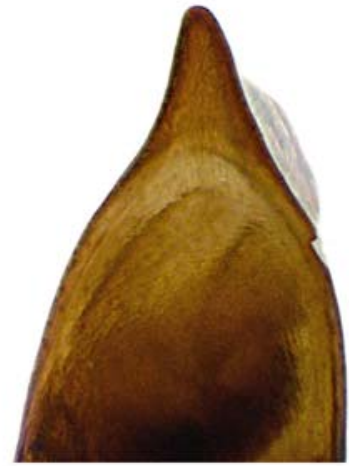

94

Figs 87-97. Apex of aedeagus median lobe, ventrobasal aspect: 87 - Parathlibops crenatus; 88 - P. abramovi sp.n.; 89 - P. alveolatus sp.n.; $90-P$. cylindronotus sp.n.; 91-92 - P. puncticollis, holotype (91) and specimen from Nyaunggon (92); $93-P$. paviei; $94-$ P. bulirschi sp.n.; $95-$ P. minor; 96-97 - P. integricollis. Scale bar - $1 \mathrm{~mm}$.

Рис. 87-97. Вершина средней доли эдеагуса снизу и сзади: 87 - Parathlibops crenatus; 88 - P. abramovi sp.n.; 89-P. alveolatus sp.n.; $90-$ P. cylindronotus sp.n.; 91-92 - P. puncticollis, голотип (91) и экз. из Nyaunggon (92); $93-P$. paviei; $94-P$. bulirschi sp.n.; $95-P$. minor; 96-97 - P. integricollis. Масштаб - 1 мм. 

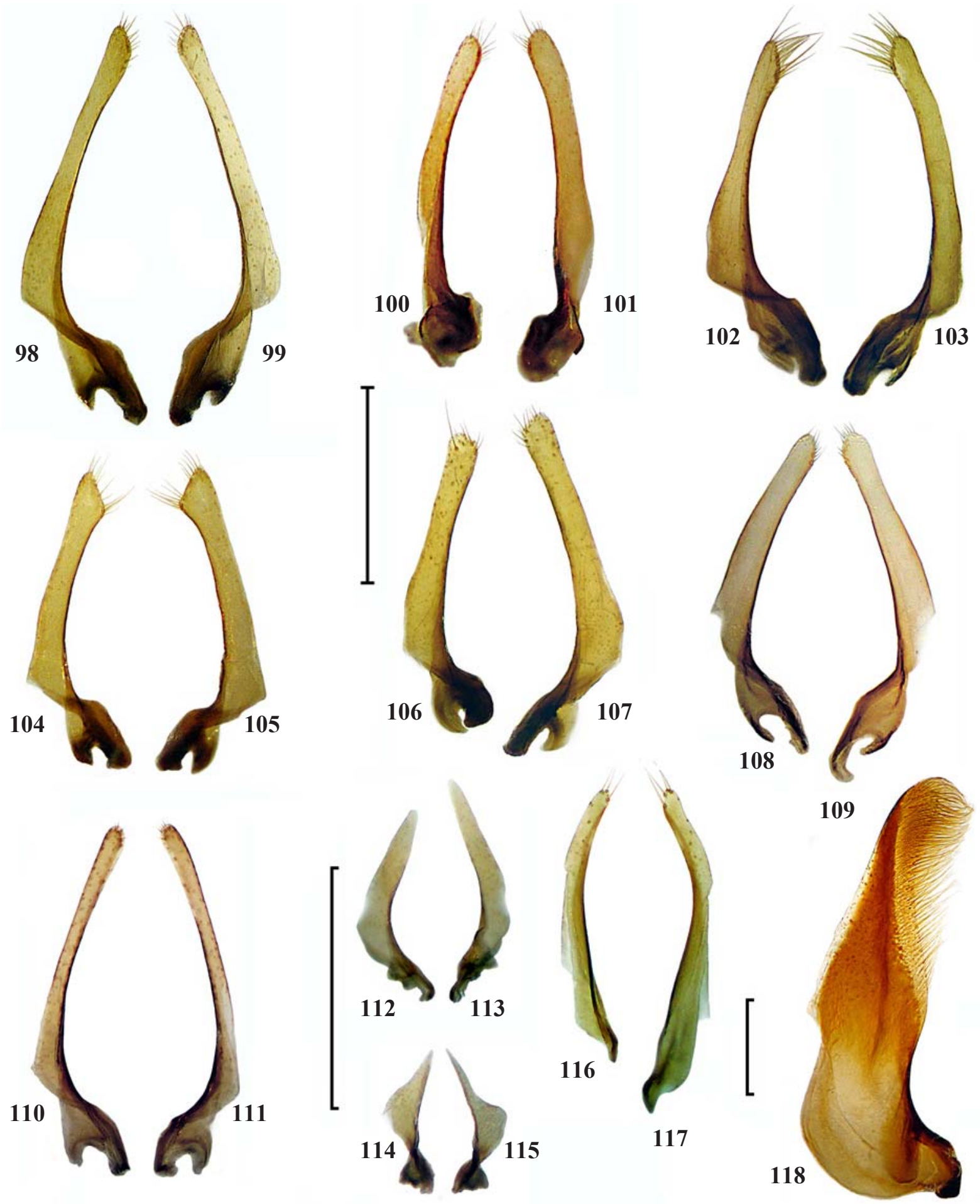
and anterolateral, metacoxal setae present. Aedeagus (Figs 7982) stout in lateral view, with apex small and rounded.

COMMENTS. The genus Thlibops was erected to accommodate three species: Scapterus dohrnii Chaudoir, 1863, S. longicollis Putzeys, 1846, and S. crenatus Chaudoir, 1863. The earliest described species, S. longicollis from Senegal, was then selected as type species by Andrewes [1929], who also provided a detailed redescription of the genus; however, his redescription was based on the Oriental species only and thus actually defined the taxon later described as Parathlibops.

Differences between the two Thlibops species can be presented as follows:

1(2) Fig. 55. Neck densely punctate behind eyes, with punctures traceable medially all the way to pronotal margin. Pronotum with one anterolateral seta; basal sulci straight, running parallel to median line or slightly converging forward; groove just inside basal bead rather wide; median line, basal sulci and marginal groove mostly minutely and densely punctate. Mentum subcarinate along middle in apical half, median tooth slender and nearly simple. Protrochanter with two ventral setae, without $\left({ }^{\circ}\right)$ or with $\left(\bigcirc^{7}\right)$ two small and pointed tubercles, one between setae, the other in front of them. Abdomen a bit less densely punctate at sides. Protibia with both movable spurs rather small and slender, preapical spur convex to subcostate ventrally (Fig. 34). Elytra with one parascutellar setigerous pore, striae deeper, intervals slightly more convex, $1-4$ free at base, $5^{\text {th }}$ curved outwards and joining $6^{\text {th }}$ which almost joining $7^{\text {th }}$; interval 3 with 0-4 (3) pores, interval 5 with $0-5$ (mean 2). Aedeagus slender (Figs 79-80), with apex longer and a wide, longitudinal, ventral groove in apical half; parameres boomerang-like, tapering gradually in apical half (Figs 112113). - Senegal, Mali, Gambia, Benin, Nigeria, Central African Republic ........... Th. longicollis (Putzeys, 1846)

1(2) Fig. 56. Neck densely punctate at sides yet impunctate medially. Pronotum with 1-2 anterolateral setae; basal sulci anteriorly slightly curved outwards; median line, basal sulci and marginal groove (latter, throughout or except in apical third) impunctate. Mentum sharply carinate on each side of a fine, deep median groove; median tooth trifid (Fig. 12). Protrochanter with one ventral seta, similar in both sexes. Abdomen very densely punctate; on basal sternites, punctures confluent laterally. Protibial movable spurs widely oval and very flat, foliaceous, preapical spur ventrally with a sharp median carina (Fig. 35). Elytra with two parascutellar setigerous pores, striae barely shallower, intervals slightly less convex, stria 5 less curved outwards, striae 5-7 less deep and mostly narrowly separate; interval 3 with 3-6 (5) pores, interval 5 with 3-5 (4) pores. Aedeagus (Fig. 81-82) stout, with very short apex and no ventral groove; parameres triangular, much narrower apically than medially (Figs 114115). - Republic of Congo, Zaire, Central African Republic...... Th. congoensis Basilewsky, 1958

\section{Discussion}

We follow Kryzhanovskij [1976, 1983] in recognizing scaritine carabids as the supertribe Scarititae that includes two tribes, Scaritini Bonelli, 1910 and Clivinini Rafinesque, 1815.

The Scaritini includes the subtribes Pasimachina Putzeys, 1866, Carenina MacLeay, 1888, Acanthoscelitina Csiki, 1927, Scaritina s.str., Oxylobina Andrewes, 1929, and Scapterina Putzeys, 1866. Dyschiriini Kolbe, 1880 and probably also Salcediini (s.str.) Alluaud, 1930 may be tentatively placed as subtribes in the Clivinini.

The group 'Scaptérides' [Putzeys, 1866] was erected for the genera Scapterus, Thlibops, and Listropus Putzeys, 1863 (the latter is now treated as a subgenus of Schizogenius Putzeys, 1846 in the Clivinini) and defined by the following four characters: ligula short and glabrous medially; palpi with terminal joints attenuated apicad; maxillae rounded; mandibles very short. Putzeys treated the genera Acanthoscelis and Passalidius as transitional from 'Scaritides' to 'Scaptérides', while noting great similarity between Passalidius and Scapterus in many characters. Bänninger [1937] added Oxylo-
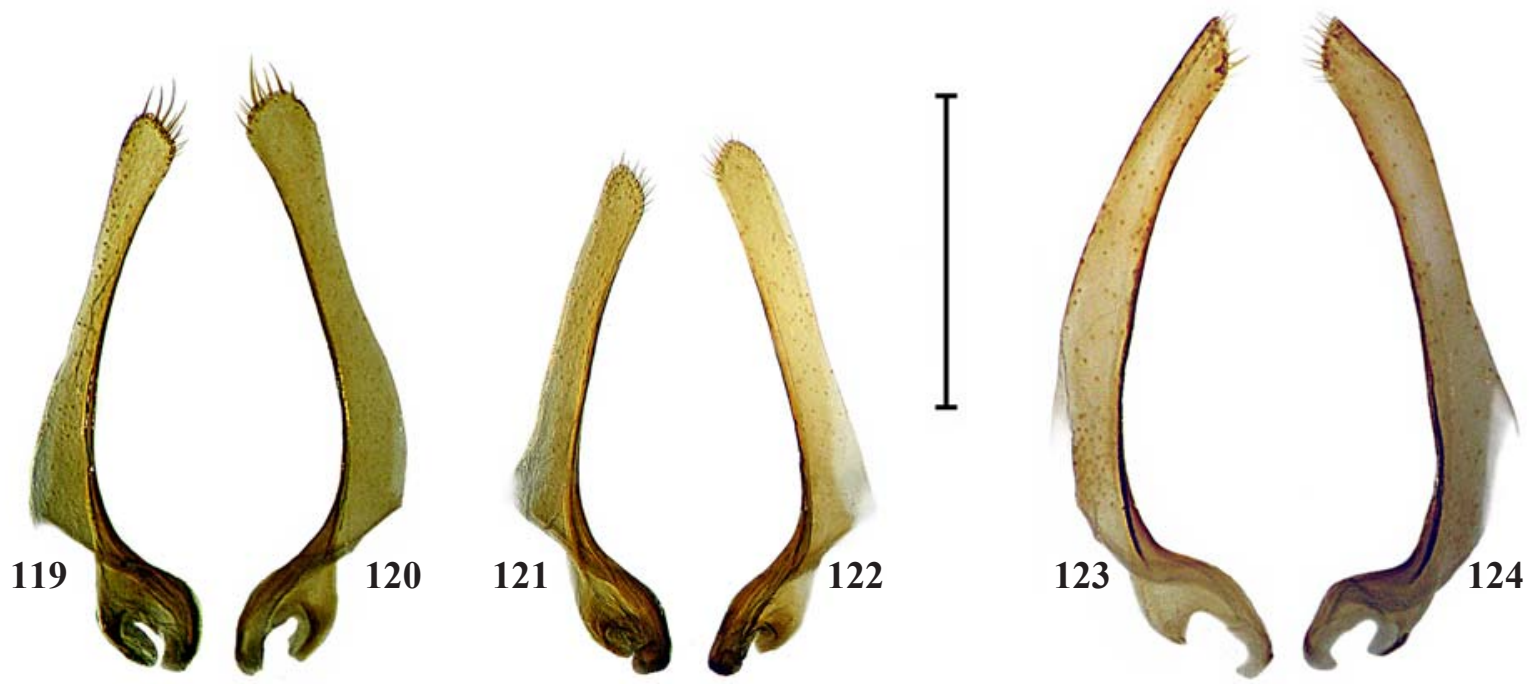

Figs 119-124. Parameres of aedeagus: 119-122 — Parathlibops minor, males from North Luzon (119-120) Mindanao (121-122); 123124 - P. integricollis; 119, 121, 123 - right paramere; 120, 122, 124 - left paramere. Scale bar - $1 \mathrm{~mm}$.

Рис. 119-124. Парамеры эдеагуса: 119-122 — Parathlibops minor, О7 О7 с Северного Лусона (119-120) и Минданао (121-122); 123-124 - P. integricollis; 119, 121, 123 - правая парамера; 120, 122, 124 - левая парамера. Масштаб - 1 мм. 
bus and Ochryopus (today a member of Scaritina) to the list of intermediate taxa, and Basilewsky [1973b] placed Acanthoscelis closer to Scaritina (= Scaritini sensu Basilewsky). Jeannel [1946] included Passalidius in the Scapterina, but his interpretation of the 'trib. Scapterini, sensu novo' was rather erroneous. First, he placed Scapterina among the Clivinini and defined this tribe in the key by two supraocular setae present on each side, combined with a short antennal scape, stipulating that only Thlibops had no seta, even though Figure 94 [ibid.] showed no seta also in Passalidius and just one seta in Scapterus. Basilewsky [1958] moved the Oriental species of Thlibops to a closely related yet distinct genus Parathlibops. So, the subtribe Scapterina of the Scaritini could be diagnosed based essentially on two characters: (1) the markedly rugose or rugose-striated head and (2) the median tubercle on frons, conspicuous in Thlibops, Parathlibops and Scapterus (Fig. 57) but reduced to a flat square bump between deep frontal sulci in Passalidius (Fig. 10). Additional feature of the Scapterina is the very convex (sub)cylindrical body.

The monobasic subtribe Oxylobina (as 'Subgroup II. Oxylobides') was introduced by Andrewes [1929] to reflect the fact that the genus Oxylobus was so much unlike the members of Chaudoir's 'Scaritides'. Andrewes defined the 'Oxylobides' by (1) short buccal fissure, (2) sometimes unusual shape of the left mandible in male, (3) bisetose penultimate labial palpomere, (4) deep and narrow frontal sulci, and (5) very convex body.

Our morphological analysis of available taxa of the Scarititae reveals two rather distinct lineages within the subtribe Scapterina (sensu novo).

The first lineage, that includes Scapterus, Acanthoscelis, and probably also Passalidius, is definable primarily by the following synapomorphies: protibiae slender, with a long sublateral row of dense setae on anterior side and usually also (Acanthoscelis, Scapterus) with both the movable apical spurs and tarsomere 1 very long and

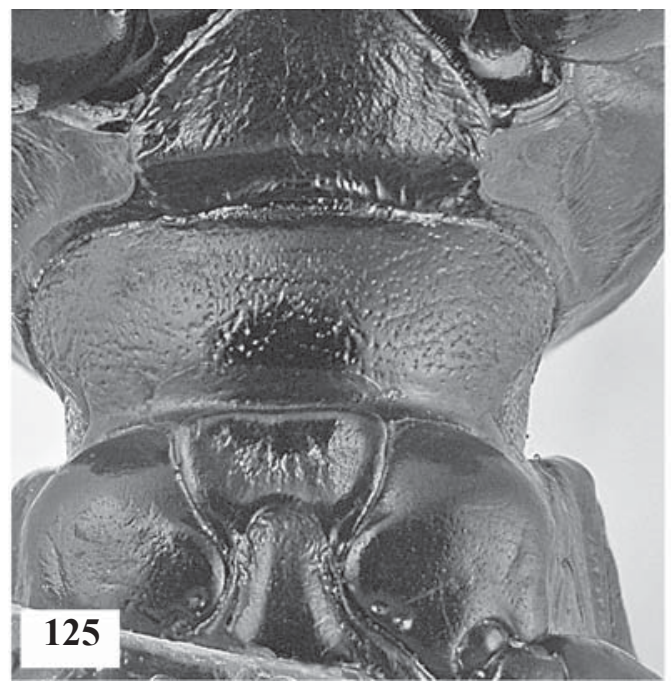

slender; and mandibles with dorsal side slanted laterad because of the underdeveloped dorsal scrobal ridge. The three taxa have bodies quite similar in shape and proportions, but for the rounded sides of the pronotum and elytra in Acanthoscelis. This, however, just as the strongly incrassate head in Passalidius, seems to be a secondary development. Other shared characters include: penultimate labial palpomere plurisetose ( $v s$. 2-3-setose); pronotum subquadrate and as wide as, to much wider than long (vs. tapering forward and mostly distinctly longer than wide); abdominal sternite VII with two (vs. 1-0) pairs of setae; inner metacoxal seta always missing ( $v s$. present but secondarily lost or increased in number in some Parathlibops); apical declivity of the elytra nearly vertical (vs. slanted). Finally, in Acanthoscelis and Scapterus the sternites IV-V each are with additional lateral setae; this arrangement is unique within the Scapterina. On the other hand, and the lateral setae of sternite III in Acanthoscelis are common among Scaritina, but missing in the Scapterina.

The second lineage includes the genera Thlibops, Parathlibops and Oxylobus; its synapomorphies are: abdominal sternite VII with anal grooves well marked (vs. rudimentary or lacking); mandibles dorsally flat, with ventral scrobal ridge less marked (Oxylobus) or weak (Thlibops, Parathlibops). Protibia is either very slightly modified (Oxylobus) or short and strongly dilated apicad. Other character states are alternative to those listed above for the first lineage.

Passalidius is more likely to be still closer to the second lineage. The shared characters include the anal grooves on abdominal sternite VII; labial palpomere 2 short, clearly shorter than 3 ; and mentum with dual-edged lateral margin. The elytral lateral margin in Passalidius looks more like that of Oxylobus than of Scapterus or Acanthoscelis. Apotypic characters that Passalidius shares with Oxylobus are: buccal fissure posteriorly reduced, gula reduced to a suture, and apical transverse impression

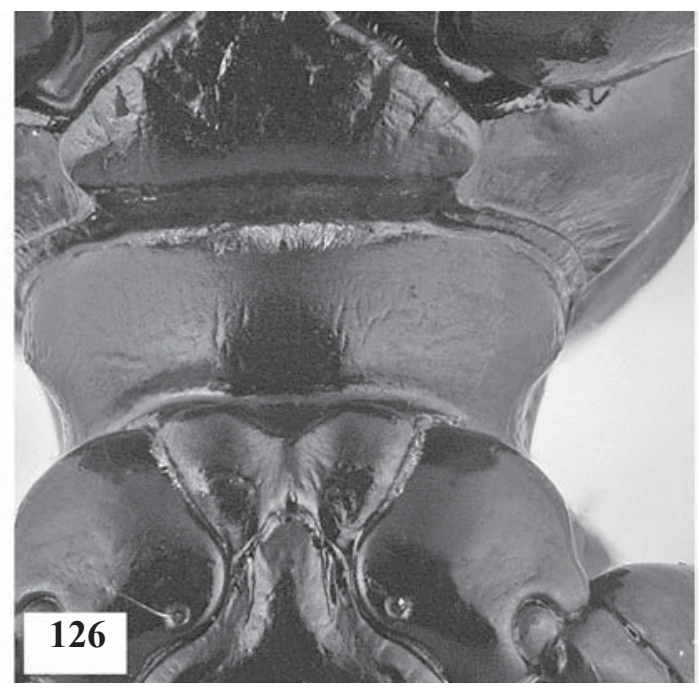

Figs 125-126. Mesoventrite ventrally: 125 - Parathlibops integricollis; 126 - P. punctipennis sp.n.

Рис. 125-126. Мезовентрит вентрально: 125 — Parathlibops integricollis; 126 — P. punctipennis sp.n. 
of the pronotum obliterate except at sides. Also, Passalidius (Figs 83-84) is more similar to Parathlibops than to Scapterus (Figs 85-86) in shape and structure of the aedeagus: apical lamella of the median lobe is triangular (vs. much desclerotized and rounded) and X-shaped sclerite short (vs. long). It is hard to tell whether the weaker anal grooves of Passalidius are incipient or a result of reduction. If the former is true, Passalidius should be sister to Oxylobus + (Thlibops + Parathlibops $)$; under the latter scenario, Passalidius is closer to Oxylobus.

The suggested groundplan of the Scapterina is as follows:

Body macropterous, cylindrical or subcylindrical. Head broadened just slightly, rugose-striated dorsally, with two subcontiguous supraocular setae on each side. Eyes moderately large, vertical, not or barely embedded into the head, i.e., shorter than high in lateral view, with posterior margin emarginate at middle; genae very short and thin in dorsal view. Frons with a median tubercle, frontal foveae supposedly as deep parallel sulci; clypeus bisetose. Antennal scape fairly short, barely longer than antennomeres 2 and 3 combined.

Labrum trilobed, with four equally spaced setae. Mandibles with subequally developed dorsal and ventral scrobal ridges. Maxillar lacinia apically hooked, maxillary palpomere 4 oblong-oval (subfusiform), slightly longer than 3. Buccal fissure entire, paragenal tooth ?missing. Mentum with one (medioapical) pair of setae and beaded lateral lobes; labial pits external and deep, located just in front of mentum suture; tooth of mentum triangular ventrally, with a high dorsal process associated with ligula and wedged between labial palps. Ligula wide and short, much dorsal to the mentum tooth, with one pair of setae in ?medio-apical position; labial palpomere 2 ?bisetose at inner margin and about as long as ?3. Submentum bisetose and moderately long; gula moderately wide nearly throughout.

Pronotum subquadrate, with basal angles denticulate; median line deep throughout, both apical and basal transverse impressions well-developed, the latter running between basal foveae close to base; margins beaded throughout, including at apex just inside the angles. Basal foveae short and deep, diverging forward. Supposedly, one posterolateral and one to a few anterolateral setae present on each side.

Elytra cylindrical, very convex, with humeri protruding and toothed. All striae deep, entire and free at bases. Intervals $2-8$ subequally wide at apex, with $8^{\text {th }}$ touching $1^{\text {st; }}$ interval 9 fairly narrow, with a deep groove bearing umbilical setae at bottom. Sides and base granulate or tuberculate; base with several umbilical setae. Intervals 3, 5 and 7 with serial setigerous pores. Lateral edge concealed by interval 8 at least behind shoulder.

Legs. Profemora slightly incrassate; protibiae slightly dilated apicad and slightly flattened, with three rather small lateral teeth, including apical spine, and several setae along anterolateral edge (inside lateral teeth); apical spurs long and slender. Mesotibiae and metatibiae slender, slightly flattened; anterolateral and posterolateral edges separate. Outer preapical spur of me- sotibia is enlarged tooth of posterolateral edge of the mesotibia, close to its apex. Metatibia along anterolateral and posterolateral edges with setae more or less dense and ensiform (no long nematiform setae). Tarsi medially carinate. Trochanter with one, distal, seta; profemur with two ventral (anterobasal and posterobasal) setae and one posteroventral seta in preapical position; mesocoxa with two, inner and outer, setae; metacoxa trisetose; metafemur unisetose (anteroventral seta).

Underside. Prosternum medially neither tumid nor carinate; propleural ridge entire. Metaventrite beaded along anterior margin; metepisterna very long. Abdominal sternites without basal sulci; sternites IV-VI with one pair of ambulatory setae; sternite VII bisetose each side; sternite III ?without additional setae concealed with femoral bases. Apical margin of sternite VII (concealed by elytra) narrow and smooth, without anal grooves.

Female gonostyli well sclerotized. Male aedeagus symmetrical; median lobe with apex subtriangular and well sclerotized; parameres long and densely pubescent along ventral (inner) margin.

The majority of the above features are plesiotypic for Scaritini. Features unique to Scapterina are in boldface; the first and the third may be considered autapomorphies of the early Scapterina. The second one is hard to interpret. In most carabids, including Clivinini, a bisetose labial palpomere 2 is a plesiomorphic condition. In some members of Scapterina, the bisetose palpomere is fairly short. On the other hand, in most Scaritini palpomere 2 is plurisetose and tends to be long. So, a shorter, bisetose palpomere evolved into a longer one, or it could have been the other way around. In some Oxylobus there are three, rather than two, setae clustered at the very tip of the palpomere; this may support the latter hypothesis.

Moreover, most every scapterine genus differs strongly from other genera and from the groundplan in some, often highly derived, characters. The same is true for most combination of the genera. This makes arranging the genera in a sensible way a difficult task.

To illustrate, let's compare two pairs of genera: $O x y$ lobus (especially some of its highly specialized members) and Thlibops (or Parathlibops) against Acanthoscelis + Scapterus. Some features of Oxylobus, such as the rather robust body, the incrassate, smooth head (Fig. 9) with deep frontal sulci, the reduced buccal fissure, and the unspecialized (within the Scaritini) protibiae are much unlike those in Thlibops or Parathlibops. Similarly, Acanthoscelis and Scapterus differ strongly in many characters, such as mouthparts (primarily labium), meso- and metatibiae, and body shape. The parallel-sided body of Scapterus looks quite different from the rounded Acanthoscelis, yet otherwise the two genera show similar body proportions and sculpture, in addition to the synapomorphies listed above; this suggests close affinity between Scapterus and Acanthoscelis.

Because of this considerable transgression of characters, the Scapterina is defined by a combination of a few polythetic, additive characters. For instance, the frontal tubercle is characteristic to Thlibops, Parathlibops and Scapterus, but lacking it the other genera. 
Prosternum is medially tumid to sharply carinate in all the scapterines except Passalidius. Well-developed anal grooves are present in Thlibops, Parathlibops and Oxylobus, but not in the rest of the genera. Finally, the protibiae and the mandibles are distinctive in each of the two scapterine lineages, further suggesting that the Scapterina is a relic scaritine group.

Labial structures shed little light on relationships within the Scaritini. The combination of a flat mentum tooth and a long, fairly thick ligula with one pair of apical setae in median position is considered a simplesiomorphy of Pasimachus, Mouhotia, and probably also Carenina. A very short and thin ligula, combined with a high, wide dorsal process of the mentum tooth wedged between the apical setae and between labial palps, seems to be a derived condition, probably synapomorphic in Scaritina and Scapterina. Ligular setae are usually numerous in both subtribes, except for Scapterus and Thlibops that have bisetose ligula (asetose in Parathlibops). Also, Scapterus is unique in having (1) rather a thick ligula (2) with setae in dorsoapical, rather than lateral, position, and (3) well-developed internal labial pits opening in the mental suture. Character 3 is an autapomorphy (homoplasy with many Clivinini), whereas the first two, especially when combined, are hard to tell which ancestral condition they may have evolved from.

Some scapterines, especially Thlibops, look more like Clivinini than Scaritini, a similarity further underscored by a number of other traits, such as smaller size, two supraocular setae on each side, bisetose penultimate labial palpomere, bisetose ligula, well-developed external labial pits, entire buccal fissure without paragenal tooth, and elytral intervals 7-8 subcostate at apex. However, the trilobed labrum, the overall scaritine type of mandibles, the short ligula closely associated with the dorsal mental tooth, and one pair of mental setae (or none) all suggest that the characters the Scapterina share with the Clivinini should have evolved independently. Female reproductive tract provides more evidence supporting this conclusion: in Scapterina it is of Scaritini type, quite different from that of Clivinini [Liebherr, Will, 1996].

Conclusions. The labium provides a synapomorphy supporting the monophyly of Scapterina + Scaritina. The Scaritina is defined chiefly by the combination of the single supraocular seta 1 ( $v s$. originally two in Scapterina) and the paragenal tooth. The Scapterina is defined by the combination of the (1) anal grooves, (2) median tubercle on head, (3) distinctive protibia, (4) scrobal ridges, (5) two-edged lateral margin of mentum, (6) elytral interval 9 with a bicarinate groove, (7) additional setae on abdominal sternites IV-V(VI). The fact that Scapterina share anal grooves/openings with $\mathrm{Mou}$ hotia and Pasimachus needs further study. The suggested relationships within Scaritini are as follows: (Carenina + Pasimachina + Mouhotia $+((($ Thlibops + Parath libops $)+$ Oxylobus + Passalidius $)+$ Scapterus + Acanthoscelis) + Scaritina). Scapterus and Acanthoscelis are probably closely related; Oxylobus is closely related to Passalidius. Mouhotia is more closely related to Pasimachus than either of them to Carenina.
Based on our results, the Scarititae can be classified as follows. First, Thlibops and Parathlibops should be placed in the same suprageneric taxon with Oxylobus (Oxylobina) and probably also with Passalidius. On the other hand, the close relationship between Scapterus and Acanthoscelis, if confirmed, suggests including the latter in the Scapterina, so that just two subtribes, the Oxylobina (Oxylobus, Parathlibops, and Thlibops) and the Scapterina (Scapterus and Acanthoscelis), would be retained. I will, however, make one step further, move all these genera to Scapterina, and consider Oxylobina Andrewes, 1929, syn.n., and Acanthoscelitina Csiki, 1927, syn.n., to be synonyms of Scapterina.

Note on Corintascaris ferreirae Basilewsky, 1952. This peculiar and enigmatic species (Fig. 58) was described in great detail and excellently illustrated. Later Basilewsky [1973a] proposed a separate tribe for it, equal in rank to Scaritini, Clivinini, Dyschiriini, and Salcediini. Subsequently, the genus was placed in the subtribe Scaritina, and Corintascarini synonymized with the latter [Lorenz, 1998; 2005].

Below I provide minor corrections of the otherwise good description, and my comments.

First, when examining a female of $C$. ferreirae (CB: South Africa: KZN, Mkuze Game Reserve, $27.362^{\circ} \mathrm{S}$ $32.132^{\circ}$ E, XII.1987, P.E. Reavell, At light at night), I was surprised to see a fully developed mandibular scrobal seta, perhaps the only important character omitted in the description. This trait makes the genus even more peculiar, and sets it apart from all other Scarititae.

Second, the head is in many ways quite unlike anything found among scaritines or clivinines, primarily in the clypeus being slightly transverse, hexagonal, produced forward way beyond the supra-antennal plates, and wings of clypeus nearly reduced and fused to its median part. In some Clivinini the medial part of clypeus does project beyond its lateral wings, but in those cases the parts are well separated by grooves. Otherwise the head resembles in shape and sculpture that of Scapterina; however, two carinae, the supraocular one and the one similar to the intermediate carina of Scapterina or to the elongated facial carina of some Clivinini, run parallel and are long or very long, respectively. Labrum is bilobed, but has certainly evolved from a trilobed one: a small yet distinct remnant of the median lobe can be seen as a tubercle separating the lobes and the two medial setae. The six labral setae present are typical to Clivinini rather than Scaritini. Pronotum looks like that of Parathlibops or Oxylobus among Scapterina, due chiefly to the combination of the porrect apical angles; the fine marginal bead; and the lack of basal angles, basal foveae, and transverse impressions, basal or apical. Elytra resemble those of Dyschiriini in shape, but those of Scaritini in general structure, with umbilical setae numerous and reaching the suture basally. The lateral margin, obstructed in basal third with interval 8 , combined with stria 8 being obliterate throughout, is typical to some members of Scapterina and Scaritina. Intervals 3, 5, and 7 (not just 3 and 5 , as the description says) with $3,5-7$, and 11-12 
minute 'setigerous' pores (I saw no seta). Mouthparts are distinctive and generally primitive, but for several apomorphies. There are two setae on each side of mentum (not one, as in the original description [Basilewsky, 1952, Fig.3]). In this plesiotypic feature combined with other characters of the labium, Corintascaris is more similar to, and perhaps slightly more primitive than Clivinini, as far as the labium is concerned. This similarity is further supported by the internal labial pits that opens in the mental suture, an apotypic feature. Another apomorphy, the asetose submentum, sheds no further light.

The underside of the body and the legs show no helpful features, either. The propleural ridge is nearly entire yet indistinct. Abdomen with just two apical setae on sternite VII, and no other fixed ventral setae; such reductions are rare, and occurred independently in the Clivinini and at least four lineages of the Scaritini, including Scapterina, Scaritina, Carenina, and Mouhotia. Abdominal sternites V-VII are transversely sulcate (said to be asulcate in the description), as in Clivinini and Dyschiriini, but abdominal sternite III lacks the intercoxal Ëshaped stria typical for both taxa. Legs are distinctive, due chiefly to a fairly short basal tarsomere; the absence of immovable, apical or preapical, spurs on meso- and metatibiae; rather long movable apical spurs; and very short mesotibiae. Leg setae are as follows: one ventroapical protrochanteral seta; profemoral seta formula $0+0+1$, posteroventral setae being in medial position; mesocoxa bisetose; mesofemur with anteroventral (preapical) row of setae extending basad into the anteroventral row without interruption; metacoxa and metafemur asetose. Protibia with a conspicuous anterolateral ridge in basal half, which is characteristic of Scaritini (especially Scapterina) rather than of Clivinini.

Female gonostylus is well-developed, falcate, indistinctly subdivided into two segments, and bears numerous long setae, i.e., is of fossorial type characteristic of Clivinini.

Finally, there is no unguitractor plate, and antennomeres 1-4 are glabrous (although antennomeres 2-4 bear some additional setae, and antennomeres 5-11 each have true pubescence at dorsal and ventral ridges separated with a wide glabrous area). These two characters, combined with numerous umbilical setae on elytral base and some other characters discussed above may suggest closer relationship between Corintascaris and Scaritini.

This character combination, especially the mandibular scrobal seta, suggests a highly isolated position of Corintascaris within Scarititae, and may warrant a different supertribal placement. I thus reinstate the tribe Corintascarini as equal in rank to Scaritini or Clivinini.

ACKNOWLEDGEMENTS. I am very grateful to Petr Bulirsch (Prague), Dr. Boris M. Kataev (ZISP), Dr. Kirill V. Makarov (MPSU), Dr. Maria Tavano (MSNG) and Ricardo Sciaky (Milan) for the loan of material under their care. I also thank Dr. Alexander E. Anichkin (Yoshkar-Ola) and Igor V. Melnik (Moscow) for donation of material, and Vassily V. Belov (College Station, TX, USA) for suggestions that have improved the manuscript.

\section{References}

Andrewes H.E. 1929. The fauna of British India, including Ceylon and Burma. Coleoptera. Carabidae. Vol. I.-Carabinae. London: Taylor \& Francis. XV+430 p.

Bänninger M. 1937-1938. Monographie der Subtribus Scaritina (Col. Carab.) I, II // D. Entomol. Zeitschr. 1937, S.6-160; 1938, S.41-100.

Basilewsky P. 1952. Descriptions de deux Carabiques nouveaux du Mozambique (Col. Carabidae) // Bull. \& Ann. Soc. Ent. Belg. T.88. P.227-233.

Basilewsky P. 1958. Coléoptères Carabidae africaines nouveaux. IX // Rev. Zool. Bot. Afr. T.57. P.322-334.

Basilewsky P. 1973a. Insectes Coléoptères Carabidae Scaritinae // Faune de Madagascar. Vol.37. Paris. 322 p.

Basilewsky P. 1973b. Contributions à l'étude des Scaritinae d'Afrique (Coleoptera Carabidae). II. Tableau des genres afro-malgaches de la sous-tribu des Scaritina // Rev. Zool. Bot. Afr. T.87. Fasc.1. P. 174-180.

Casale A. 1980. Ergebnisse der Bhutan-Expedition 1972 des Naturhistorischen Museum in Basel. Coleoptera Fam. Carabidae, subf. Scaritinae, Trib. Scapterini // Ent. Basil. Vol.5. P.5-9.

Chaudoir M. 1863. Description de Cicindélètes et de Carabiques nouveaux // Rev. Mag. Zool. 2 ${ }^{\mathrm{e}}$ sér. T.15. P.111-120.

Chaudoir M. 1879. Monographie des Scaritides (Scaritini). $1^{\text {re }} \mathrm{pt} / /$ Ann. Soc. Ent. Belg. T.22. P.124-182.

Csiki E. 1927. Carabidae. Carabinae I // Coleopterorum Catalogus. Vol.1. Pt.92. Berlin: W. Junk. P.317-621.

Gestro R. 1883. Sopra alcuni Coleotteri di Birmania raccolti del Capitano G.B. Comotto // Ann. Mus. Stor. Nat. Genova. T.18. P.297-317.

Heller K.M. 1916. Philippinische Käfer, gesammelt von Prof. C. Fuller-Baker, Los Banos // D. Ent. Zeitschr. H.7. S.269-311.

Heller K.M. 1921. New Philippine Coleoptera // Philipp. J. Sci. Vol.19. No.5. P.523-627.

Heller K.M. 1923. Some new Malayan Carabidae, especially Philippine // Philipp. J. Sci. Vol.23. P.295-307.

Hogan J.E. 2012. Taxonomy, Systematics and Biogeography of the Scaritinae (Insecta, Coleoptera, Carabidae). PhD Thesis. Oxford Brookes University. 288 p.

Jeannel R. 1946. Coléoptères Carabiques de la region Malgache. I // Faune de 1'Empire Français. Paris. T.6. P.1-372.

Kryzhanovskij O.L. 1976. [An attempt of revision of the system of ground beetles (Coleoptera, Carabidae)] // Ent. Obozr. Vol.55. No.1. P.80-91 [in Russian].

Kryzhanovskij O.L. 1983. [Beetles of the suborder Adehaga: families Rhysodidae, Trachypachydae; family Carabidae (introductory part and review of USSR fauna)] // Fauna SSSR. Zhestkokrylye. Vol.1. No.2. Leningrad: Nauka. 341 p. [in Russian]

Lesne P. 1896. Cicindélides et Carabides Indo-Chinoise requellis par M. Pavie. Diagnoses des espèces nouvelles et d'un genre nouveau // Bull. Mus. Hist. Nat. Paris. T.2. P.238-245.

Lesne P. 1904. Famille des Carabides // Pavie A. Mission Pavie IndoChine 1879-1895. Études diverses. III. Recherches sur l'histoire naturelle de 1'Indo-Chine orientale par Auguste Pavie. Paris: E. Leroux. P.62-81.

Liebherr J.K., Will K.W. 1998. Inferring phylogegnetic relationships within Carabidae (Insecta, Coleoptera) from characters of the female reproductive tract // Ball G.E., Casale A., Vigna Taglianti A. (eds.). Phylogeny and Classification of Caraboidea. Proceedings of a Symposium (28 August 1996, Florence, Italy) XX International Contress of Entomology. Museo Regionale de Scienze Naturali, Torino, Italy. 1998. P.107-170.

Lorenz W. 1998. Systematic list of extant ground beetles of the World (Insecta Coleoptera "Geadephaga": Trachypachidae incl. Paussinae, Cicindelinae, Rhysodinae). 1st Edition. Tutzing. 502 p.

Lorenz W. 2005. Systematic list of extant ground beetles of the World (Insecta Coleoptera "Geadephaga": Trachypachidae incl. Paussinae, Cicindelinae, Rhysodinae). 2nd Edition. Tutzing. 530 p.

Moore B.P., Lawrence J.F. 1994. The extraordinary larval characters of Carenum Bonelli and their bearing on the phylogeny of the Scarititae (Coleoptera; Catabidae) // Can. Ent. Vol.126. P.503-514.

Putzeys J. 1846. Monographie des Clivina et genres voisins // Mém. Soc. Sci. Liége. T.2. P.521-663.

Putzeys J. 1867 (1866). Révision générale des Clivinides // Ann. Soc. Ent. Belg. T.10. P.1-242. 